\title{
Examining the effect of acquired limb loss on the family network: A grounded theory study
}

\author{
Sophie Mitchell \\ A thesis submitted for the degree of Doctorate in Clinical Psychology
}

School of Health \& Social Care

University of Essex

April 2018 


\section{Acknowledgements}

First and foremost, I would like to thank the participants for openly sharing their stories. Sincere thanks go to those numerous organisations that assisted in recruitment. These have not been named in order to protect the anonymity of the participants, but their enthusiasm for the research was greatly appreciated.

Secondly, thanks are extended to my supervisors, Dr Leanne Andrews and Dr Hilary Engward for their continued support in the research and writing. Leanne demonstrated an unwavering kindness and constant enthusiasm for the work. Hilary provided tireless support to the research and writing process in Grounded Theory.

Thirdly, I am thankful to a number of other people who provided input into this research at various stages. Thanks go to Matt Fossey and Kristina Fleuty at the Veterans and Families Institute at Anglia Ruskin University, for guidance in planning and coding. Helen Scott of Grounded Theory Online provided training and mentorship in Grounded Theory. Andy Sluckin (Systemic Psychotherapist) and Dr Emma Patten (Clinical Psychologist) offered valuable insight and advice into the theoretical and clinical service concepts. I am additionally particularly grateful to my father, John Mitchell, for all his meticulous and tireless proof-reading across the entire writing process. I would like to also extend personal thanks to Jessica Walburn and Ronan Miller, for their thoughtful support and advice in conducting interviews as a researcher who stammers.

Finally, I am tremendously thankful for my own precious network of family and friends. Their encouragement, kindness and unwavering belief in me has not been forgotten. I am also particularly grateful to the eleven other trainee psychologists on my cohort with whom I have shared this journey with. 


\begin{abstract}
Background: Children and adults with limb loss acquired through disease or trauma, are faced with a range of physical and psychological challenges. Their family networks become an important platform for coping and recovery to occur, although little is known about the experiences of these networks. The small amount of research so far has only examined the views of spousal and parental carers.
\end{abstract}

Aims: This research aimed to: 1) explore the experiences of family networks following a limb amputation within their family; and 2) to develop a theoretical model to explain how the family network experiences the limb loss. The use of 'network' was adopted to include kin identified as family, without legal or biological ties.

Method: Data collection and analysis were guided by the Grounded Theory method. Members of the family networks $(n=14)$ were recruited nationally and interviewed over Skype or telephone. Interviews were conducted in a process moving from unstructured to semi-structured and structured interviews.

Findings: A theoretical model was developed around the interaction of five core categories. Family members witness the perceived difficulties faced by the person with limb loss, leading to an evoked responsibility to provide support based on this witnessing. Families subsequently experience the shared impact and challenges of limb loss; together with numerous emotional reactions. This leads to the use of various forms of coping in order to resolve these experiences and associated emotions.

Conclusions: Families are involved in the processes and challenges following on from an amputation in another family member, regardless of gender, relationship 
structure and type of amputation. The theoretical model can be understood through the integration of ideas from systemic theory and social psychology. The issues identified must be considered in services, to support families who aid recovery following on from an amputation.

Key words: limb loss, amputation, family, kinship, grounded theory. 


\section{Contents}

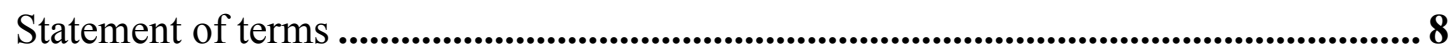

Tables and figures ...........................................................................................................9

Chapter 1: Introduction ....................................................................................................... 10

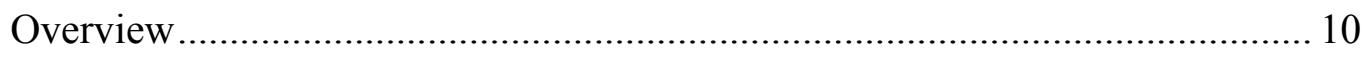

Part 1: Clinical and social context ........................................................................................ 11

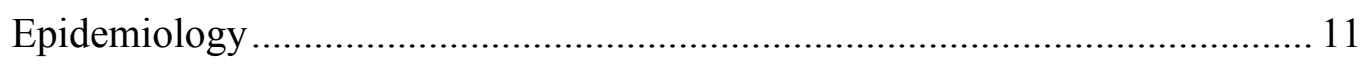

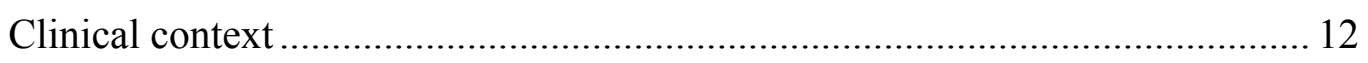

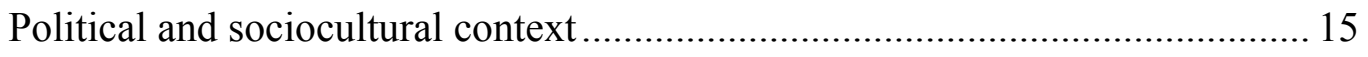

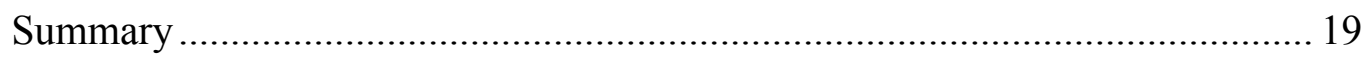

Part 2: Individual perspective on limb loss..................................................................... 19

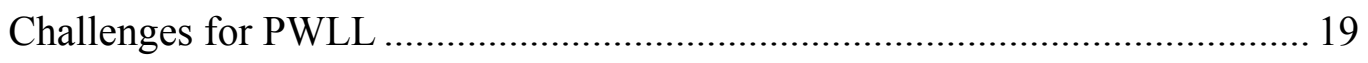

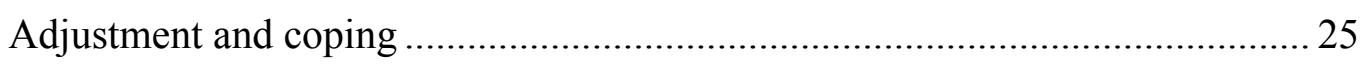

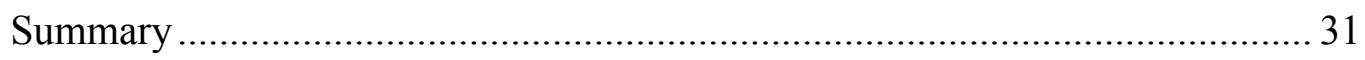

Part 3: Family perspective on limb loss ....................................................................... 31

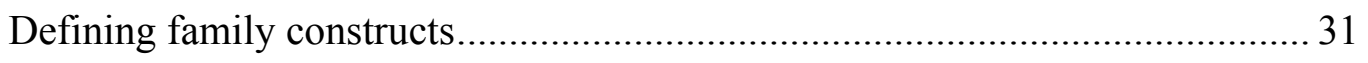

Theoretical frameworks of family systems .................................................. 33

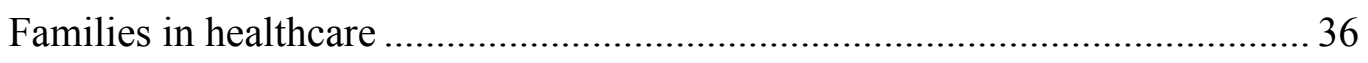

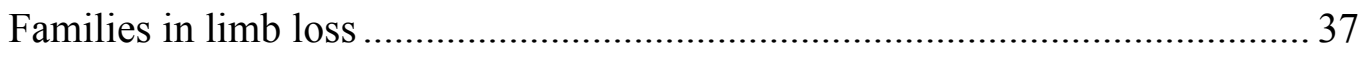

Part 4: Rationale for research............................................................................. 44

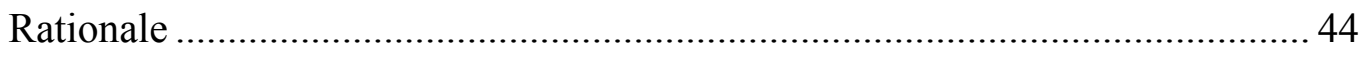

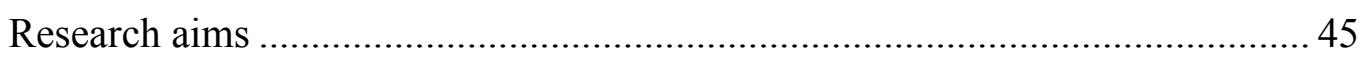

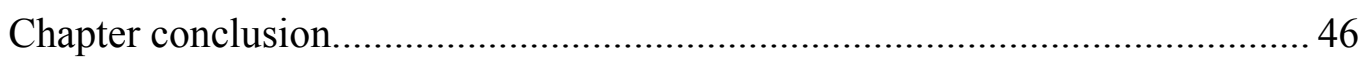


Chapter 2: Methodology

Overview

Part 1: Background and philosophical assumptions .......................................................48

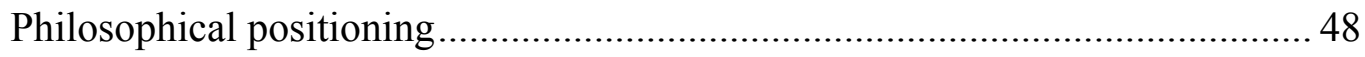

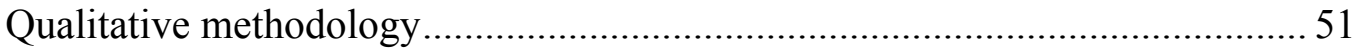

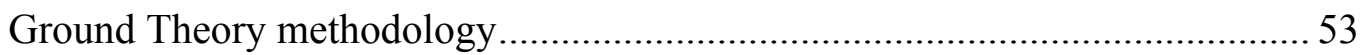

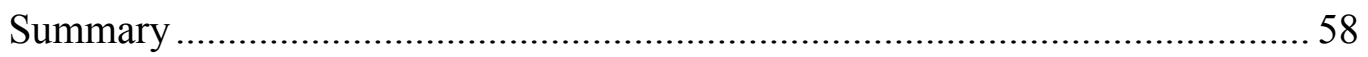

Part 2: Method.................................................................................................................................5 58

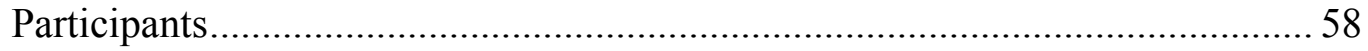

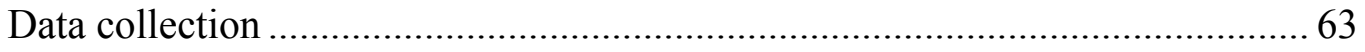

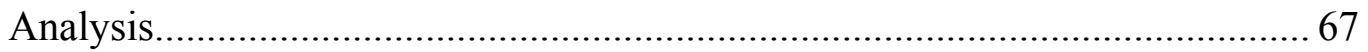

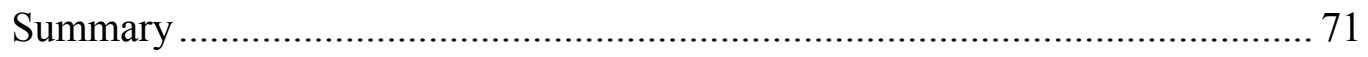

Part 3: Quality in research.................................................................................. 71

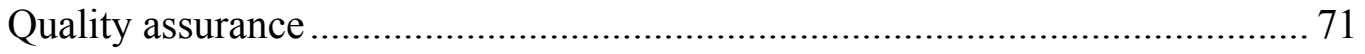

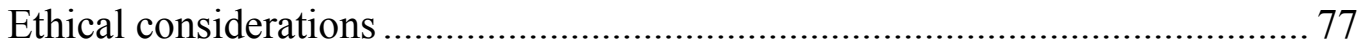

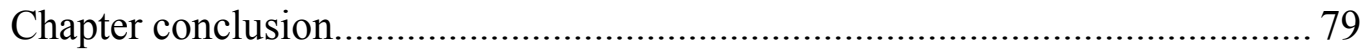

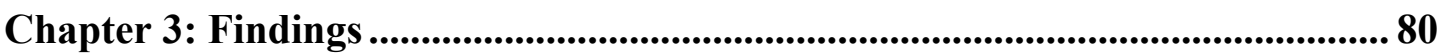

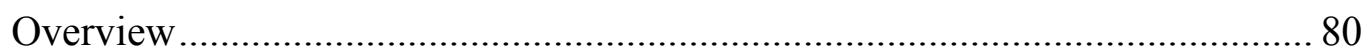

Part 1: Overview of theoretical model ......................................................................881

Part 2: Presentation of the theoretical model .....................................................................8 82

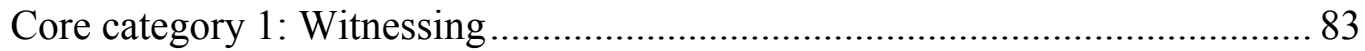

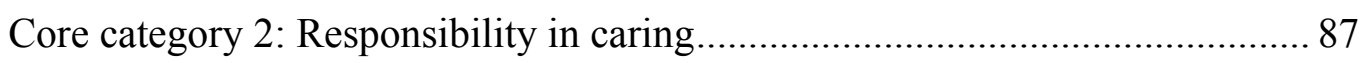

Core category 3: Sharing the impact and challenges ..................................... 91

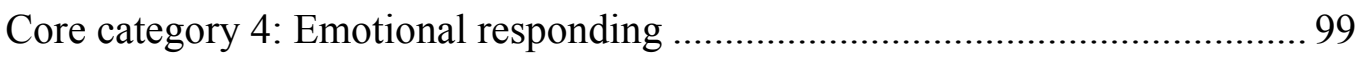




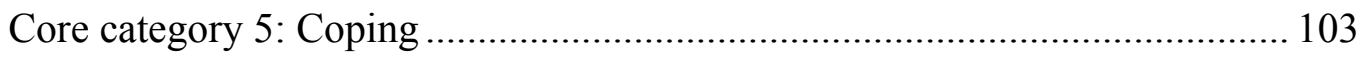

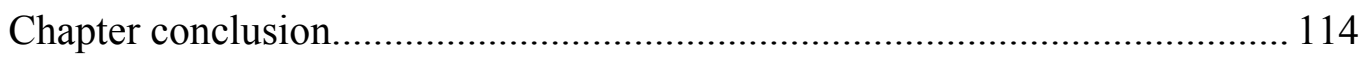

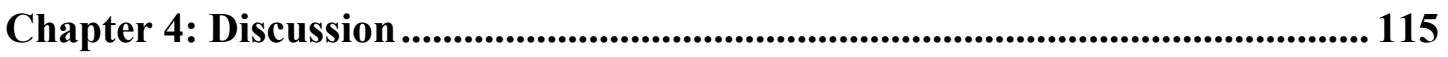

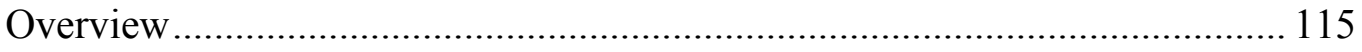

Part 1: Theoretical framework ................................................................................... 116

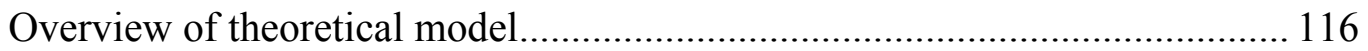

Integration of theoretical \& empirical literature ......................................... 117

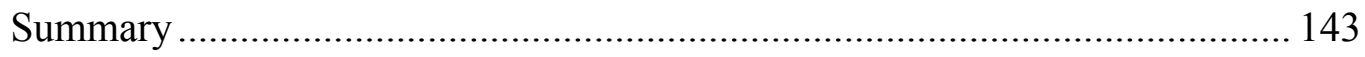

Part 2: Evaluation of research ......................................................................................... 143

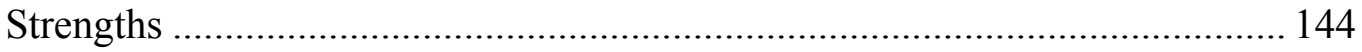

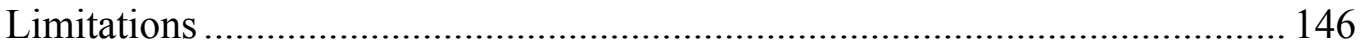

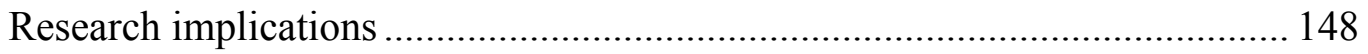

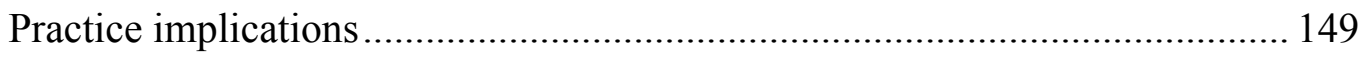

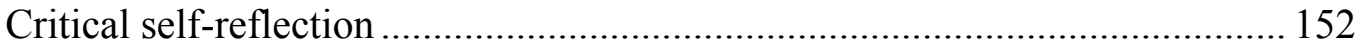

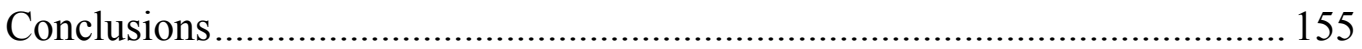

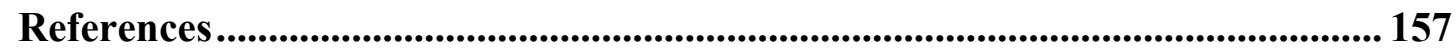

Appendices..................................................................................................................... 181

Appendix A: Systematic literature search strategy .................................... 181

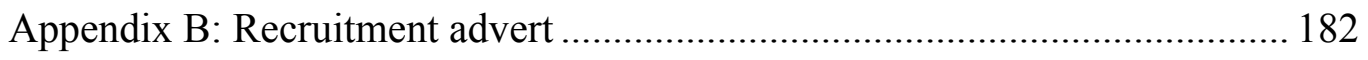

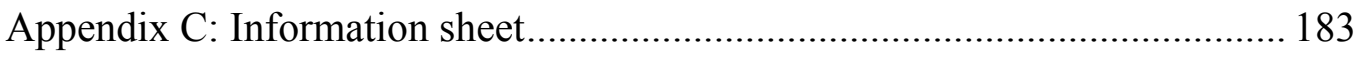

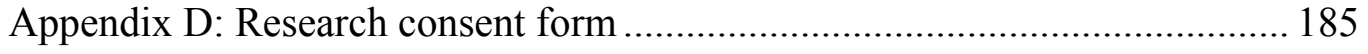

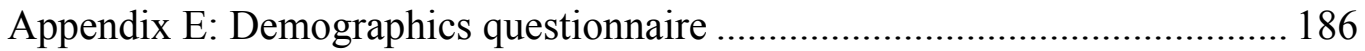

Appendix F: Example extract from field notes ........................................... 188

Appendix G: Semi-structured interview schedule ...................................... 189 
Appendix H: Structured interview schedule. 191

Appendix I: Payment receipt form......................................................... 193

Appendix J: Example of open coding (Louise) ............................................. 194

Appendix K: Example of selective coding (Petra) ......................................... 195

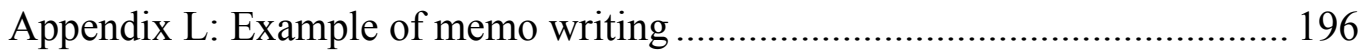

Appendix M: Participant respondent email .................................................... 197

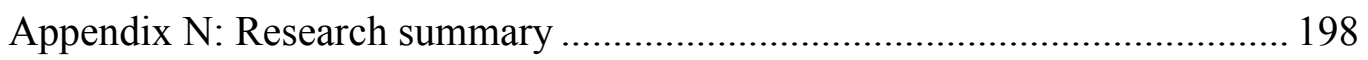

Appendix O: University of Essex ethical approval documentation................. 200

Appendix P: Summary of core categories literature search strategy ................203 


\section{Statement of terms}

Amputation: A surgical procedure by which a part or whole of a limb is removed (Amputation Coalition of America, 2008). This term will only be used in this thesis when referring to the medical procedure itself.

Limb loss: The wider literature refers to amputation and limb loss interchangeably. The term 'limb loss' will be used in this thesis to refer to the wider personal psychosocial experience following on from a surgical amputation (rather than solely the medical process).

Family network: This term is used in this thesis as a liberal definition of family membership. This allows the inclusion of all kin not related through biological or legal ties, who have been identified as 'family' or 'like-family' by those in the network.

CID: Chronic illness and disability.

GTM: Grounded theory method.

PWLL: Person(s) with limb loss. 


\section{Tables and figures}

\section{List of tables}

Table 1: Description of sample

Table 2: Examples of coding development

Table 3: Application of model of reflexivity

\section{List of figures}

Figure 1: Diagram of analytical procedure

Figure 2: Diagrammatic representation of emerging theoretical framework 


\section{Chapter 1: Introduction}

\section{Overview}

This chapter provides an overview of the existing knowledge on limb loss, in four parts:

Part 1: Clinical and social context. This places the topic of limb loss within its clinical, political and sociocultural context, with a consideration of how this influences the experience of both the individual and those around them.

Part 2: Individual perspective on limb loss. This summarises the research into the experiences and challenges faced by individuals who have lost a limb.

Part 3: Family perspective on limb loss. This summarises the theories and research into limb loss from the perspective of the family. This draws on wider physical healthcare and chronic illness and disability (CID) research.

Part 4: Rationale for research. This concludes the existing research into limb loss and families, then outlines the rationale and aims of the present study. 


\section{Part 1: Clinical and social context}

\section{Epidemiology}

Amputations occur as a result of trauma or complication from a physical illness, such as diabetes, cancer, vascular conditions or infections. The level of amputation can vary from a single digit to the whole limb, in an upper or lower limb. In lower limb loss, for example, this could vary from the loss of toes, to the loss of the entire leg and partial sections of the pelvis (Limbless Association, 2012). Rates of amputation in the UK are increasing, which is in part associated with increasing rates of diabetes and poor foot care (Diabetes UK, 2016). Amputations are also more prevalent as medical technology advances and patients are surviving life-threatening injuries or diseases, but do so at the cost of an amputation (Edwards, Phillip, Bosanquet, Bull \& Clasper, 2015). The latest published data for prosthetic limb fitting centres in the UK shows that 5,906 referrals for prosthetic treatment were received in the year 2011/2012 (Limbless Statistics, 2013). Of these, 70\% of referrals were for male patients; and 70\% were for lower limb loss. The most prominent causes were vascular problems, including complications from diabetes $(70 \%)$, followed by trauma $(12 \%)$ and infection $(8 \%)$.

The physical impact of an amputation can include the loss of mobility and functional precision, with some more substantial amputations requiring the use of prosthetics (where accepted by the individual). The extent of the physical impact of amputation is greatly amplified when it involves the loss of a joint. For the sake of convenience for the researchers, research tends to focuses on lower-limb loss, as this accounts for the largest proportion of amputation (Limbless Statistics, 2013). If all amputations have potential medical and psychological consequences, the type of 
impact differs depending on which limb has been lost. Lower limb loss is associated with impairments in mobility; whereas upper limb loss is associated with difficulties in more intricate functions and social communicative behaviours (Rybarczyk \& Behel, 2008).

Acquired limb loss differs somewhat from congenital limb deficiency, when children are born without any or the full development of their $\operatorname{limb}(\mathrm{s})$ as a result of the effects of genetic and/or environmental factors (Ephraim et al., 2003). In the wider disability research literature, there is a general consensus that congenital disability is associated with a greater sense of acceptance by the individual (Li \& Moore, 1998), disability self-concept and assured identity (Bogart, 2014). It is suggested that children with congenital limb deficiency and their families have a longer process for adjusting to difficulties and thus would be less at risk of adverse outcomes, compared to children with acquired limb loss (Tyc, 1992). This thesis will focus on the experience of acquired limb loss, in order to examine the transition that the individual and their families experience from life with the limb to life without it.

\section{Clinical context}

Limb loss is a prevalent public health issue, with a substantial cost to public services. This is predominately associated with the costs of long-term health and social care, rather than the medical costs of the amputation itself (Ephraim, Dillingham, Sector, Pezzin \& MacKenzie, 2003). Within the NHS, services for the longer-term care of this population are predominately provided through 35 regional limb fitting centres, with a range of private facilities also available. It is estimated that between 45,000-60,000 patients are actively using these services, creating an estimated cost of $£ 60$ million per year to the NHS (British Healthcare Trades 
Association, 2016; NHS England, 2015, 2017). These services are typically made available after the surgical amputation, once the initial healing has taken place (Limbless Association, 2017a). The focus of these services is highly orientated towards the rehabilitation of functionality and mobility through the use of prosthetics to address the primary impairment in limb loss. The relevant NICE guidelines focus particularly on the requirements for post-amputation care for disease-related amputations (NICE, 2015) and for associated pain (NICE, 2013). As such, the policy focus for this population is geared towards specific features.

The biomedical model has held dominance in modern healthcare, emphasising the medical and biological factors involved in disease. There is criticism that this holds a reductionist view of health, as a range of psychosocial factors influence an individual's experience of physical and mental health conditions, such as whether they adopt a sick role (Engel, 1977; Wade \& Halligan, 2004). In line with this, clinical practice for supporting the rehabilitation of the person with limb loss (PWLL) should ideally adopt a biopsychosocial approach, delivered through multi-disciplinary teams of consultants, nurses, rehabilitation and prosthetic engineers, occupational therapists, physiotherapists and psychologists (NHS England, 2015). This approach enables better decisions to be made about whether the PWLL would be suitable for a prosthetic limb and whether it would enhance their quality of life (Murray, 2010). This is particularly relevant to managing difficulties associated with limb loss which create secondary disabilities (e.g. mental health disorders, chronic pain), and reducing the impact these have on physical rehabilitation (Gallagher, Desmond \& MacLachlan, 2008; NHS England, 2015). It is recommended that post-amputation care includes access to counselling or clinical psychology services, particularly for those individuals who experience limb loss as a result of trauma (British Society of 
Rehabilitation Medicine, 2003). Psychological interventions such as relaxation and cognitive therapy have also contributed effectively to medical interventions for the management of associated pain (Ehde \& Wegener, 2008). However, it has been argued that such psychological interventions should not focus solely on difficulties in limb loss, given that for some with chronic medical issues, the amputation may be a source of relief from ongoing discomfort. There is a call for research, policy and treatments to consider aspects of positive adjustment to limb loss, in order to achieve the primary goal of enhancing the individuals' quality of life (Gallagher et al., 2008). Overall, it is evident that psychological therapies will account for part of the longterm financial cost of limb loss.

Family members often act as formal or informal caregivers, with a substantial personal influence on day-to-day health behaviours and the management of healthcare (Carers UK, 2015). As such, their role may well influence an individual's adaptation to their health condition and their compliance with advice from professionals. This underlines the importance of taking a collaborative approach with families in longer-term care, which psychologists should consider from a systemic perspective (Eliott \& Rivera, 2006). NICE guidelines do consider the significance of the role of caregivers in healthcare, although the focus has so far been on familial caregivers in the context of dementia (NICE, 2006). However, new guidelines are expected to be published in 2019 for the provision of support for all adult caregivers, whether they have formal or informal caring roles in the family (NICE, 2017). This will provide a context whereby a wide range of caregivers can be considered in services (rather than solely those related to dementia), which will therefore affect clinical provisions to familial caregivers of PWLL. 


\section{Political and sociocultural context}

The social experience and rehabilitation of this population are heavily influenced by the wider sociocultural, economic and policy context. A range of biopsychosocial factors are relevant with medical, political, economic and social dimensions in all healthcare (Engel, 1977; Wade \& Halligan, 2004), including limb loss (Ferguson, Sperber-Richie \& Gomez., 2009; Wegener, Hofkamp \& Ehde, 2008). In cases of paediatric limb loss, for example, lower socioeconomic status (SES) is associated with poorer psychological adjustment to the use of prosthetics (Boyle, Tebbi, Mindell \& Mettlin, 1982). This finding is now relatively outdated and may not reflect the influences affecting PWLL in the current socioeconomic climate. However, it remains the case in general healthcare that low-SES is associated with poorer outcomes for mental and physical health, including reduced affect. It is suggested that low-SES creates a highly stressful environment, with less capacity and access to resources in order to manage these stressors (Gallo \& Matthews, 2003). In applying this to limb loss, it may be that PWLL in low-SES communities are not in an optimum environment to facilitate coping and recovery.

From an anthropological perspective, it is considered that limb loss represents a disability that has particularly difficult connotations in terms of the individual's interactions with society, given that the body is a social entity. Messinger (2008) illustrates this point by identifying types of limb loss that may limit some social communication behaviours, such as the loss of a right hand limiting the social act of hand-shaking; and the loss of a left hand hindering social recognition of the person's marital status.

Sociocultural views regarding the acceptance of disability will determine whether or not a PWLL perceives themselves to have a disability. That is, messages 
are created by external cues in the environment (e.g. how accessible it is) or the language and definitions which are used in society about disability. These in turn influence the narrative that is created by the PWLL regarding their limb loss (Schaffalitzky, Gallagher, Desmond \& MacLachlan, 2010). The political and traditional view of disability tends towards a strong emphasis on the medical model, defining disability (including but not limited to physical disability) in terms of a biological impairment to the body. The development of the social model of disability has created a social movement which pushes against this assumption. This model states that a disability is not created by an impairment in the individual, but is instead created by the social, environmental and economic restrictions that are placed on them (Oliver, 1983). In revisions to this model, it has been acknowledged that other individual factors are highly relevant to the conceptualisation of a disability status, such as gender and race. Its aim is more to provide a general framework for the recognition of the rights of people with a disability, rather than being a specific model to account for all experiences of people with disabilities (Oliver, 2013). In limb loss, one should therefore not presume a status of disability, but instead recognise the sociocultural context which influences whether a person with limb loss considers themselves to have a disability.

The social experience of limb loss and disability will also be influenced by UK legislation. The Equality Act 2010 defines a disability as a condition which creates a substantial and long-term impact on an individual's ability to undertake daily activities. We can reasonably assume that limb loss would be included within this. The UK legislation does aim to protect the rights of people with disabilities and any associated individuals (e.g. parents and carers), particularly to live a life free of discrimination and to be able to access employment and public services. On an 
international level, the United Nations Convention of the Rights of Persons with Disability (United Nations, 2008) continues to protect the rights of this population. This policy emphasises the importance of personhood in disability, focusing on the individual rather than the disability. This influences the language that is used about disability at a socio-political level, as it determines that the disability must be described as secondary to the individual. For example, a person who has experienced a limb-loss should be defined as a 'person with limb loss' (PWLL) rather than 'amputee'. The term of PWLL has therefore been used in this thesis.

The political attention given to limb loss has been particularly driven by historical and current military conflict, with a focus on prosthetics (Messinger, 2008). As rates of traumatic amputation and associated costs in the military increase, the public and government focus on the physical and psychological effects of military conflict continues (Edwards et al., 2015). One government report revealed that active members of the military receive excellent and comprehensive rehabilitation after limb loss, but that this standard of care is not matched in the NHS for veterans returning to civilian services (Murrison, 2011). This report went on to note the importance of research in examining the experience of PWLL and their families, in order to understand how they can be better supported in both military and civilian services. In response to Murrison’s report, the government announced a 2-year £11million investment into military prosthetics services, with the NHS being able to access $£ 6.7$ million of this funding. The intention here was for any improvements in military services to be applied as a template for NHS services (Ministry of Defence, 2013). While the government in the UK has changed since the publication of this report, the focus on wounded veterans in a political and societal sphere continues to be an important influence on the experience of PWLL. There remains a plan in place from 
NHS England commissioning groups to review the use and effectiveness of limbfitting services, although the review remains largely focused on assistive technologies such as electronic prosthetics (NHS England, 2017). This focus on prosthetics is illustrated again in a recent government statement, which announced a funding release of $£ 750,000$ for the provision of sports prosthetics for children (Department of Health, 2017). Currently, the review of services by NHS England is in its early stages, which involves collaborating the views of service users through patient groups and limb loss charities (Limbless Association, 2017b). This highlights the importance of conducting research into limb loss within the current socioeconomic climate.

These social influences in limb loss have been examined in research, although this has largely been within the military context (Messinger, 2008). This military emphasis is mirrored on a wider cultural level, with media coverage of PWLL focusing particularly on veterans or Paralympians, perhaps representing a public perception of "heroes" for a proportion of this population. The social influence on recovery in the military is thought to centre on the sense of mental toughness and comradery which promotes pro-active coping (Desmond \& MacLachlan, 2006). This is supported in interviews with military women, who have explained that one must be familiar with the military before being able to understand their coping with limb loss (Cater, 2012). In particular, they have noted that their military training provides a specific network of support and creates a tough mental attitude; both of which have facilitated their coping. This sociocultural influence may also affect the construction of the emotional connection and meaning that is associated with the limb loss. In particular, civilian PWLL have reported that they would have felt a sense of honour if they had lost a limb in military combat, rather than through disease (Sjödahl, Gard \& Jarnlo, 2004). 


\section{Summary}

The issue of limb loss is once of national importance due to the level of need that should be met by the NHS. The experience of a PWLL may be affected by the wider social and cultural context in which they live.

\section{Part 2: Individual perspective on limb loss}

\section{Challenges for PWLL}

Losing a limb can create various challenges and difficulties, which can represent secondary disabilities. In the immediate after-math of the amputation, the PWLL may experience shock in relation to both the amputation and its aetiology. Individuals whose amputation takes place a long time after the aetiology are also at risk of other medical complications (Krueger, Wenke, Cho \& Hsu, 2014). All PWLL are at an increased risk of experiencing various sensory and psychological difficulties, including body image disturbances, pain and psychological distress (Horgan \& MacLachlan, 2004; Senra, Oliveira, Leal \& Vieira, 2012). In general, research indicates that PWLL commonly perceive themselves to have a high sense of disability and a poor quality of life, particularly in the first six months of their recovery. Longer-term outcomes are variable and may be influenced by a range of individual and social factors (Coffey, Gallagher \& Desmond, 2014). The psychological challenges of limb loss for the PWLL will be examined further here.

\section{Body image}

It is commonly reported that PWLL experience changes in their body image as 
they adjust to various new versions of their body. These include their self-image of the healing body, the traumatized body, the body with new components (prosthetics), how the body looks under clothes, and the kinetic body (how the body looks when in motion) (Gallagher, Horgan, Franchignoni, Giordano \& MacLachlan, 2007). It is hypothesised that the need to adjust to a new version of the body is a key element explaining why people with acquired limb loss differ from those with congenital limb deficiency. The latter group are more likely to have already developed a self-concept and body image without the limb, whereas the former group will experience a change in their body image (Rybarczyk \& Behel, 2008). However, body image disturbances can occur even in children and adolescents with acquired limb loss, possibly as their body image concept is not fully established at the time of amputation (Tyc, 1992).

The likelihood of people experiencing body image disturbance is influenced by various biopsychosocial factors. For example, disturbances in kinetic body image are particularly prevalent where the amputation impairs the person's balance or mobility. The quality of any prosthetics used also influences body image. In a survey of lowerlimb PWLL, it was found that there was a strong negative correlation between prosthesis satisfaction and body image disturbance for both males and females (Murray \& Fox, 2002). However, for males, an improved sense of body image only occurred when the PWLL was satisfied with the functional quality of the prosthetics (Rybarczyk \& Behel, 2008). It has been suggested that body image is the psychological aspect of limb loss which is most sensitive to sociocultural processes, given the stigma that exists for individuals who are visibly different from others.

Over time, PWLL are able to develop a new and healthy self-concept and body image (Rybarczyk \& Behel, 2008). 


\section{Assistive technologies}

Assistive technologies include the use of prosthetics, wheelchairs and adaptations to homes and vehicles. Most research focuses particularly on the use and perception of prosthetics. These come in various forms and are intended to improve mobility or function. In qualitative interviews, PWLL who have lower-limb prosthetics have recognised the benefits of these technologies in allowing them to increase their independence and thus reduce the need for support from others. Prosthetics have also served to allow PWLL a greater sense of purpose and hope for functional restoration. However, these individuals also identify a sense of alienation and the objectification of the prosthetic, so that it becomes 'the leg' rather than 'my leg' (Dunne, Coffey, Gallagher, Desmond \& Ryall, 2015). This sense of objectification was reported particularly when the PWLL was experiencing unpleasant physical sensations as a result of the prosthetic. Research has highlighted the occurrence of these secondary issues, which include unpleasant sounds or smells, pain, functional limitations, and body image and sexual identity disturbance (Cater, 2012; Murray, 2010; Sjödahl et al., 2004). These difficulties may affect the decisions PWLL make as to whether to accept or decline the use of prosthetics.

The choice of whether or not to accept prosthetics, and what type to use, will also be influenced by factors such as appearance, comfort, functionality and whether the PWLL perceives that prosthetics will help or hinder these facets (Biddiss, 2010). However, individual differences exist within this. There is some evidence that males are more likely to select a prosthetic based on its functional quality, whereas females are more likely to select based on its aesthetic quality (Murray, 2010). These findings suggest a potential process by which social influences affect the experience of limb loss, given that women particularly may experience increased pressure to confirm to 
societal norms in their appearance. Ultimately, people's decisions about and use of prosthetics are matters of individual experience. If the PWLL rejects them, they will eventually go through a process of learning to adapt without their use.

\section{Pain}

Amputation-related pain can be divided into several types: acute post-operative pain, residual pain, phantom pain and other secondary pain. Individuals may attempt to manage their pain through medication, self-management, mirror therapy, or TENS machines (Kulkuarni \& Grady, 2010). In a survey into lower-limb loss, residual pain (felt in the remaining stump) was reported in $70 \%$ of participants. Rates of phantom sensation (feeling as though the missing limb was still there) were higher in one study at $79 \%$, although most respondents felt that these were not bothersome (Ehde et al., 2008). Other studies have found that phantom limb pain remains a common phenomenon and is highly correlated with the experience of phantom sensation (Ketz, 2008; Kulkuarni \& Grady, 2010). Pain is an experience which can occur regardless of the age of the PWLL (Burgoyne et al., 2012). However, it is a phenomenon specifically related to acquired rather than congenital limb loss (Tyc, 1992). The mechanisms by which phantom pain occurs are complex. Evidence indicates that this is most likely to be neuropathic pain caused by the activity of the central nervous system, as the nerve endings in the stump continue to send signals to the brain (Richardson, 2010).

Many individuals with lower-limb loss also report secondary pain in other areas of the body. In one study, $50 \%$ of respondents reported back pain, with a further $50 \%$ of these individuals reporting that their back pain was severe enough to disrupt their daily functioning (Ehde et al., 2001). It is thought that secondary pain is caused by 
poorly fitting prosthetics or the excess strain to the back or the other limb, if the PWLL repeatedly hops to move around (Ehde \& Wegener, 2008; Ehde et al., 2000; Kulkuarni \& Grady, 2010).

A biopsychosocial model is relevant to our understanding of pain and its consequences. This is evident in limb loss due to the commonality of pain and subsequent psychological distress in this population, with rates of anxiety and depression being higher when residual pain is reported (Desmond \& MacLachlan, 2006). The psychological processes associated with pain are highlighted by findings that while men and women do not report differences in the intensity of the pain, women do report that it causes greater interference in their lives. This suggests that people's responses and adjustment to pain can differ (Hirsh, Dillworth, Ehde \& Jensen, 2010). It is suggested that where the amputation is perceived to be traumatic, that is where post-traumatic stress disorder (PTSD) or other trauma symptoms are occurring, the pain may act as a trigger for psychological distress and vice versa. This argument makes sense, given that similar neural pathways are associated with both pain and PTSD (Giummarra et al., 2011; Poundja, Fikretoglu \& Brunet, 2006; ScioliSalter et al., 2015). Pain may also be associated with and triggered by social processes. One study found that $16 \%$ of individuals with phantom pain experience pain synaesthesia as a trigger, that is that their phantom pain could be triggered by the sight or thought of another person in pain (Fitzgibbon et al., 2010). While this experience only affected a small minority of people in this study, its findings can be taken with other research to support the biopsychosocial perspective of amputationrelated pain. 


\section{Psychological distress}

Affective distress (i.e. anxiety, depression, PTSD) is relatively high in PWLL (Horgan \& MacLachlan, 2004; Stevelink et al., 2014). However, some experience low levels of distress and instead report feeling that they are able to grow and develop psychologically from their experience (Benetato, 2011). Children and adolescents also experience distress and responses akin to a grief reaction following an amputation (Turgay \& Sonuvar, 1983). The prevalence of psychological distress in PWLL has been estimated at 20-28\% for depression; and 35-37\% for anxiety (Desmond, 2007; Hawamdeh, Othman \& Ibrahmin, 2008). Depression in particular has been found to be associated with poor quality of life in PWLL (Epstein, Heinemann \& McFarland, 2010). A range of factors are likely to affect the level of distress individuals experience, such as: whether they are able to make a decision about having an amputation (Hamill, Carson \& Dorahy, 2010); whether they receive interpersonal support for prosthesis use (Legro et al., 1999); and whether they experience phantom or residual limb pain (Desmond \& MacLachlan, 2010). The latter may be particularly important given the commonality of this symptom and its associated limitations to the lifestyle of the PWLL (Copuroglu et al., 2010; Ephraim, Wegener, MacKenzie, Dillingham \& Pezzin, 2005).

There has been a debate in the literature about the extent to which PTSD and trauma symptoms are related to the aetiology of the amputation. In systematic literature reviews, the authors conclude that there is conflicting evidence as to whether aetiology is related to these symptoms, or indeed any form of psychological distress. However, one possible conclusion is that trauma-specific amputation is often accompanied by a sense of denial, with persistent feelings of distress and disability; whereas disease-based amputation is more commonly associated with anger (Horgan 
\& MacLachlan, 2004; Perkins, De'Ath, Sharp \& Tai, 2012). While many may feel that the process of a CID and losing a limb in itself is traumatic, some research indicates that the risk of PTSD is greater in cases where the limb is lost through trauma, for example as a result of a road traffic accident or warfare. In these circumstances, the limb loss could create a "double-trauma" effect (Cavanagh, Shin, Karamouz \& Rauch, 2006).

\section{Adjustment and coping}

The PWLL is faced with a range of challenges to which they must adapt. The literature predominately adopts an assumption that adjustment to these challenges can be assessed through measures of anxiety and depression. There is a particular emphasis in research into the adjustment to pain and prosthetics. As such, other issues of importance for this population may be ignored. Whatever the challenges faced, the process of adaptation is an incremental one involving various stages, with adjustment being the final phase in which the PWLL feels able to reintegrate into their lives, hold a positive attitude about themselves and their bodies and maintain a sense of a positive quality of life (Bishop, 2005; Desmond \& Gallagher, 2008). This final level of adaptation (i.e. adjustment) may not be possible for all individuals (Ferguson et al., 2009).

A review of paediatric limb loss concluded that overall there is a better sense of adjustment to prosthetics, daily activities and developmental transitions in children and adolescents than in adults. This is surprising given that many developmental tasks for children (e.g. gaining independence away from parents) rely on physical ability (Tyc, 1992). Some have argued that adjustment to limb loss is just one that occurs as a natural process over time, given the important processes and changes in recovery 
which occur in the first year after amputation (Benetato, 2011; Hawamdeh et al., 2008; Kratz et al., 2010; Sjodahl et al., 2004). It has been postulated that the process for the PWLL and those around them evolves over time, so that the various forms of coping that individuals adopt changes as they face new and different challenges, this impacting on their interactions with their environment (Ferguson et al., 2009; Hirsh et al., 2010). Overall, the process of adjustment is influenced by both individual and systemic factors.

\section{Individual factors}

In determining the individual factors which influence psychological adjustment, the literature is underpinned particularly by the 'Transactional model of stress and coping' (Lazarus and Folkman, 1984). This assumes that the PWLL's adjustment is mediated by their use of coping strategies, which can be broadly divided into either: practical based strategies (with instrumental actions to alter environmental difficulties); or emotion-based strategies (to alter the meaning made of the situation). This model postulates that one's somewhat conscious choice of strategies will depend on situational demands and the appraisal which is made regarding the stressor (i.e. in this instance, whether the limb loss is perceived as a threat, challenge, loss, neutral change, etc.). Over time, a reciprocal interaction occurs between the strategies, the individual and their environment, modifying each of these components. Overall within the limb loss literature, coping strategies have been found to account for a third of the variance in adjustment, when measured by levels of psychological distress (Desmond, 2007; Sjodahl, Gard \& Jarnlo, 2004).

In the wider research on coping, the general assumption is that how people cope depends on situational demands. However, this may be associated with factors related 
to the individual. In the experience of physical pain, attachment styles have been found to be a significant predictor of coping strategies. Individuals with attachmentanxiety and attachment-avoidance are more likely to use catastrophizing and less likely to engage in social support when they are in pain, compared to those with higher attachment-security (Kratz, Davis \& Zautra, 2011). Attention is paid in the limb loss literature to other individual factors influencing coping. There are some general gender differences, with female PWLL being more likely than males to select emotion-based strategies (Hirsh et al., 2010). PWLL from a military context have reported using relaxation, increased activity and alcohol to cope with pain (Desmond \& MacLachlan, 2006; Ketz, 2008). These strategies are additionally associated to measures of psychological adjustment, with active problem-solving strategies leading to an increase in adjustment to prosthetics, and decrease in psychological distress. Conversely, avoidance is associated with greater psychological distress (Desmond, 2007). Overall, there is some evidence to indicate the importance of practical and active coping strategies in limb loss.

The majority of the research into limb loss also reveals substantial use of cognitive and emotional-based strategies such as humour, PWLL comparing themselves to people who are worse off, and cognitive processing. The selection of emotion-based strategies may be particularly appropriate in limb loss given the permanency of amputation (Cater, 2012; Oaksford, Frude \& Cuddihy, 2005; Stutts, Bills, Erwin \& Good, 2015). Cognitive processing is defined as the process by which the PWLL can find meaning and sense from their amputation. Positive meaning making involves finding acceptance, becoming satisfied with coping, having a sense of moving on, and cognitive restructuring. Negative cognitive processing includes rumination, catastrophizing, anger, denial and counterfactual thinking (Phelps, 
Williams, Raichle, Turner, \& Ehde, 2008). Paradoxically, these seemingly dysfunctional negative processing strategies have in fact been associated with improved psychological adjustment, when measured by levels of post-traumatic growth (Benetato, 2011) and depression (Hanley et al., 2004). The mechanisms of cognitive processing may be developmental over the process of recovery, as negative processing is said to be prevalent and associated with distress in the early stages; whereas positive processing is utilised and facilitates positive adjustment in the longer-term (Phelps et al., 2008). Children and adolescents have also been identified as using meaning-making strategies; although the process involved may depend on the age and cognitive capacity of the child. For example, findings reveal that the level of confusion surrounding amputation may mean that children react to the amputation by attributing it to their own bad behaviour (Turgay \& Sonuvar, 1983). Overall the research indicates that, whether positive or negative, this cognitive processing allows the PWLL emotional space to make sense of their experience and adjust to its associated consequences.

\section{Systemic factors}

Social support is widely identified as a vital coping mechanism in adjustment to both paediatric and adult limb loss, as well as other forms of CID. Reviews in general healthcare have found that social support buffers against the effects of additional stressors in ill health (Ross, Mirowsky \& Goldsteen, 1998; Uchino, Cacioppo \& Kiecolt-Glaser, 1996). It is primarily provided by families or friends, with couple relationships being a particularly important source of this support for adults. Social support comes in various forms for PWLL, but it particularly involves practical support, financial aid, help with problem-solving, reassurance and emotional support 
for boosting morale (Kratz et al., 2010; Tebbi, Stern, Boyle, Mettlin \& Mindell, 1984; Tyc, 1992; Valizadeh, Dadkhah, Mohammadi \& Hassankhani, 2014). The type of support provided is liable to change as recovery proceeds, for example with the PWLL needing more intensive practical help in the early stages of returning home from hospital. Support may also be provided by the wider social network, with employers playing a vital role in supporting the PWLL to return to work by making adjustments in the workplace (Ferguson et al., 2009). Other studies focus on the benefit of support through broader and newly formed networks consisting of other PWLL. This peer support may serve to allow the PWLL to feel validated and understood in their experience (Cater, 2012). The impact of social support is positive, with research indicating that it can facilitate adjustment. Specifically, higher levels of perceived social support are associated with lowered levels of anxiety and depression (Desmond \& MacLachlan, 2006; Hawamdeh et al., 2008); and enhanced levels of post-traumatic growth and quality of life (Benetato, 2011; Brier et al., 2018).

The mechanisms by which social support aids adjustment are complex, involving not just the extent of support and the number of people available and actively helping the person concerned, but also about their felt sense of the support. That is, the positive benefits are found to be related by the PWLL's subjective assessment of support, without objective assessment of how much support is actually provided to them (Murray, Simpson, Eccles \& Forshaw, 2015). For instance, a positive impact on reducing anxiety and depression exists even if social support is only provided by one person (Hanley et al., 2004).

Longitudinal research suggests that the mechanisms of social support and adjustment involve a process of social integration during recovery. PWLL have been found to adjust well if they are able to continue to engage in social relationships that 
are associated with important hobbies or activities (Williams et al., 2004). That is, PWLL will perceive themselves to be part of a supportive network, if they are still able to participate in activities that are common to that network. As an example, this might mean that a PWLL with lower-limb loss may feel better supported if their social network was formed through an art group, rather than a PWLL with friendships arising from a running group.

Assumptions should not be made that the presence of others is necessarily positive and conducive to recovery. Reactions of pity from others are reported to be a particular source of frustration for PWLL (Tebbi et al., 1984). Instances of conflict between the PWLL and their caregivers have been found to be associated with poorer adjustment and quality of life, even when other factors are controlled for (Brier et al., 2018). The effect of specific types of communication in these dyads may be one mechanism by which conflict occurs. Solicitous responding (where someone provides support in a way that takes over the task) can undermine the level of functioning and ability in the PWLL. The effects of this may include the maintenance of disability behaviours, increased levels of depression and greater pain interference (Hanley et al., 2004). However, these relational processes in social support have only been examined from the perspective of the PWLL, rather than also the family and social network. These findings underline the importance of researchers and clinicians examining specific communication and relational processes between the PWLL and their network, in order to identify important systemic factors in rehabilitation. 


\section{Summary}

Limb loss creates various physical and psychological challenges for the PWLL. Their overall rehabilitation as they recover from the amputation will be especially influenced by the social network around them (most likely their family), who provide the most support to them on a daily basis.

\section{Part 3: Family perspective on limb loss}

\section{Defining family constructs}

When researching family systems, one must first consider which definition of family to adopt in order to identify membership of the system. The researcher or clinician's view of this may differ to that of the participant or patient. It is generally accepted that there are three approaches to defining membership in family systems: structural (membership based on presence in the same household); functional (based on combined social functions, e.g. provision of materials, upbringing of children); and transactional (through shared family identity) (Miller, 2013). While there is no universal agreement as to which definition should be used, the structural definition widely dominates the research and policy literature. Miller argues, however, that this definition does not reflect socioeconomic and demographic changes over time in Western society, such as increases in divorce and blended families. As these changes occur, the family becomes a construct which relates more to emotional ties, rather than ones made through blood or marriage (Treuthart, 1990).

A more lenient definition has been adopted in healthcare research, for example in the examination of family processes in relation to the human immunodeficiency 
virus (HIV). Here family members can be identified as individuals who take on familial roles (e.g. parenting of children) or provide caregiving to the ill person (Pequegnat \& Bray, 1997; Stajduhar, 1998), without necessarily being related to them. This ties in with the terms of "fictive kinship" where familial ties can be extended, for example having an "aunty" who is not technically a relative. This notion of fictive kinship is particularly relevant where no familial ties are available. These relationships have been found to be particularly prevalent in minority communities such as homosexual and BME communities (Miller, 2013); as well as in smaller families (Ibsen \& Klobus, 1972) and the lives of older adults (Rae, 1992). Critics have argued that describing these ties as fictive suggests that they are not real. Through interviews, the term "voluntary kinship" was developed, which includes four sub-types: substitute kin (used due to no contact with own family); supplemental kin (additional to family in instances of unmet need); convenience kin (selected based on context of time or place); and extended kin (members of further extended family) (Braithwaite, Bach, Baxter, DiVerniero \& Hammonds, 2010).

A postmodernist view, which is now gradually becoming more accepted in society, allows for individuals to define for themselves those who have membership within their family system (Miller, 2013). As such, there is a suggestion for services and research to consider that individuals (including PWLL) and their families will vary in their definitions and inclusions of chosen kinship. A wider range of individuals may therefore need to be examined in research and treatment of family systems (Eliott \& Rivera, 2006; Ell, 1996). This approach will be adopted in the current research study, in order to consider the family network as encapsulating not just blood and legal relatives, but also other kin. This broader definition of family will reflect the networks of individuals who provide social support to PWLL. 


\section{Theoretical frameworks of family systems}

In understanding family processes, it is useful to draw upon existing theoretical models which conceptualise these systems. Within healthcare specifically, these system models must be considered alongside individualist approaches, in order to ensure a comprehensive view of patient and family recovery and of coping with a CID, including limb loss (Ell, 1996). Several family theories will be presented here, although this is not intended as an exhaustive list of all possible theoretical frameworks. Those referred to have been selected as frameworks which aim to explore how and why systems respond to illness and disability. They may provide insights into how this occurs in families affected by limb loss.

\section{Family systems theory}

The family systems theory (Bowen, 1966) defines the family as an emotional, relational, communicative and active unit. The behaviours and emotions of an individual in this system are learnt subconsciously or consciously through generations. They are based on family roles which are set within the system, where each individual is attributed their own characteristics and labels, including clinical symptoms. Transactions between family members are made with the purpose of maintaining the equilibrium of these roles and the system. For example, in times of illness in one family member, other family members will over-function to compensate and so maintain equilibrium. The extent of their impact on each other's level of functioning is determined by the intensity of their emotional connectedness to one another and by their differentiation of self (the degree to which they are influential as people). Their connectedness normally serves to maintain family functioning, although the presence of anxiety or stress can mean that this 
connectedness can become overwhelming for one or more members of the family. The most accommodating person in the system will take on the family anxiety and may subsequently develop clinical symptoms, whether emotional or physical. One of several family patterns will emerge in order to resolve family tensions or anxieties: marital conflict; focusing on dysfunction in one spouse; emotional distancing; or transmissions of problems onto offspring (whereby parents project by presuming the child has a difficulty and focusing on them accordingly). This theory presents a view of how families work as a system and how emotional difficulties develop, particularly in times of family stress, such as the CID of one member.

\section{Family life cycle}

The family life cycle theory (Carter \& McGoldrick, 1988) builds upon Erikson's individualist life cycle model, with the idea that families go through different developmental stages over time. These stages each include their own emotional processes and developmental tasks to be achieved, such as offspring leaving the family home or parents becoming grandparents. The theory states that these stages occur within the family's sociohistorical context and may influence family roles and behaviours. For example, the gender roles in the family may be defined by cultural norms and messages passed through generations. Therefore, family processes are influenced by the wider extended family, the community and culture in which they are embedded.

Families are not seen as static, as evolutionary changes occur (e.g. births and deaths) and these create stress. This stress is seen as a necessary experience enabling the family to move forward to the next developmental stage. Such transitions can be a difficult time for families, particularly as they try to redefine their relationships and 
roles in the system. Conflict or emotional distress may also arise at times, caused by stressors that are either predictable (e.g. stigma passed between generations) or unpredictable (e.g. a CID). Problems may also develop if a family member becomes stuck in a certain phase or if they adopt roles which are not in sync with their developmental stage (e.g. if a parent encounters a difficulty that elicits parenting behaviours from their child). In times of such difficulty, the family may lose the continuous movement of the life cycle and become fixated on the present or on a feared future.

In the application of this model to physical health (Newby, 1996), it has been considered that the occurrence of a CID can change the developmental process of the family. For example, the illness may serve to pull family members together in order to focus on the ill person. An additional stress is created if the illness occurs at the same time as a developmental transition, as it will be reappraised in light of the developmental task at hand. In particular, the family may respond with increased difficulty to a CID (including limb loss) if it creates a discrepancy with the developmental task of another family member, such as an older relative who is about to transition into retirement but then must take on a demanding caregiving role.

\section{Problem determined systems}

The problem-determined systems theory (Anderson, Goolishian \& Windermand, 1986) is influenced by family therapy and social-constructivist ideologies. It conceptualizes a system which extends beyond the traditional family structure. More specifically, it postulates the existence of a hierarchy of social constructs, where each individual construct is defined both by language and the position in which it rests within the hierarchy. Thus, the concept of an individual is 
defined by the family; the family is defined by society; and society is defined by the wider culture. The theory argues against the assumption that a pathological problem, be it physical or emotional, sits outside of these systems and is created by external forces. Instead, there is a dual process of causality between the system and the problem. As such, the system comprises those people who communicate about the problem; and the definition and nature of the problem is defined by the collaborative language of this system. In other words, the physical or emotional concept becomes a problem as everyone has made a collective decision that it is a problem. The authors use this theory to suggest that researchers and service providers need to think beyond purely structural family constructs in defining a system. This approach allows for a system to be defined as all those who communicate about the problem, including professionals. Within healthcare and limb loss specifically, this points to the system being constructed by family members, romantic partners, friends, physiotherapists, psychologists, etc., through their shared language around the limb loss.

\section{Families in healthcare}

The research discussed in part two of this chapter highlights the importance of the network around an ill or injured person in facilitating their recovery, including for a PWLL. We must next consider what this experience is like from the perspective of members of that network. This will help us to understand more about the family and relational processes involved, as well as what it is like to provide this support. From a clinical perspective, this provides a greater understanding of how to assist the patient and family with rehabilitation (Ell, 1996).

In the literature of familial relationships and healthcare, the focus lies on the substantial stress and burden placed on family carers (particularly spouses and 
parents) and the various risk factors associated with this stress (Etters, Goodall \& Harrison, 2008; Lim \& Zebrack, 2004; Pitceathly \& Maguire, 2003). These include factors related to the carer (e.g. financial burdens, managing multiple roles, dealing with psychological and physical demands; acceptance); as well as factors relating to the illness, such as whether it is seen as developmentally appropriate to the individual (Eliott \& Rivera, 2006). However, the experience of carer burden is not necessarily related to which CID has developed. For example, an examination of the impact of spinal cord injuries on spousal carers found that the caregiving burden did not focus on the spinal injury itself, but on the impact that it had on their relationships (Chan, 2000). The burden on relationships could go on to affect the extent and quality of caregiving or general support a family can provide, thereby creating a complex interdynamic process in health and support. In a review of families in healthcare, Ell (1996) found that, while most research focuses solely on the relationship between the individual and their caregiver, these inter-personal processes may affect multiple relationships in the whole family and may lead to both positive and negative changes in these wider relationships. The changes and ties formed in such families can be inclusive to the point that families do not seek support from services until desperate, often when there has been a significant deterioration in physical wellbeing. This highlights the important need to consider what processes occur for these families and how they react to changes in physical health, in order to understand how to better support them in services.

\section{Families in limb loss}

Within limb loss, it seems that the after-effects of amputation are felt across the whole network and not just the PWLL. In a personal reflective account of her 
mother's traumatic amputation, Agne (1993) considered how the role of the family in the early stages of the decision to amputate may create difficulties in developing acceptance post-amputation. She described the upset in seeing her mother experience emotional distress, particularly when using prosthetics. A change of roles was particularly evident in her example. She described how she and her sisters had to take responsibility for caring and rehabilitation as limited services were available where her mother lived in the Philippines. This shifted her role from a daughter to that of a parent. She found that her mother's long-term rehabilitation was harder on the family than the early stages of her recovery, with the need for them to provide adaptations to the home and gradually support her mother (as the PWLL) to return to a life of 'normality'. Whilst useful, this example is a personal anecdotal one, rather than empirical research by which we can draw appropriate conclusions.

Clinical services, along with research, have attempted to consider the importance of the family in limb loss, although this has most often focused on spousal relationships. However, in one Canadian surgical service, parents are offered time to see their child after the amputation and before the anaesthetic has worn off. This allows them to get used to their child's altered body and thus be able to focus on supporting the child with this later on (Jaraway et al., 2013). From a research perspective, families and carers have been used in samples as a method of triangulation for understanding specific issues in limb loss, including body image disruption (Jeppsen, 2016); the selection of prosthetics in congenital limb deficiency (Vasluian et al., 2013); and the process of recovery from traumatic limb loss (Ferguson et al., 2009). Even with the inclusion of the family, these studies have not considered the impact of limb loss on family members themselves and their relationships with the PWLL. 
Within caregiving specifically, one study has examined family carers (predominately wives) of individuals with a minor amputation (i.e. foot) from diabetes. In this study, carers were assessed six months after amputation, with selfreport questionnaires used to investigate their lifestyles, carer burden, psychological and family functioning, and quality of life (Alves-Costa \& Pereira, 2017). The results indicated a correlation between improved mental quality of life, reduced carer burden, increased family functioning, and their own increased levels of physical activity. However, the effects of this were moderated by the amount of other support carers could access, and how long they had been caring for. As such, the authors highlighted the need to provide input and support to carers after an amputation, to encourage physical activity (perhaps as an adaptive coping strategy) and to consider whole family functioning in recovery, to benefit both the carer and PWLL.

There is still little known about the experiential and relational processes family networks go through after an amputation. Indeed, a review which attempted to explore the impact of traumatic amputation on the family could not reach any clear conclusion as to what the effects were, due to insufficient research. Instead, this became focused on the effects of poly-trauma on the family (Fossey \& Hacker Hughes, 2014). Furthermore, little research has been undertaken into the family and parental processes which occur in paediatric limb loss. Although it is known that children with acquired limb loss are relatively resilient (Tyc, 1992), it is not known whether families may continue to be affected regardless of this. It is potentially the role of the family network to facilitate this better adjustment. In the absence of research, it may be useful to apply findings from the wider health and disability literature. However, it appears important to consider and understand the experience of 
multiple types of family relationships within limb loss specifically and to consider this within various stages of recovery $($ Ell, 1996).

\section{Lived experience of families}

As indicated, efforts should continue to be made to examine the impact of all amputation types on families, given their important role in healthcare. This includes going to greater lengths to include the voices of carers and family members through qualitative methods (Eliott \& Rivera, 2006). A systematic literature search (Appendix A) was completed to identify the qualitative research which has examined the perspectives of the carers and families of a PWLL, with various causes of amputation. This revealed five papers, all of which examined either parental or spousal carers (predominately wives), most of whom were interviewed with the PWLL present.

In the immediate aftermath of an amputation, spouses report experiencing a range of emotions such as confusion, grief and fear; with a sense of acceptance developing in their place over time (Livingstone, van de Mortel \& Taylor, 2011; Reed \& Claunch, 2002). These spousal carers are generally at an increased risk of developing significant psychological difficulties, with further significant impact of limb loss on their economic wellbeing (due to giving up work in order to provide care and the financial demands of providing for the PWLL's needs) and their social wellbeing (Thompson \& Haran, 1985). Spouses often reported that their needs would be ignored by health and social care services for the PWLL, which contributed to a sense of social isolation and that their needs were of reduced importance (Reed \& Claunch, 2002; Thompson \& Haran, 1985).

The caring role that a spouse has with the PWLL may develop over time. In the immediate aftermath of an amputation through trauma, wives reported that they 
focused on the survival of the PWLL and the practical aspects of problem-solving and providing support. Later on, the process they described was one of sheltering and protecting the PWLL from any negative experiences, particularly emotional distress (Reed \& Claunch, 2002). As such, this new role may have an impact on the traditional role they take in their relationship with the PWLL. Overall, there is an identification that returning to 'normality' occurs at a cost to changes in their relationship (Reed \& Claunch, 2002), particularly due to the changing roles and activities each fulfils at home (i.e. taking over previous tasks or the addition of new caregiving tasks) (Livingstone et al., 2011). It is possible that spousal relationships are more susceptible to different changes in limb loss, given that their relationship includes sexual intimacy. In examining this aspect of relational changes following limb loss, spouses identified changes in their sexual relationships as a result of the limb loss, but these related more to functional rather than psychological elements of sexuality. Changes in sexuality were not necessarily conceptualised as negative, or directly attributed to the loss of the limb itself. Rather, participants spoke of the natural effects of relationships changing over time or about the related illness (e.g. chemotherapy effects in cancer). These relational changes were deemed to be secondary to focusing on the survival and health of the PWLL (Verschuren et al., 2013). This may again represent a process in which spouses diminish their own needs in order to focus on the PWLL.

Only one study could be identified which examined the experiences of other family types of family relationships. Turgay \& Sonuvar (1983) examined the experiences of parents where the child was referred to a psychiatrist following the amputation. It was identified that parents undergo a similar grief reaction to their children following the amputation, in addition to their own feelings of guilt. Their 
reaction appeared to be dependent on a range of systemic factors including family functioning and relationships with the medical professionals. Parental emotions of anxiety may be projected into their child, or feelings of anger may be targeted towards the medical professionals. However, parents would cope by focusing on the practical steps that needed to be taken, or focusing on a feeling of relief. This was in the instances where the amputation was performed to save the child's life from a serious illness, and thus parents expressed that the loss of limb was easier to cope with, compared to the loss of their child. These conclusions into parental experience are perhaps not normative of the broader experiences of families in limb loss, given that these findings are concluded from a sample of parents where the children were experiencing severe distress requiring psychiatric input.

The conclusions drawn from this limited pool of research may be limited, given the methodological issues involved. Of those studies that utilized a sample with both the PWLL and their family member, some of the interviews were conducted with the PWLL present. As such, it would be reasonable to doubt the openness with which family members approach the interview, especially given the finding that spouses will sometimes repress their own feelings to protect the PWLL (Reed \& Claunch, 2002). The findings of these studies may therefore not be a true reflection of the feelings and experiences of these or other family members. In the writing of these studies, the results sections integrate the experiences of PWLL with views of the families in their own experience (e.g. Thompson \& Haran, 1984; Turgay \& Sonuvar, 1983). As such, there is a poor differentiation through research and little is known of their own individual reactions to limb loss.

In addition, the sampling strategies used in these studies create a limited perspective of the lived experiences of other carers, family members and friends in 
the PWLL's social network. The only qualitative research studies to examine lived experience from a family perspective have mainly focused on spousal carers and, within this, predominately on wives (with the exception of the research into parental carers). This makes sense given that the large proportion of amputations are carried out on males. However, this approach largely excludes the perspective of the wider network that provides social support for a PWLL; and perhaps only applies to families where the PWLL is a married, heterosexual adult male. The experience of the spouses who participated may be unique in the sense of their having made a choice to stay in the relationship. Indeed, one study notes explicitly that the participants involved only included those where the marriage has not dissolved following the limb loss (Reed \& Claunch, 2002). As such, we cannot infer how the family and social network manage their own experiences, including that of providing support for the PWLL.

This reductionist view of the network's experience also arises as the research has so far been limited in its focus to specific issues within limb loss. This includes examining only sexuality (Verschuren et al., 2013); or using an interview schedule based on a previous schedule for PWLL (Thompson \& Haran, 1984). With one exception (Livingstone et al., 2011), participants have not been provided with the freedom to determine their own issues of importance. There is additionally a bias in the sampling strategies used, as all but one study (Reed \& Claunch, 2002) recruited from hospitals or clinics. As such, participants were all from the same geographical areas and were only drawn from people engaged in services. This means they are either from families where the PWLL has been hospitalized and was in the early stages of recovery; where the PWLL was accepting the use of prosthetics; or where the PWLL required psychiatric input. As a result, the research leads to little 
understanding of families of PWLL who have rejected the use of assistive technologies and as such may be more reliant on the family network. Lastly, only one of the five studies was conducted in the UK (Thompson \& Haran, 1984) and therefore there is a limited view as to how families are affected by limb loss in the current UK and NHS climate.

To summarise so far, family systems can be conceptualized in a number of ways and understood through various theoretical frameworks. Limb loss, in line with various types of CID, creates an impact on the family system.

\section{Part 4: Rationale for research}

\section{Rationale}

This chapter described how most of the relevant psychological research has focused on the experiences of the PWLL and their adjustment to amputation. Various studies have highlighted the importance of the family and social network in this process of adjustment. Some research, albeit limited, relates to the experiences of members of this network and how they cope. However, this has focused on spousal and parental carers, and little is known about the experiences of the wider network of other family and kin relationships. The experiential and relational processes in families affected by different health issues should be considered, in order to understand how they can best be supported in services (Ell, 1996). This must be examined within limb loss specifically, given the unique challenges faced by this population. In addition, research should consider whether family processes differ in military and civilian contexts, given the sociocultural and political influences at play. 


\section{Research aims}

Given the very limited empirical information available in this area, an open approach has been used in defining the aims for the current study. This enables the participants to define for themselves the issues of importance, rather than the researcher imposing assumptions of importance upon them. The aims are:

1. To understand the experiences of acquired limb loss from the perspective of members of the family network.

2. To develop an explanatory framework to examine how acquired limb loss affects the family network.

The term "family network" has been adopted in order to utilise a definition of the family system which encompasses biological, legal and kinship ties. Moreover, in consideration of sociocultural and political influences, the study examines these issues in only non-military (i.e. 'civilian') family networks.

The findings will be used at a later date alongside a similar research study currently being conducted at the Veterans and Families Institute, Anglia Ruskin University. This study (entitled: "caring and Coping: the family perspective of living with limb loss") is in conjunction with the charity Blesma, as funded by the Forces in Mind Trust. This examines the experiences of the family network for a PWLL in a military context. It is anticipated that the findings from both studies will complement one another and together they provide a more comprehensive view of family processes, embedded in a wider sociocultural and political context. 


\section{Chapter conclusion}

Surgical amputations can affect both the PWLL and their family network. This can be understood through theoretical and research literature into CID and systemic family processes. This leads the way for the rationale of the current study. 


\section{Chapter 2: Methodology}

\section{Overview}

This chapter describes the methodology in three parts:

Part 1: Background \& philosophical assumptions. This provides information into the background and purpose of qualitative and Grounded Theory research.

Part 2: Method. This describes the procedures used in the study for participant recruitment, data collection and analysis through the Grounded Theory method.

Part 3: Quality in research. This details the methods used to ensure that the research is of high quality and adheres to ethical guidelines. 


\section{Part 1: Background and philosophical assumptions}

\section{Philosophical positioning}

An important step in the selection of a research method is to consider the philosophical assumptions underpinning the method and the standpoint of the researcher themselves (Evans, 2013). It is important to make explicit declarations about the assumptions being made, given the broad range of philosophies that can be seen across research and underpinning specific frameworks (Charmaz, 2006). This step presents the method in the context of its philosophical assumptions, identifying both philosophical and practical implications for psychological investigation (Annells, 1996). It has been suggested that questions about ontology (concerned with what there is to know) and epistemology (concerned with how it can be known) are particularly useful in explicit declarations of the philosophical standpoints of inquiry in research (Guba \& Lincoln, 1994).

\section{Ontology}

The philosophy of ontology relates to the nature and properties of reality. Ontological viewpoints can be broadly placed on a spectrum from realism to relativism (Rawnsley, 1998). Realism postulates that there is one reality, governed by the laws of science. Seeing this as a reductionist view, critical realists instead propose that, while reality is indeed objective, it can be modified by individuals within limits determined by social structures (Orlikowski \& Baroudi, 1991). This assumes that an objective reality exists which is external to our minds, but that this reality is seen through a filter of language and social context (Oliver, 2011). Conversely, relativism 
assumes that multiple realities exist, each purely defined by the individual and their social context.

The researcher here adopted the critical realist position, with a belief that there is an objective truth to reality, but this is shaped by both social and scientific processes. This critical realist position has been said to be appropriate for physical healthcare research, as it can accommodate both the reality of the medical situation whilst acknowledging the individual lived experience (Broom \& Willis, 2007). Within Grounded Theory method (GTM), the original method (Glaser \& Strauss, 1967) can be seen as holding a critical realist position, as it is concerned with seeing the true meaning of reality which is grounded in data rather than in the researcher's interpretation (Uruquhart, 2013). It accepts that there may be multiple ways to examine reality, reflecting Glaser's presumption that "all data is data" (Oliver, 2011). Furthermore, critical realism allows us to understand both a concrete reality and the meaning-making process that occurs for participants regarding this said external reality. Applied to this field of enquiry, a critical realist GTM approach would aim to examine a group of individuals both in their experience of an event within reality (i.e. limb loss) and also their meaning-making of this (i.e. how they make sense of the event happening to a loved one) (Oliver, 2011). This ontological position is well suited to the research question at hand.

\section{Epistemology}

Epistemology concerns how knowledge is defined and gained (if at all), as well as the relationship between the researcher and subject. Broadly speaking, epistemological viewpoints can be placed on a spectrum from positivism to constructionism, and can be paired with ontological positions (Broom \& Willis, 
2007). Positivism is rooted within a Western realist perspective and assumes that a concrete reality can be objectively examined and measured by researchers using scientific methods. As such, the production of knowledge from participants would be taken at face value. Researchers should therefore ensure that a comfortable environment is created whereby we can assume that participants are offering the truth of their experience (Willig, 2012). Critics of this viewpoint question the objectivity of researchers and argue that it does not allow sufficient explanation of the intricate social processes involved in research. In response, a post-positivist approach, reflecting a critical realist ontological position, argues that methodological rigour allows researchers to maintain objectivity in research, but that the knowledge they obtain is only a probable representation of reality (Guba \& Lincoln, 1994).

In contrast, constructionism reflects a relativist position, assuming that reality is not measurable as knowledge is co-constructed in the language between the researcher and participant (Gergen, 1985). This standpoint became popular with the development of qualitative methods, where the researcher holds a more subjective view, seeking to understand the lived experiences of participants by identifying social patterns to create knowledge (Broom \& Willis, 2007).

Within GTM, the epistemological position of the original method (Glaser \& Strauss, 1967) may be seen as post-positivist, given that it postulated that knowledge emerges from the participant's data, rather than from the researcher's preconceptions, so that research aims to discover, rather than verify, knowledge (Annells, 1996). Glaser and Strauss (1967) originally saw GTM as nestled between quantitative and qualitative methodologies. It straddles both the systematic approach of a positivist and quantitative method, alongside a qualitative and interpretivist epistemology that would enable researchers to reach a deeper understanding of the social processes 
involved within an emerging theory. If their initial model suggests that quantitative and qualitative research methods are distinct categories at opposite ends of an epistemological spectrum, later interpretations are more nuanced, recognising the potential for overlap, particularly within GTM (Uruquhart, 2013). Glaser (1988) argued pointedly against the idea of considering philosophical viewpoints, as he felt this detracted from the focus of the research, which was to press on with the method itself. Others argue that, as with all qualitative methodologies, GTM can hold a range of epistemological viewpoints, whether positivist, interpretivist or critical, allowing freedom for the researcher to successfully apply whichever philosophy and method they deem fit (Urquhart \& Fernandez, 2006). Understanding knowledge through a critical realist ontological perspective allows a researcher to collect data to understand the experience of participants, but does not take their information at complete face value in order to understand the mechanisms underlining their experience, as it is assumed that participants may not be consciously aware of this. Researchers working from this philosophical position would instead combine literature (through research and theory) together with data, in order to understand the experiences and those mechanisms that underpin them (Willig, 2012). For the purposes of clarity, it can be concluded that this study will adopt a post-positivist epistemological position, in line with a critical realist ontological stance.

\section{Qualitative methodology}

Choices between quantitative and qualitative research methods are additionally informed by the goals for the research being considered and the relative merits of these different approaches. Underpinning these approaches are different ontological and epistemological positions. The presumption is that quantitative methods are 
aligned with a realist and positivist philosophy, aiming to confirm knowledge through experimental manipulation; while qualitative methodologies have relativist and constructionist underpinnings, with their aim being to explore knowledge (Foss \& Ellefsen, 2002). In reality, complexities and nuances blur these distinctions, and some specific research tools (e.g. questionnaires) may overlap in their aims and philosophical assumptions.

In considering their relative strengths, quantitative approaches tend to be seen as robust and scientific, providing guidelines which allow statistically reliable inferences to be made. Policy makers may interpret such inferences as generalizable scientific facts when applying findings to healthcare, for example when applying the findings from a treatment trial. In contrast, qualitative methodologies (for example, a focus group of patient views) may be overlooked. These are perceived to have limited objectivity, trustworthiness, power and generalizability, often due to small sample sizes (Kvale, 1994). Such criticisms may be addressed by applying appropriate quality assurance procedures.

It is argued that any healthcare research must be capable of capturing the complexity of phenomena being considered while holding real-world applications for services (Foss \& Ellefsen, 2002), although the selection of which method to use should be grounded within the aims of the research (Robson, 2002). Qualitative methodologies have two useful functions: to gain a richer understanding of the participant's experience; and to generate new hypotheses on a concept (Greenhalgh \& Hurwitz, 1999) before it can be measured using quantitative methods (Pope, 1995). This present research study aimed to examine a little known area of how families experience and process limb loss. As there are no existing theoretical frameworks in this area, a qualitative methodology was selected as appropriate for this study. 


\section{Ground Theory methodology \\ Overview of Grounded Theory}

GTM aims to guide various research activities, from literature review to data collection and analysis. Put simply, it seeks to provide a systematic way of generating a theory which is grounded in the data through a cyclical process moving between data collection and analysis (Bryant \& Charmaz, 2010). GTM is a general method for both quantitative and qualitative data, although is widely applied as a qualitative method. This is preferential where sufficient resources are available and the research aim dictates its appropriateness (Glaser, 1999; Morse, 2009).

GTM was originally developed by Glaser and Strauss (1967) in order to bring greater scientific rigour to qualitative methods. This was in response to criticisms of qualitative research at that time of being too subjective and untrustworthy for representing the participants' truth. They proposed a framework with a procedural structure to reliably examine both objective data and participants' lived experience in society, prioritising the views of the participants over those of the researcher, thus reducing its subjectivity (Bryant \& Charmaz, 2010). Differences of view led Glaser and Strauss to later forge their own paths in research. Over time, the method they first set out has gone through various modifications. GTM can now be placed into three broad types: classic GTM (Glaser \& Strauss, 1967); qualitative data analysis (Corbin \& Strauss, 1990) and socio-constructivist GTM (Charmaz, 2006). These types involve different qualities and techniques, which will be summarized here.

\section{Classic Grounded Theory (Glaser \& Strauss, 1967)}

This focuses on developing a theoretical explanation for the behaviours of participants, through a continuous process of moving between data collection and 
analysis. The key focus here is to ask: what is the concern of the participant and how do they attempt to resolve that concern; and to allow the emergence of a theory through the data (Glaser \& Strauss, 1967). As such, participants can state their concern from their perspective, rather than this being dictated by the researcher. The development of the emerging theory can then be expanded on by more participants, potentially through more structured methods. When conducting interviews, this includes the development from unstructured to structured interviews. Starting with unstructured interviews allows us to hear the participants' narrative and build potential ideas and codes, with later structured interviews being used to test out emerging ideas until the codes are saturated and a theory has emerged (Wimpenny \& Gass, 2000). Later participants can be selected through a process known as theoretical sampling: the selection of similar participants to clarify codes; or diverse participants to find a broader theoretical scope (Glaser, 1998; Glaser \& Strauss, 1967).

The subsequent process of data analysis involves coding in an open format (open coding), then coding based on only the emerging categories (selective coding), then coding based on the relationships between these categories (theoretical coding). Two different research activities coincide throughout this process: constant comparison, whereby all data and codes are compared to each other to form the emergent theory; and memo-writing, whereby the researcher records notes to form initial theoretical ideas about how the codes link together (Glaser, 1998). The aim of the coding is to build a theory which provides a full picture to make sense of the data (Birks \& Mills, 2015). Glaser and Strauss (1967) defined that a theory should: fit the area it discusses; be comprehensible for non-professionals in the area; be generalizable to a wide range of situations in the area; and provide sufficient explanation even over time. In order to ensure high quality, the researcher must not 
force the data, and should include ideas from other schools of thought (e.g. sociology, economics) in the final stages of analysis (Glaser, 1967).

The approach taken in Glaser's use of literature reviews is a key feature setting it apart from other types of GTM. Glaser and Strauss (1967) advise that a literature review should not be conducted until after data collection has been completed, arguing that reading previous literature stifles the research process and does not allow the theory to emerge naturally from the data. They suggest that if a researcher goes to test out pre-existing theoretical ideas on the topic, then they will not form a theory which is grounded in the participants' data. With this in mind, they advise that a literature review should be conducted at the end of analysis, in order to better understand the theory, how it is woven into existing literature and to identify its contributions to the field. Glaser (1998) acknowledges that excluding initial literature reviews is pragmatically difficult in doctorate settings. A suggestion is made that this can be resolved through the use of a broad primary literature review to understand the boundaries and definitions within the chosen topic (as presented in Chapter 1, Introduction); and then a secondary review can be conducted later based on the emerging theory, in order for it to integrated within previous literature (as presented

in Chapter 4, Discussion) (Dunne, 2011). The influence of pre-existing conceptions may additionally be managed through the use of memo-writing and constant comparison (Glaser, 1998).

\section{Qualitative Data Analysis (Corbin \& Strauss, 1990)}

In this form of GTM, the principles of GTM are amended to a more prescriptive and procedural approach, with the addition of a further level of coding referred to as axial coding. This involves placing codes within a matrix and examining them in 
various ways, to explore their relationships with one another, contexts and consequences. This development marks the point at which Strauss and Glaser's ideas began to diverge, as Glaser felt that this coding matrix represented a forcing of the data, rather than allowing the data to tell the story for itself (Urquhart, 2013). A distinguishing feature of this method is that participants are selected for later interviews on the basis of the pre-existing theoretical frameworks, rather than the data. It also offers wider scope for reflexivity and use of pre-existing literature. It is the least frequently used version of GTM, criticised as being unnecessarily complex and prescriptive, with limited freedom for the interpretative process (Evans, 2013).

\section{Socio-constructivist Grounded Theory (Charmaz, 2006)}

This involves similar levels of coding (initial, focused, axial and theoretical), but it differs in both its philosophy and use of pre-existing literature. Charmaz (2000) held the view that concepts are co-constructed (rather than discovered) through the language between the participant and researcher. Central to this philosophy is the idea that there are multiple realities that can be formed, rather than one reality to be discovered. With this in mind, Charmaz highlights the important role of the researcher's own views and background in the construction of knowledge. This method also allows for a literature review to be conducted prior to data collection, allowing the researcher to gain a theoretical understanding which will be used to guide their interviews and analysis. The approach has been criticised for straying too far from the original intentions of GTM (Gibson \& Hartman, 2013). 


\section{Application of Grounded Theory}

In selecting a research method, Glaser acknowledges that GTM is one possible option and is not appropriate for all research questions and topics (Glaser, 1998). Its application is appropriate in instances where little is known about the research topic, or where an explanatory framework may be useful (Birks \& Mills, 2015). The popularity of GTM within clinical health research suggests it is relevant for the present field of study (Rohleder, 2012; Tweed \& Priest, 2015). The researcher selected GTM as an approach particularly suited to the aims of the research, as it examines the how processes that occur within the participants. This is in contrast to other methodological frameworks, such as Interpretative Phenomenological Analysis, which examines what the experiences of participants are, and discourse analysis, which examines the process of language (Starks \& Brown-Trinidad, 2007). As a reminder, the current research aimed to examine the process of the family network in limb loss. The aim was not simply to find out what the experience is, but how it is experienced. GTM was therefore selected as appropriate.

As previously explained, GTM has changed over the years into various frameworks for research. In selecting a framework to be used, a researcher should consider which is most appropriate, rather than simply working with the most recent development of GTM. In this instance, Glaser's method was selected for three reasons: it provides a framework for a more explanatory theory of how families process the experience of living with limb loss and therefore is suitable for the research aims; it can be used where there is no prior literature available to be used in guiding the interviews; and it fits with the epistemological and ontological stance of the researcher. It is acknowledged that this method takes less account of the relationship between the researcher and the participant. In order to resolve this, the 
researcher applied a model of reflexivity (to be demonstrated later in this chapter)

which allows the relationship to be considered appropriately within Glaser's GTM.

\section{Summary}

This qualitative research is underpinned by GTM with a post-positivist epistemological position, in line with a critical realist ontological stance. This is suitable for the aims of the current research.

\section{Part 2: Method}

\section{Participants}

\section{Sampling strategy}

The aim was to recruit a total of 12-20 participants. This took account of the potential for publication, the scope of the study within the academic context of the researcher and GTM guidance. GTM defines that the complete sample will be achieved when theoretical saturation has occurred (i.e. where no new codes emerge). It has been estimated that this will occur within 8-24 interviews (Evans, 2013).

The sampling strategy was based on GTM procedures. Initially, participants were selected through purposive sampling, based on expressions of interest and whether they met inclusion criteria for the research. Following on from the initial interviews, further participants were selected through theoretical sampling for more structured interviews. The intention was to select successive participants according to their demographic or family information, in order to find the maximum theoretical variation in the data and to consolidate emerging codes. This meant selecting 
participants for the final interviews to include in the sample a range of different relationships with the person with limb loss (PWLL) from the rest of the sample, in order to define the scope of the emerging theory and to test out its application with diverse familial relationships. This was done in line with GTM principles, with some homogeneity of participants necessary in order to consolidate the existing codes to develop the depth, rather than the breadth, of the theory.

\section{Inclusion criteria}

Inclusion criteria were developed following a preliminary literature search to define the context for participants (e.g. types of limb loss) and to take account of the aims of the study. This intended to allow for a broad scope in initial recruitment, with the potential for later selective inclusion through theoretical sampling. The criteria were also informed by the criteria for a veterans' comparative study.

Participants were included if they were an adult member of a family network (including partners, spouses, close family friends), within a non-military context. They were able to take part regardless of psychological state (i.e. whether or not they experienced anxiety, depression, stress, or carer burnout), although considerations were made into whether this had an impact on their ability to engage in the interview. The associated PWLL must have experienced the loss of a major limb (arm or leg) through any aetiology (i.e. disease or trauma), with or without the use of prosthetics.

\section{Exclusion criteria}

Potential participants were unable to take part in the study if they or the PWLL was currently or previously employed by the military. Cases of congenital limb loss were also excluded. Participants had to be over the age of 18 and living in the UK, in 
order to allow them to be signposted to services during debriefing in case of incidents of distress. Participants had to be able to communicate and understand English sufficiently in order to be able to engage in the interview process without the use of an interpreter. One potential participant was excluded from interviews for ethical reasons, as the PWLL would not allow their family member to be interviewed alone, thus limiting participant confidentiality and privacy.

\section{Recruitment procedure}

In order to recruit members of a family network, a liberal and wide definition of the word family was adopted. This was done in order to reflect the diversity of modern society (as discussed in Chapter 1). As such, the sampling strategy aimed to include individuals within wider family networks, such as non-wedded partners and those included within voluntary kinship.

Participants were recruited through numerous organisations which provide direct support to families or carers, or to PWLL. This included limb loss based charities and support groups; charities focusing on specific diseases such as diabetes and sepsis; and disability based charities. These organisations were initially approached either by email, telephone, or through social media, in order to generate interest in the study. The researcher provided documentation for a recruitment advertisement and evidence of ethical approval.

A recruitment advertisement (Appendix B) was placed through these organisations, either on their websites or social media channels. Once a potential participant made contact by email, initial broad screening took place and any immediate queries were answered by way of an information sheet (Appendix C) or through communication with the primary researcher. Once satisfied, participants were 
sent an electronic version of the consent form (Appendix D) and brief demographics sheet (Appendix E). Once these forms were returned, the researcher confirmed that the participant met all inclusion criteria and was appropriate to take part. If so, the participant would either have an interview date confirmed, or be told that they would be contacted in due course for a later interview. While awaiting their interview, participants were contacted by email to keep encouraging them to take part and provide a time frame where possible. As the planned interview approached, a reminder was sent of the agreed date and time.

\section{Sample characteristics}

The characteristics of the sample can be found in Table 1. The first column relates to the order in which the participants were interviewed, based on GTM principles. 
Table 1: Description of sample.

\begin{tabular}{|c|c|c|c|c|c|c|c|c|c|c|}
\hline \multirow[b]{2}{*}{ Order } & \multicolumn{6}{|c|}{ Participant characteristics } & \multicolumn{4}{|c|}{ Associated PWLL characteristics } \\
\hline & Pseudonym & Age & Gender & Employment & $\begin{array}{l}\text { Marital } \\
\text { status }\end{array}$ & Relation & Aetiology & Duration & $\begin{array}{l}\text { Use of } \\
\text { prosthesis }\end{array}$ & $\begin{array}{l}\text { Type of } \operatorname{limb}(s) \\
\text { lost }\end{array}$ \\
\hline 1 & Andy & 49 & Male & Retired & Married & Friend & Sepsis & 4 months & Occasional & Arm \\
\hline 2 & Sue & 56 & Female & Employed & Married & Mother & Meningitis & 17 years & Often & Both legs, arm \\
\hline 3 & Annie & 32 & Female & Employed & Single & Daughter & Sepsis & 6 years & Always & Both legs, fingers \\
\hline 4 & David & 67 & Male & Retired & Married & Husband & Sepsis & 6 years & Always & Both legs, fingers \\
\hline 5 & Louise & 45 & Female & Unemployed & Married & Mother & Cancer & 1 year & Often & Leg \\
\hline 6 & Addison & 47 & Female & Employed & Divorced & Mother & Meningitis & 10 years & Occasional & All limbs \\
\hline 7 & Simon & 63 & Male & Retired & Married & Husband & Accident & 8 years & No & Arm \\
\hline 8 & Maria & 56 & Female & Retired & Married & Wife & Accident & 38 years & Often & Leg \\
\hline 9 & Christina & 69 & Female & Retired & Divorced & Friend & Accident & 8 years & No & Arm \\
\hline 10 & Daniel & 48 & Male & Employed & Married & Father & Meningitis & 6 years & Often & Arm \\
\hline 11 & James & 32 & Male & Employed & Married & Father & Meningitis & 1 year & Often & Leg \\
\hline 12 & Petra & 56 & Female & Employed & Divorced & Friend & Cancer & 20 years & Occasional & Leg \\
\hline 13 & Julie & 57 & Female & Employed & Married & Grandmother & Meningitis & 9 years & Often & Both legs \\
\hline 14 & Greg & 36 & Male & Employed & Married & Son & Accident & 8 years & No & Arm \\
\hline
\end{tabular}




\section{Data collection}

\section{Measures}

\section{Demographics questionnaire}

Participants completed the demographics questionnaire (Appendix E), in order to provide key information about themselves and the PWLL. This ensured inclusion to the study, in addition to fulfilling theoretical sampling and to ensure a rich description of the sample could be provided. The questions about the PWLL were based on broad categories deemed to define limb loss, as identified in the primary literature review done for the planning of the research (as seen in Chapter 1, Introduction).

\section{Interviews}

Interviews were conducted over the telephone or through Skype, due to the varied geographical locations of the participants. The use of technology in interviewing has been deemed to be appropriate within a GTM framework (Scott, 2011). Of the 14 interviews, eleven were conducted over the telephone and three conducted through Skype. There did not appear to be any differences in the nature or quality between telephone and Skype interviews.

Each interview lasted approximately 30 minutes to one hour, including an introduction and debrief, as per standard research protocol. The introduction included a reminder of the key points in the consent form and an assurance that they could stop the interview at any time. It additionally included a statement that the interview was to establish their experiences of the PWLL's limb loss and that this would be done either with or without a list of questions, depending on the type of interview. The debrief will be elaborated on further in this chapter. 
Alongside the data collection, reflective field notes were completed (Appendix F). This was done before interviews in order to acknowledge any pre-conceptions that may be held prior to the interview, as well as after the interview to note reflections on the interview itself (e.g. any topic that appeared to trigger distress, tone of voice, or a felt sense of that person). This served to prompt the researcher to reflect on any process issues that may have influenced the interview, and their personal responses to the participant. These field notes were held separately to the memos (discussed later in this chapter), as they related more to thoughts on the data collection, whereas memos were related more to the analytical process.

In line with the GTM framework, an unstructured approach was used for the first seven interviews, in order to establish the broad areas of importance for the participants. Each interview began with a question of: "could you tell me about your experience of living with [name of PWLL's] limb loss?" This opening question allowed a broad interpretation from the participant, in order to ensure that the research was not at this point, based on a specific aspect of limb loss. Investigative or specifying questions were only used as an aid for the participant (e.g. "can you tell me more about that?") and were only related to the material brought by the participant themselves.

These interviews were analysed through open coding, in order to establish the emerging codes and gaps of knowledge which could be addressed in further interviewing. From this analysis, a semi-structured interview schedule was developed which aimed to be sufficiently open to allow participants to disclose any additional views that they wished to express (Appendix G). This was used for a total of five participants. Further specific coding was conducted at this stage to confirm, disconfirm and explore codes further. For the final stages of interviewing, a 
structured interview schedule was developed (Appendix H) which tested the emerging theory by allowing participants to confirm or disconfirm their views in relation to the emerging theory, as well as having an opportunity to add any additional views as necessary. This was used for two participants.

\section{Debrief \& payment}

A full debrief was completed at the end of each interview. This was done extensively for any participant who displayed distress during the interview itself, in order to support their wellbeing. The debriefing process consisted of first checking how participants were feeling, and if necessary, whether they had sufficient support or pleasant activities to improve their mood. This was necessary for two participants who were tearful in the interview. They were all signposted towards charities and organisations, where appropriate. In case of any distress or high risk, it was planned that this would include signposting to their GP and mental health charities or services. This was done for one participant who disclosed a concern about historic risk in the PWLL. The next stage of the debrief was to inform the participant of the rationale and detailed aims of the research. At this point, some participants volunteered their consent to be contacted for further clarification if necessary.

All participants were told about the dissemination process during this debriefing. This included explaining the future submission of the research to academic journals and the publication of a summary by the relevant charities. Participants were informed that this summary of the research would be sent directly to them. All participants accepted this.

The final part of the debrief was to thank participants and to confirm that they would receive a $£ 10$ Amazon voucher as a token of thanks for their time. Once the 
payment had been arranged, they were asked to complete a short receipt form (Appendix I) and to return this by email. All participants were offered an alternative voucher if they did not wish to use Amazon. Two participants declined any payment and requested that a donation be made to a charity of their choosing instead. One participant explained that the payment would be used to purchase a present for the daughter of the PWLL.

\section{Data transcription}

All interviews were audio recorded. Telephone interviews were recorded using an Olympus TP8 telephone microphone headset, with an Olympus Dictaphone. Skype interviews were recorded using QuickTime software. All recordings were held on a password protected Kingston G3 encrypted USB drive.

In using a GTM approach, Glaser (1998) states that interviews should not be transcribed and that only the field notes should be analysed, as the analysis should focus on the content of the data, rather than how it is communicated. Despite this, a decision was made to transcribe the interviews. This was decided in the view of the novice status of the researcher and to improve the trustworthiness of the research through transparency in the process of analysis. A clean verbatim transcript of each interview was written, to include only the content of speech. All sentence fillers (e.g. umm's and ahh's), natural speech repetitions and grammatical errors were omitted from transcripts. This was done to reflect the purpose of the analysis in GTM to examine behaviours, rather than the discourse. The interviews were transcribed as soon as possible after the interview and stored on NVivo software. The data was anonymised by using pseudonyms for individuals and all family members, and removing any reference to locations or NHS services. 


\section{Analysis}

Data was analysed according to the guidelines set out in the GTM literature (Chametzky, 2016; Glaser, 1998; Glaser \& Strauss, 1967). A diagrammatic representation of the whole process can be found in Figure 1.

Figure 1: Diagram of analytical procedure.

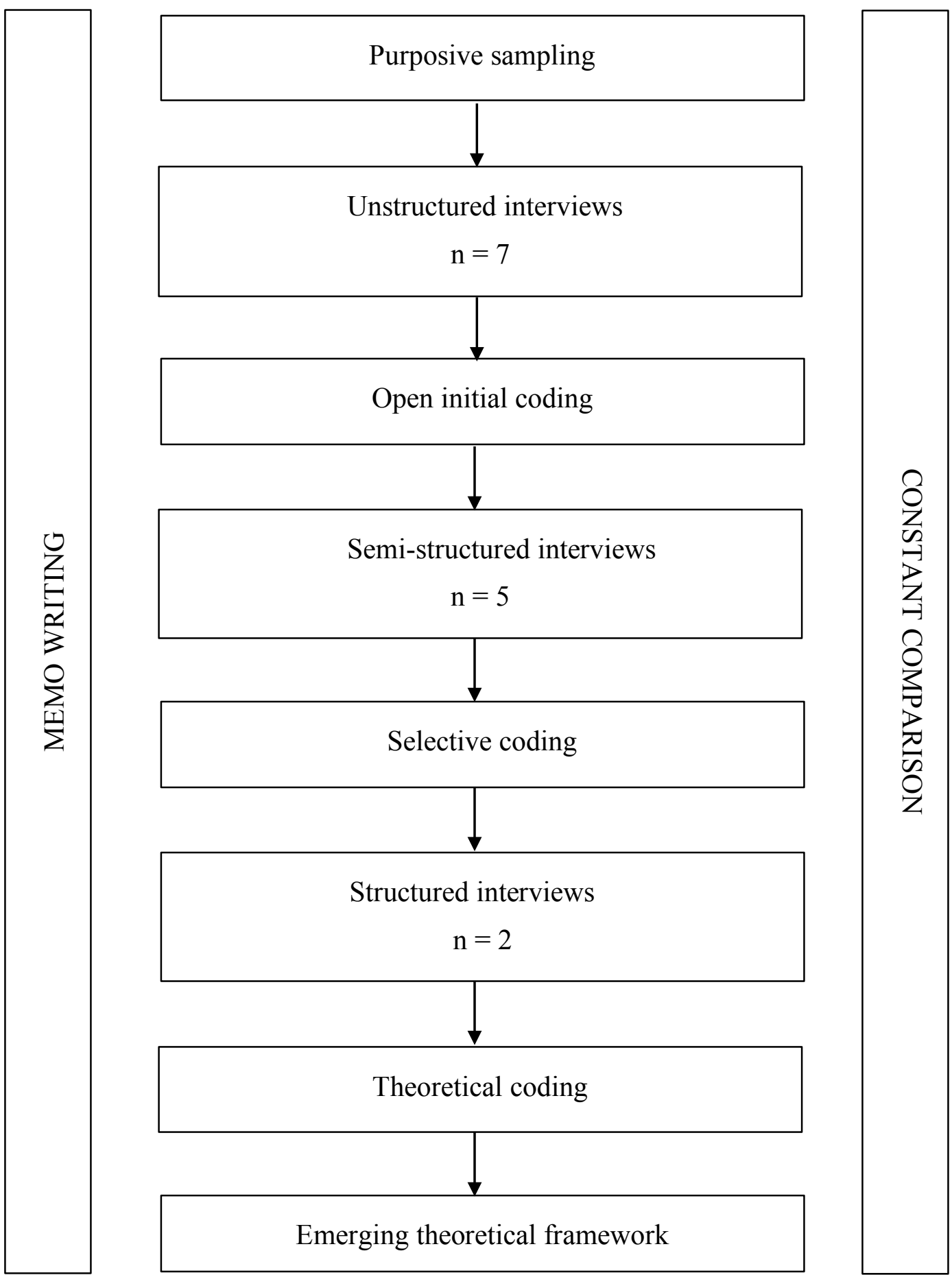




\section{Initial coding}

This is the first open level of coding, which aims to remain close to the data and to be open to all theoretical avenues (see Appendix $\mathbf{J}$ for example). This is done through sentence-by-sentence coding for all data, where each sentence is labelled as an 'incident'. Glaser (1978) recommends this as a way to become familiar with the data and to ensure that coding is grounded in the data, rather than on preconceptions (i.e. this is therefore a representation of bottom-up coding; Urquhart, 2013). At this stage, labels may be descriptive, but they are based predominately on examining what behaviours are associated with the incident. For each incident, the researcher must ask themselves what code does this incident represent and what is the concern of the participant? There may be more than one label for each incident, or the incident may need to be broken down into smaller incidents. In undertaking this open coding, the researcher ends up with a wide variety of potential labels for categories. These are organised by comparing each category to another, examining whether they are qualitatively different or can be grouped together.

\section{Selective coding}

The next level of coding is selective coding (see Appendix $\mathrm{K}$ for example). This takes place when no new codes are emerging from the data from unstructured interviews, leading instead to the emergence of a core category (Urquhart, 2013). This core category is defined as the phenomenon with the greatest importance and frequency, which integrates codes together. Glaser (1978) emphasised the importance of establishing theoretical sensitivity within this, which is defined as the capacity to understand what data is relevant to be extracted. 
In subsequent interviews, the researcher continues to apply similar principles of coding (using memo writing and constant comparison), but is coding to examine data related to the core category, rather than examining each individual sentence in the interview. Therefore, coding is only directed to that core category. Having previously organised the categories, the most significant categories can be used together to create broader categories which can be used to sift through larger amounts of data. These broader categories are also used to examine the data and analysis from previous interviews (i.e. coding the codes), through the constant comparison between different categories. At this point, the categories can become more conceptual; that is, they may now be able to explain the behaviours which occur in the data.

\section{Theoretical coding}

Theoretical coding is the final level of coding within the analysis. This is a process of developing a theoretical framework to explain how the categories fit together, something that can only be achieved once all data has reached saturation (i.e. when no new codes emerge). This also allows an explanation of the properties of the core category. These are the contextual factors or competencies which must occur for a specific phenomenon to take place. It is said that this is not essential for this process to take place within GTM and, in fact, it has not been achieved in various research studies using GTM (Chametzky, 2016). However, at this stage, previous literature can be examined to indicate where the categories fit into existing literature; and how they can be conceptualised within a theoretical framework.

The examples in Table 2 illustrate the process in which the coding developed from open to selective coding. This additionally demonstrates the process of naming of the codes from descriptive to conceptual labelling. 
Table 2: Examples of coding development.

\begin{tabular}{|c|c|c|c|}
\hline Participant data & Initial open code & Selective code & Category \\
\hline $\begin{array}{l}\text { "We have had some } \\
\text { conversation about that, saying } \\
\text { 'don't beat yourself up if you } \\
\text { can't do this.", (Andy) }\end{array}$ & $\begin{array}{l}\text { Managing their } \\
\text { expectations }\end{array}$ & $\begin{array}{l}\text { Providing } \\
\text { emotional support }\end{array}$ & $\begin{array}{l}\text { Responsibility } \\
\text { in caring }\end{array}$ \\
\hline $\begin{array}{l}\text { "I did have a bit of an issue } \\
\text { with the language in medical } \\
\text { terms. Stump, I cannot cope } \\
\text { with." (Louise) }\end{array}$ & $\begin{array}{l}\text { Struggling with } \\
\text { jargon }\end{array}$ & $\begin{array}{l}\text { Navigating health } \\
\& \text { social care } \\
\text { services }\end{array}$ & $\begin{array}{l}\text { Sharing } \\
\text { challenges }\end{array}$ \\
\hline $\begin{array}{l}\text { "I just worry that she's not } \\
\text { doing enough because I don't } \\
\text { want her to miss out on things } \\
\text { that she should have been } \\
\text { doing anyway.” (Annie) }\end{array}$ & $\begin{array}{l}\text { Worrying about } \\
\text { missed } \\
\text { opportunities }\end{array}$ & Anxiety & $\begin{array}{l}\text { Emotional } \\
\text { responding }\end{array}$ \\
\hline
\end{tabular}

\section{Memo-writing}

During the process of coding, the researcher wrote memos to be used within each stage of the data analysis (Appendix L). These were used to consider potential ideas about how the categories can be organised and to record initial thoughts on the connections between incidents, as the researcher continued the process of constant comparison. This allowed the researcher to remain grounded in the data throughout. Memos allow for a space to consider the connections between the core category, the codes and their properties (i.e. what specifies a concept) and degrees (i.e. the size of a concept). A further suggestion is made by modern GTM researchers, that the memos can be used to consider what literature might be relevant to the codes when building the theoretical coding (Urquhart, 2013). 


\section{Summary}

This study utilised GTM in a procedural manner, to constantly move between data collection and analysis. This allowed for emerging ideas in analysis to be tested and developed by the participants themselves.

\section{Part 3: Quality in research}

\section{Quality assurance}

A number of steps can be taken to ensure that research is of a high standard. Guba and Lincoln (1994) proposed four standards for defining the quality of qualitative research: credibility, transferability, dependability and confirmability. For thoroughness in this chapter, reflexivity has also been added as a further process for quality assurance. These have all been considered within the GTM framework.

\section{Credibility}

This standard relates to the need for the conclusions drawn to reflect the truth of the data. In the present research, this was assured by constantly comparing interviews to each other as the analysis proceeded. The process used for interviews allowed for participants to confirm or refute the emerging ideas generated from earlier interviews. This ensures that the analysis was grounded in the data and true experience, rather than in the researcher's assumptions. Additionally, triangulation of the data was applied by examining various viewpoints and relationships within the family network. Member-checking procedures were used at the end of the data analysis, to ensure that the conclusions reflected the participants' true experience. This final step was taken 
by sending an email to the participants (Appendix M) asking them to comment on whether they felt that the summary of the research findings (Appendix N) was a fair and reasonable portrayal of their experience.

\section{Transferability}

This requires that the conclusions drawn must be applicable to other contexts. This standard was met by ensuring that this chapter includes a rich description of the sample, in order for the reader to make a judgement about whether or not it is applicable. This has been done in the earlier section of this chapter.

\section{Dependability}

Here, research must demonstrate that findings are dependable through the rigorous and consistent use of the chosen research method. This is particularly important given the different philosophical and methodological approaches that can be taken within GTM. Sufficient training is required to ensure that this standard is appropriately applied throughout the research (Birks \& Mills, 2015). In order to achieve this, the researcher attended a two-day workshop on Glaser's GTM method and then continued to receive supervision and mentoring support from two academic researchers who use this approach. Dependability was also ensured by providing a rich description of the method in this chapter and by providing an audit trail through memo-writing to record how analytical decisions were made.

\section{Confirmability}

This standard requires conclusions that are made about the data to be grounded within the participants' experience and not based on the researcher's pre-existing 
assumptions. Within GTM, this is a key benchmark for the quality of research, in that its nature is to be grounded in the data and participants' experience. Glaser (1978) states that this can be ensured through the method of constant comparison and by encouraging the researcher to "stand back" from the data in analysis. The present researcher applied this approach by being clear on their position to the data through a model of reflexivity (discussed later in this chapter) and one of critical self-reflection (applied in Chapter 4, Discussion). Confirmability was also ensured by using

supervision and personal reflection to identify any assumptions or beliefs which could affect the analysis; using various viewpoints of participants; discussing analytical decisions in supervision; and using respondent validation throughout the interviews.

\section{Reflexivity}

In the application of reflexivity in research, researchers must be self-critical of their influence within data collection, analysis and writing, in order to improve the rigour, transparency and credibility of the research (Berger, 2013). This includes the consideration of position and power, whereby the researcher reflects on their own position as an outsider or insider within the research, depending on whether they have personal or professional experience of the topic under examination (Berger, 2013). This is of particular importance when researchers hold a dual professional identity (i.e. researcher and therapist). Research interviews and therapy sessions have a similar sense of emotional intimacy and as such, require similar skills from the professional. It becomes necessary to use self-reflexivity, in order to ensure that the boundaries of a research interview do not blur into a therapeutic exercise (Birch \& Miller, 2000; Bulpitt \& Martin, 2010).

Glaser (1978) originally felt that the neutrality of the researcher meant there 
was no need for reflexivity within GTM. However, reflexivity has successfully been applied in GTM and in qualitative research generally, as it remains useful for ensuring methodological rigour and quality. This can include, for example, by defining our positon in relation to the participants, given that this may influence power dynamics in the dyad (Birks \& Mills, 2015). Here, the Alvesson and Skoldberg (2009) model has been applied with consideration of reflexivity at different levels of the research process (see Table 3). This was selected due to its previous use alongside the GTM model (Engward \& Davis, 2015). 
Table 3: Application of model of reflexivity.

\begin{tabular}{|c|c|c|}
\hline Level of reflexivity & Focus of level & Methods in current research \\
\hline $\begin{array}{l}\text { 1. Interaction with } \\
\text { model }\end{array}$ & $\begin{array}{l}\text { Systematic use of } \\
\text { research techniques }\end{array}$ & $\begin{array}{l}\text { - Using GTM guidance and texts (e.g. Glaser \& Strauss, 1967) } \\
\text { - Freedom of participants' expression through unstructured interviews (see Method, p.63) } \\
\text { - Data transcription completed immediately after interviews (see Method, p.66) } \\
\text { - Use of supervisory team throughout (research supervisors and GTM mentors) }\end{array}$ \\
\hline 2. Interpretation & $\begin{array}{l}\text { Analysis remains true } \\
\text { to participant }\end{array}$ & $\begin{array}{l}\text { - Analysis remained close to participants' main concern (see Method, p.67) } \\
\text { - Dropping codes that are not prominent (i.e. not frequent or related to main concern) } \\
\text { - Simultaneous analysis and data collection as verification of analysis, particularly with } \\
\text { structured interviews and respondent validation }\end{array}$ \\
\hline $\begin{array}{l}\text { 3. Critical } \\
\text { interpretation }\end{array}$ & $\begin{array}{l}\text { Consideration of socio- } \\
\text { political context and } \\
\text { power }\end{array}$ & $\begin{array}{l}\text { - Use of 'Position statement' biography to state professional position as } \\
\text { researcher/practitioner (see p.76) } \\
\text { - Respondent checking to verify understanding (checking interpretation not just based on } \\
\text { researcher's individual context) }\end{array}$ \\
\hline $\begin{array}{l}\text { 4. Language in } \\
\text { representation of } \\
\text { problem }\end{array}$ & $\begin{array}{l}\text { Text production and } \\
\text { selection of voices }\end{array}$ & $\begin{array}{l}\text { - Only selecting codes relevant to participants' main concern (see Method, p.68) } \\
\text { - Use of field notes and memos to identify most salient information to be included in } \\
\text { presentation of emerging model (for example, see Appendix L) } \\
\text { - Respondent validation (see Appendices M and N) } \\
\text { - Use of numerous participants and interview exerts in presentation of model (see Results). }\end{array}$ \\
\hline
\end{tabular}




\section{Position statement}

Throughout my career, I have held an interest in how individuals cope with and manage experiences of physical illness and injury. My interest in the area of limb loss came from a time of working in chronic pain management as an Assistant Psychologist, where phantom limb loss was often used as a framework to understand that pain can occur even when the physical damage of the body has healed. In this post, I would often discuss with clients the impact their physical health has on their family and relationships, but I did not have the opportunity to work directly with those individuals in the system. In the later stages of this thesis, I began to work in a specialist placement with a hospital-based specialist psychological therapies team that supports children, adults and their families adjusting to physical health conditions. My own caseload of clients has not included any individuals with limb loss, but this condition is seen by the wider service. As part of the wider training programme, I was also receiving teaching on systemic family therapy. This included teaching on the construction of family systems and how they interact during distress.

With regards to family, I am very much orientated to family life and the importance of inter-connectedness in my social network. I see the family as a construct which goes beyond the realms of marriage and blood, as I have several individuals in my family who would fall under the definition of voluntary kinship. I attribute high value to the support that I provide and that I am given within my family network in times of difficulty or distress. I come from a family that encompasses two Western cultures which both attach great importance to the concept of family, although I maintain a level of individualism rather than dependence on the family for support in times of distress.

I myself have not experienced limb loss, nor have I experienced it within my family or wider social network. I have not experienced a significant illness or accident, either for myself or within this network. My family includes various professionals in the fields of 
medicine, health and social care. As such, I have been taught throughout my life to be aware and respectful of the disabilities of others. We do primarily view the medical model as important within physical health, although my psychological thinking is seen occasionally to be conflicting with those medical views of my extended family. As a wider culture, I feel that the medical model continues to dominate, although I recognise a shift within society in perceptions of disability. I am aware, for example, that the community in which I live does make attempts to encourage accessibility for individuals with disability. However, my own friendship with two individuals who use wheelchairs has made it clear to me that there are limits to accessibility and to our fairness as a society.

\section{Ethical considerations}

\section{Ethical approval}

Ethical approval was obtained from the University of Essex Health and Social Care Board (Appendix O). All sources of recruitment were provided with a copy of the evidence that the research had obtained ethical approval. Several ethical considerations were made throughout the planning and implementation of the research.

\section{Anonymity}

It is recognised that qualitative research can unveil a high level of in-depth and personal information, which may reduce anonymity especially in small sample sizes. The risk of participants being identified may increase where the sample is taken from charities or support groups. That is, participants could be aware of each other if they have created a community for support. Measures were taken to increase anonymity as much as possible, such as removing obvious identifiers from the write-up of the study (e.g. names, locations, hospitals). 
Participants consented to the confidentiality arrangements in this study, primarily that anonymised data would be shared with supervisors and kept for further publication; and that confidentiality would need to be broken in instances of substantial risk.

\section{Harm \& benefits}

There remained a moderate risk of psychological distress for participants or in their family networks from their having reflected on these issues. However, the level of any potential distress would be no greater than what they would be facing on a day-to-day basis, through having to cope with limb loss. Psychological distress was monitored and managed throughout the interview, using the researcher's clinical skills. It is acknowledged that it can be more difficult to pick up on silent or non-verbal cues of distress on the telephone. Participants were given space and time if they became distressed, with a plan that the interviews would be stopped if this distress should reach a significant or worrying level. However, this was not deemed necessary within any of the interviews conducted.

A full debrief was completed with all participants and extended for those participants who displayed distress. This was done to ensure that: participants were emotionally stable; that they had coping plans and support; and that they could be signposted to relevant organisations if necessary (e.g. Mind, Samaritans, carer/disability/limb loss charities).

The interviews were conducted with an awareness of assessing risk of harm to self or others (e.g. if the participant were to disclose potential harm to themselves or someone in their family). The researcher aimed to discuss this with participants during or after the interviews, if and when a risk issue was to arise. This was planned to obtain sufficient information to be passed on to relevant authorities (e.g. police, social care, GP). Participants were informed in the consent forms of this confidentiality loophole. However, this was not necessary for any of the participants during the course of data collection. 


\section{Storage of data}

Data was collected in two ways: a brief questionnaire for demographic information; and recordings/transcripts of interview data. All questionnaires were held on a password protected encrypted USB drive, with any hard copies destroyed immediately. All interview data, including recordings and transcripts of interviews, were also kept on the encrypted USB device. The data was stored in line with the Data Protection Act. The audio files were transcribed as promptly as possible and were then destroyed by removing them from all necessary devices and software. Only the anonymised interview transcripts were kept for analysis. These were only accessed via a password protected personal computer. Anonymised transcripts have been kept for future publication and secondary research use (i.e. for the comparative veterans and families study). All necessary information regarding storage of data was included in the consent forms given to participants.

\section{Chapter conclusion}

This chapter has provided a description of the procedural elements of the research study, in line with the GTM approach. There is a clear rationale as to why this approach was selected, which takes account of the methodological and philosophical considerations. Additional research issues have been considered, including processes for ensuring quality and ethical practice. 


\section{Chapter 3: Findings}

\section{Overview}

This chapter presents an emerging framework of the effect of limb loss on the family network, in two parts:

Part 1: Overview of theoretical model. This provides a diagrammatic and written overview of the theoretical model.

Part 2: Presentation of theoretical model. This presents the full theoretical model and all conceptual categories.

\section{Note for the reader}

Direct quotes from interviews are included in italics within this presentation of the model. They are identified with a pseudonym for the purposes of confidentiality. Any bold text within these quotes signifies a question from the interviewer. Any text in brackets has been added either for clarity, or to remove identifiable information (e.g. names of towns or healthcare services). The first seven interviews were conducted in an unstructured format; followed by five semi-structured interviews; and then two structured interviews. For an examination of which participants this relates to, please refer to Table 1 (p. 62). 


\section{Part 1: Overview of theoretical model}

The model provides a theoretical framework to explain how participants (as members of the family network) conceptualise and respond to limb loss. It describes how they cope with its impact, both on themselves and on the person with limb loss (PWLL). The model is grounded in emergent patterns in the data about the participants' experiences. It sets out five categories, each with its own sub-categories. These categories are all dynamic and interrelated concepts. The core category as the participants' main concern is witnessing, that is to say their observation and perception of the practical and emotional difficulties that the PWLL experiences on a daily basis. To manage this witnessing, the family network takes on a responsibility in caring where they provide various types of support for the PWLL. This results in sharing the impact and challenges which are faced by both the family network and PWLL; and in emotional responding (e.g. sadness, anxiety, shock, acceptance). To manage these experiences, particularly in witnessing, these members of the family network are led to utilise various strategies of coping (social, practical and emotional). This model is demonstrated diagrammatically in Figure 2. 
Figure 2: Diagrammatic representation of emerging theoretical framework

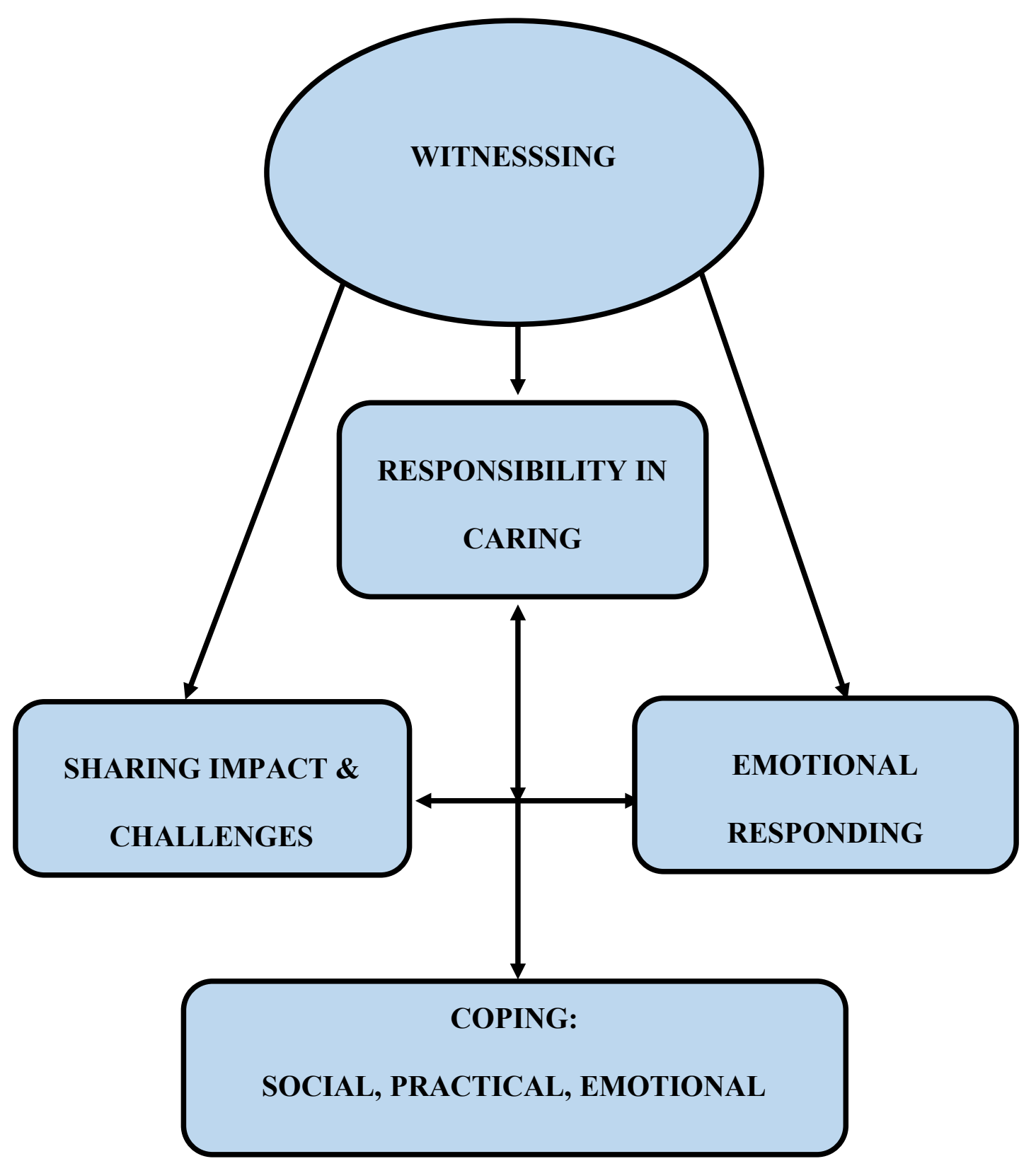




\section{Part 2: Presentation of the theoretical model}

\section{Core category 1: Witnessing}

This core category encapsulates the central concern for all the participants, regardless of relationship, family structure or amputation characteristics. This focuses on their subjective perception of the other person's limb loss and what the PWLL experiences. The importance of this process was evident as, when all participants were asked about their own experiences, they described the experiences of the PWLL. As such, this appeared to be the main concern which their experience as a family member stemmed from. This process of witnessing focused on various facets of the PWLL's life with limb loss, to be explored here.

\section{Practicalities of daily living}

All participants spoke of witnessing the practical challenges faced by the PWLL on a daily basis, with regards to tasks involved in mobility, personal care or household chores: "It's hard for her to stand up and cook for ages, she can't hold a knife properly" (Annie). These practical difficulties were a central concern which the participants observe in the PWLL, as they focused on them in their interviews, rather than on their own experience:

"So it's quite difficult for her to do quite a lot of things like lifting the pots and pans, preparing vegetables and those sort of things.... we look after our grandchildren one day a week, she can't lift them out of the cot and things like that.... buttons, she can't do buttons up with one hand. Zips on an overcoat, she can't do that. She has to have some help. Cutting up food and things like that, she can't do it." (Simon) 
This extract illustrates that the most significant concern for participants was the change within the PWLL from what they could do previously but were now no longer able to. Participants reported a concern that these practical difficulties could go on to have an "impact on where he re-integrates socially" (Andy). This creates a perception for the participant of the limb loss having a wider impact on the ability of the PWLL to lead a fulfilling social life: "Things like when other children his age started going to football clubs and things like that, and he just couldn't access anything like that" (Sue).

This perception of what the PWLL is now no longer able to do was particularly evident when describing how (where relevant), they use a wheelchair or prosthetics to assist with everyday living. Many described their perceptions of the PWLL's experiences with their prosthetics: “It's quite a difficult thing to learn how to do to wear prosthetics. It's quite painful, it's quite a lot of persistence and quite a lot of courage, I think" (David). Participants recognised the benefits of using prosthetics, but they emphasised the associated challenges for the PWLL, such as discomfort and the impact on daily living: “Buying clothes, we found quite hard. They don't design clothes with prosthetic legs in mind" (James). In cases of lower limb loss, participants also spoke of the discomfort that stemmed from the possible or actual witnessing of a PWLL using a wheelchair: "Honestly I didn't see her in the wheelchair, I felt quite uncomfortable” (Annie). If a common feature of participants' experience of witnessing is a concern that the PWLL can no longer complete tasks without support from another person or object, the use of wheelchairs seemed to be a particularly poignant reminder to participants that the PWLL had a significant 
impairment. In this excerpt, Petra describes how the wheelchair signifies disability and the inequality that this represents:

\begin{abstract}
"Yes, I mean this is a very tricky situation because even in the wheelchair she's always sitting down, she's always low, I was always above standing. That for example is something which bothers me the most. I don't know, she's always there siting down. When we're sitting its fine, but walking or going and chatting with the walk, that's something that I don't like.
\end{abstract}

\title{
So what is it about that that you don't like?
}

That's very good, you're proper psychologist! I really don't know because I was wondering myself why it's that particular detail which is possibly the least important in everything, it bothers me. But somehow it's almost like its underlining our inequality and we're not equal, something like that, and I want to be equal and I think she is equal to me and everyone else, mentally, physically, anything else except she doesn't have a leg. And Ifeel that's unfair to be like that." (Petra)

\section{Pain}

Some participants additionally spoke of witnessing pain in the PWLL. Not all the associated PWLL in the sample were perceived as experiencing phantom pain or sensations. However, when this was mentioned by participants, it was identified as "horrendous" (Maria). This was a key and emotive element of the witnessing process, with feelings of "concern" (Simon), "upset” (Christina) or being "completely hopeless and helpless" (Petra). There was a sense that this upset was due to the continued presence of the pain: "it's hurting and still hurts after all these years" (Simon). Pain was conceptualised as something that can never be fully eradicated, due to the lack of concrete solutions and as such, it continues to have an impact on their lives: "There are occasions for no reason 
whatsoever, Michael will wake up in the night with his leg quivering and horrendous leg pain. There's no real cure, answer or pills." (Maria). The pain was described as something that the participants could only witness, rather than intervene with:

"That's been very difficult, because when we were travelling she had it one day and I felt completely hopeless and helpless, I couldn't do anything. She knows what to do, she comes down, she takes her medication, but it doesn't help. I couldn't do anything, I said tell me what to do, she says you can't. It was very, very difficult, I didn't know, not even as a friend, as a medic, I didn't know what to do, to talk to her, to leave her alone, to physically do anything, to do exercise, nothing, nothing." (Petra)

\section{Emotional distress}

Participants witnessed varying degrees of emotional distress in the PWLL, ranging from low mood to intense frustration: "I could see her frustration, having just one hand to do things" (Christina). This could occur across any point following on from the amputation: "She said she would cry herself to sleep at night and that's the stuff that I couldn't bear when she was alone in hospital" (Annie). This additionally illustrates how witnessing emotional distress was difficult for families to experience, even if it was only recounted by the PWLL rather than directly witnessed in the moment.

Some related the PWLL's emotional distress to the overall impact of the limb loss on their lives: "there have been times when he has been very, very desolate and has expressed a complete lack of any self-worth or any ability to contribute anything useful" (Andy). Others related it specifically to the 
transition that had been made of what the PWLL could no longer do, with a sense of "knocked her confidence a little bit" (Greg) or "frustration around things that he'd like to do" (Sue).

There was a perception from participants that this emotional distress was understandable: "part of me thinks it would a bit odd if she wasn't a bit frustrated at times" (Daniel). In one instance, the emotional distress was seen as related directly to the aetiology of the limb loss itself, suggesting a perception from the participant that it was traumatic for the PWLL. In this excerpt, Maria describes the emotional experience that now occurs, following a motorcycle accident in which her husband lost a leg:

"When we're driving, Michael is highly agitated when people are driving on the wrong side of the road towards him, which happens very frequently when people overtake cars on our side of the road. Any driving incidences, he gets angry at anything easier than a normal person who hasn't been through a traumatic leg limb loss." (Maria)

\section{Core category 2: Responsibility in caring}

In order to resolve the process of witnessing, participants take responsibility in the PWLL's care by providing various forms of support. The most prominent types of support offered by participants are explained here.

\section{Maintaining proximity}

In the initial stages of recovery from the amputation, this support involved taking responsibility for staying close to the PWLL. For some, this was to maintain proximity during hospitalisation: "Because [hospital] was 60 miles 
away from us and that time I didn't want to leave him. I think I came home one night, and that's when he was in [town]. It was the worst night ever. It was pointless being at home" (Addison), whether or not the individual was a relative or friend: "And his wife was good enough to pave the way so I could go in and out as if I was family. So that meant I could go and see him, and I went to see him virtually every day" (Andy). For others, this proximity for support was offered in the early stages of recovery, once the PWLL was discharged to recover at home. There was an overall sense of the significance and importance given to the act of maintaining proximity: "when she got diagnosed, I promised her I would never leave her side when she was in hospital" (Louise).

\section{Emotional caring}

Participants described providing various forms of support as the PWLL began to recover, depending on what difficulty they witnessed in the PWLL. Taking on responsibility to provide care and support seemed to resolve the sense of difficulty felt in witnessing. In times of witnessing the PWLL's emotional distress, participants offered support in the form of encouragement or "psychological reassurance" (Petra). In instances of witnessing the practical constraints for the PWLL, this emotional support consisted of not only encouraging them, but also managing their expectations about what was now possible: "My wife and I try to soften that a little bit and we have had some conversation about that, saying 'don't beat yourself up if you can't do this. "' (Andy). This additionally occurred within parental relationships:

“We've just tried to make sure that she's got a positive attitude to things and will just give it a try and if she can't do it perfectly it doesn't matter, because at least she's having a go" (Daniel). 


\section{Practical caring}

Participants were particularly forthcoming in their descriptions of practical support that they provide for the PWLL. This included: "electrical projects" (Andy), "all the bits and pieces you get done at home" (David), "helping her dress" (Daniel) and "help and supervision when he's walking" (James). They appeared to be motivated by witnessing the PWLL struggle with various practical daily tasks. Participants saw it as a natural and automatic process to provide this support for the PWLL, with an acceptance of their role or "job" (Maria):

"If we've got a family around for Sunday lunch or something, I know I've got to be around to get the vegetables ready and lift the saucepans onto the stove and things like that, take them off and drain them." (Simon)

\section{Medical caring}

Across all types of relationships, there was additionally a sense of responsibility to provide medical or personal care for the PWLL, often in the early stages of recovery from the limb loss. For one person, this involved wanting to intervene under the guidance of medical staff to massage her mother's hands to reduce the likelihood of cell death and further amputation of the fingers: 'I'd think I needed to be in there with her massaging her hands to make sure this doesn't happen. In the end they were like 'you're being a bit too aggressive with it!' Because I just wanted to prevent it from happening, I cannot let it. Obviously that didn't work" (Annie). There was a sense that this type of support was something new to the participant or to their relationship with the PWLL: "With his limb loss came a scar care routine that we had to do, that we 
never had to do before" (James), but with an acceptance that this was now an aspect to their relationship:

"That was a time when the support was quite intensive, he was using a bottle for the loo. We got used to emptying that for him and it wasn't an awkwardness there. We were old enough and mature enough to know these things need to be done. It was something that he was happy for us to be involved with." (Andy)

Help with medical or personal care was most often mentioned by participants in relation to pain management. This included providing medication: "We've tried ice packs all sorts of things, in the end I mix him a cocktail of drugs and it knocks him out but he's out for a couple of days" (Maria); or mirror therapy: "What I did do is I would give her a mirror, even when she had her stiches in" (Louise). Petra described the various psychological pain management strategies that she provided help with, which were motivated by her sense of helplessness when witnessing her friend in pain. As she described working through various strategies, there was a sense of desperation to provide this support as the only thing that can be done to resolve this concern:

\footnotetext{
"Well she was just laying on a sofa and I was trying to ask the question, would you like me to try to distract, to maybe put some films, some comedy on or something. She said let's try, so we tried that, and I make a cup of tea, so I think relaxing. So I said what about talking about something again to distract you, so let's try, so we talk about some events that we are supposed to go to. It calmed down, she was talking to me, but sometimes you can see pain comes, she said it comes and goes." (Petra)
} 
The use of health and social care services represented a significant shared challenge for participants (as discussed later in this chapter). As such, it makes sense that they would feel motivated to provide support for the PWLL in navigating these services. This included helping to arrange appointments or providing support in understanding what was available: "She might have asked me for advice, maybe what do you think what's better, physiotherapy or acupuncture” (Petra). Several participants spoke of taking a more proactive approach by assisting at appointments: "I always go with her, often because if a consultant asks a question, I fill in the bits that she might have missed to try and make sure that they get a full picture of what actually happens at home" (Simon). In instances where the PWLL would be unable to speak for themselves due to the severity of their illness or their age, the family member acted as an advocate, in order for the PWLL to gain the most appropriate and effective support from services: “Just in the early days, I was Matt's spokesperson, it was up to me to get what I thought Matt should be having or in the time he should be having it" (Addison).

\section{Core category 3: Sharing the impact and challenges}

Participants faced a range of challenges as a consequence of witnessing the limb loss and needing to provide care. This category encapsulates these challenges which participants often experience jointly with the PWLL, including the impact limb loss has on their lives. Most often, the participants spoke not of the limb loss itself, but of what it has represented and created in their lives together. 


\section{Learning to respond}

Participants described a need to negotiate and learn how to respond to the limb loss. This was particularly the case for participants who had no prior experience of disability or limb loss: "I would say she was in my life, possibly the first disabled person I was in contact with. It just happened" (Petra). As such, this meant that they had to learn how to respond to both the limb loss itself and the situations that were created by it:

"At these quarters, I've never had to deal with anybody having this sort of health problem so it was quite a difficult thing to cope with and it began to pose problems that you might not anticipate." (David)

Many participants spoke particularly about how learning to respond to the limb loss meant learning to balance out their sense of responsibility to provide care and support, with allowing the PWLL to have their independence. This meant "not jumping in there, because one could come in and really take over" (Christina) and treading the "very thin line between wanting to help and being over wanting to help" (Petra). This was conceptualised by one participant as a type of "cruel love" (Maria). This involved letting go of the urge to provide caregiving or complete practical tasks for the PWLL out of ease and speed, in order for them to recognise their own abilities: "So possibly overreacting or over-helping them even feel maybe worse. It's almost like not acknowledging that they can do it" (Petra). As such, there was a conscious effort in this learning process: 
"When you see someone struggling to do something, the impulse is to reach out and help them. [In] The very early stage, I decided I wouldn't do that. If he asks me to do something, to open a bottle of something, then I'll do it. But we crossed that bridge, I don't feel awkward sitting waiting whilst he struggles to do something which I could help him with quite easily." (Andy)

\section{Acknowledging changing identity}

The process of witnessing and providing care also required participants to acknowledge what they saw as the changing identity of the PWLL as someone with a disability. This involved responding to the stigma and connotations surrounding disability: "But honestly, the stigma of being disabled, what that meant, it doesn't sound very nice to say, it's taken me a while to work through it” (Annie). For some participants, this discomfort was greater when the disability was marked through either group identification as "if you go to sports club they will put you in groups where it's a disabled group" (Louise) or the use of assistive technologies: "I think it was an acknowledgement, like saying ok yeah he is disabled, he will have to have a wheelchair. You know there was some adjustment around that" (Sue). For those participants who shared a home with the PWLL, they also spoke of the changes that had to be made to their cars or homes, at times with no financial support: "all the conversions and adaptions to the house we've funded ourselves" (Maria). These adaptations, such as hoists, emphasised the identification with disability, and this was felt to be a detriment to the PWLL: "Because to me, waking up to that every day, it was like that psychologist said, it's going to hit you like a ton of bricks one day" (Addison). As a consequence, adaptations would be reduced or made less apparent, in order 
to balance having "the place to look stylish, but [that] she needs to have certain things and amenities around her that will help her." (David).

\section{Responding to others}

Participants also described the challenge they faced jointly with the PWLL of seeing how other people, particularly strangers, notice or respond to the limb loss. They spoke about a process of getting "used to all the attention, because it is a lot of attention, lots of people will turn and look" (James) or worrying about meeting "new people, what they're going to say or how they're going to react to it" (Daniel). Some described how this had left them or the PWLL feeling upset or "a bit gutted" (Addison) and were then drawn to intervene in some way. They did so to assist where others did not know how to act or play around the PWLL, as "we'd just intervene to make that work a bit better for them and suggest things" (Sue), or for the purposes of advocating for the PWLL and educating the stranger. Some participants would do so in a discreet way: "She'd put one thing on the conveyer belt and people might get frustrated.... so I might say something, [whispers] 'well she's actually only got one arm' and they'd say right" (Christina). Others would do so more explicitly:

"We've had a few people shout at us [for cycling on a pedestrian route] and I've actually turned around and said 'look, as you can see my husband has only got one leg and this is the only way he can access this particular area, because we can't walk, he can't walk very far but he can cycle, isn't that wonderful?' and that normally stops them dead." (Maria)

\section{Navigating services}


As mentioned previously, there was also a felt need to support the PWLL in navigating health and social care services. The use of these services becomes a joint challenge for both parties and often a significant part of their shared experience of living with limb loss. The use of services was conceptualised as a challenge of communication, "they don't speak to each other at the council, they don't speak to us" (James); of navigating the various professionals and processes: "It can be confusing certainly to start with to understand who does what, what's the difference between a physio or an occupational health therapist or prosthetics people” (Daniel); or of dealing with jargon: "I did have a bit of an issue with the language in medical terms. Stump, I cannot cope with. To me that's a tree stump, I don't know there's something different" (Louise).

Despite these challenges, many participants spoke positively of the services which they and the PWLL had received help from. This was more evident when they felt that there been consistency in the professionals involved, "continuity with [consultant] knowing that he'd built up a relationship" (Addison), or a process of clear communication and information being appropriately explained: "But they're always very good at trying to explain that and explain right you go to this person if it's this sort of issue and this one if it's something else. So on the whole we've been very lucky with the care she's had and it's all been pretty positive" (Daniel). Positive experiences were also apparent when there were displays of humanity from professionals, no matter how small these were. Here, David spoke of one of these moments when a nurse provided support for another member of his family:

"There was one nurse, a carer up at the intensive care at [county hospital], who said 'well I know how June is doing, but how are you 
doing?' and I said I'm very worried, I explained the situation with my younger daughter. She said 'ok, understandable.' And she dragged her off for a coffee or something, said 'come on for a coffee', and gave her a pep talk in a nice way. I really appreciated that, it wasn't a medical treatment, it was somebody being human." (David)

\section{Changing relationships}

These experiences in limb loss have an impact on relationship between participants and PWLL, as well as the whole family:

"When she first had it [prosthetic leg], my younger son hated it and didn't want to go out in public with her when she was wearing it because he was embarrassed, so it's sort of affected the family in that way" (Daniel).

The relational change was particularly evident in marital relationships with changes to physical intimacy as the spouse becomes "more of a carer than perhaps a lover" (Maria). Both husbands interviewed noted that the support they provide to their wives involved a shift in the traditional roles within the household, as they now have to do "practical living tasks that would normally be done by, if you like, the

wife" (Simon) and they therefore "become the tired housewife" (David). The changes that participants reported in their relationships may additionally occur as other people become more involved in the PWLL's life, and thus the role of the spouse becomes less important:

"One of the other things that happens is that people who have been in hospital or care for a long time, they become institutionalised in a way. 
They relate to their carers. Family members can have a different role, they're less involved in care; that becomes an issue." (David)

The impact of the limb loss on family roles was evident in other types of familial relationships. As a mother, Addison stated: "That was a biggie to be fair, knowing that for me, because they're identical twins that they suddenly loss that identical twin-ness. They are very different now, there's not sort of 'which one are you, which one am I talking to?"' This demonstrates the impact that the physical loss of a limb itself can have on pre-defined family roles. However, friends interviewed also spoke of a continued sense of remaining roles and relationships after limb loss, as the PWLL is "still our friend" (Andy) and therefore the "relationship with her is the same" (Petra). In this, it is evident that these participants placed importance on a continued sense of identity within the PWLL which allows them to maintain their friendship.

Across all types of relationships, many participants felt that the change they had experienced in the relationship after the amputation was in fact a positive and strengthening one. Some participants related this to the amount of time they had spent together in hospital and "staying overnight in hospital when she's had stays" (Daniel). Others described their experience as a journey they had been on together: "[We] still love each other and care for each other, definitely, probably more so now because we've been through such a lot, it keeps you together. No-one else would ever know what that's like, only we've experienced it all" (Maria). For some, this strengthening of the relationship could only occur when the PWLL recovers and requires less intensive support, rebalancing any inequality between them: 
"I think I've probably drawn closer to her from it and as I say now, she's literally over the road, our friendship now has matured. Whereas before I was looking after her doing things, now it's on an even keel and I think our friendship has grown certainly from what's happened to her." (Christina)

\section{Losing shared activities}

Changes in relationships were also defined as a consequence of losing shared activities and lifestyle which participants engaged in with the PWLL. This created the sense that "It's changed my life too; there are things that we wanted to do that we will now not be able to do" (David). For some, this was about losing activities that they had planned for the future together, including changes to retirement plans for older spouses and changes for parents in how they envisaged bringing up their children:

"Before all this happened, we were quite active, we had dogs, always taking them out walking them, we went on hiking holidays, stuff like that. That was the life we'd always hoped, always envisaged we would have with him. Certainly we can't do that now." (James)

It was also evident that participants experienced a loss of joint social activities as "she obviously isn't entertaining as much as she did" (Christina). This change in activities could have a further impact on their relationships with others, such as friends linked to certain hobbies, so that "the invites stopped" (James) for social activities. This created a noticeable sense of being left out by others: "A lot of our 
friends don't include us in things because they know Michael can't do things. We see everything posted on Facebook that they've done, and we feel a bit left out" (Maria).

A further loss described was the loss of being able to go on holiday together: "Travelling is one thing. We go abroad on holiday. But we are limited, we have to choose somewhere that is suitable" (David). The challenge of going abroad was discussed by many participants, with families experiencing difficulties with accessibility in airports or at their destinations: "I'm not saying the places were geared up towards it, you might get a lump of concrete on the side of the pavement for the ramp" (Addison). As such, family members felt they must take responsibility for a significant amount of planning in order to have a holiday together, for example by "asking for ground floor accommodation, are the lifts working, how far is the swimming pool, are there any steps" (Maria). Despite these efforts, there remain difficulties in travelling for them. For instance, David spoke of how this planning led to him considering a holiday which was supposed to be tailored for individuals with disabilities, but when this was examined, he noticed that it was still not suitable to meet the needs of a PWLL:

\footnotetext{
"But you start to look at the detail and you think oh well, we won't be able to walk up Machu Picchu, but there's a train that goes up. Then you look at the picture of the train, there's a vertical ladder about 4 or 5 steps up the side of it. That could be a bit of a problem!" (David)
}

\section{Core category 4: Emotional responding}

All participants spoke of the process of emotionally responding to the limb loss. This stemmed either from the individual or combined effect of witnessing, caregiving 
and the shared impact of limb loss. This aspect of participants' experiences was individualised, in that they varied in the extent to which they felt and expressed various emotions.

\section{Feeling acceptance}

Acceptance was a key emotion for participants, identified as a process of getting "used to the idea of what's happening" (Petra). For many, this was integral to their way of responding to the physical aspect of limb loss. Its significance continued over time: "I suppose acceptance is the biggest thing and the thing that has got us through. This is how it is, this is it, we can't change it, there's nothing we can do" (Addison). Acceptance was described as a process that was "just gradual, right from the point that she came out of hospital having had the amputation, over the next year or so, having to gradually come to accept that it's happened and you're just going to have to deal with it" (Daniel). However, the majority of participants experienced acceptance as a more immediate response which allowed them to grasp a sense of "what we're going to do to move forward" (James) and switch into an active frame of mind. An important aspect of this was to accept that the limb was physically lost and that there was a permanency to the situation:

\footnotetext{
"I think right from the word go I did accept that nothing could be done so I did accept the fact that she'd lost the limb and I had to move with it rather than thinking 'oh why' [...], so there was nothing that could be done so it was acceptance straight away." (Christina)
}

\section{Feeling shock}

Another immediate response to the amputation or hospitalisation was described as one of shock: "My initial reaction was sort of terror; I didn't know 
what was happening" (David). Participants described a sense of confusion in these early stages as they tried to make sense of the experience. In particular, the shock they felt related to the speed with which the process develops, so that "just the pace of things was ridiculous, and that was sepsis so it took us all by surprise" (Andy). It was this speed that caused the most shock, even for those friends who were not physically present in the hospital: "But at the time I was shocked and traumatised with it as well, because it was so sudden" (Christina). Whilst most conceptualised the shock as relating to the early stages, two participants spoke of this continuing even years later, where "I'll look at her and I'm so shocked" (Louise). This was a recurring realisation about what has happened, leading to a fresh sense of shock and disbelief:

"There are still some times when you look at Maisy wearing her prosthetic and you think oh my goodness, how did that happen, how did we end up like this?" (Daniel)

\section{Feeling sadness and loss}

All participants, regardless of their relationship type, spoke of sadness, loss and grief in relation to either the physical loss of the limb itself or its associated consequences. This response was a distinctive process for participants, as limb loss is "such a grieving process for everyone I think, you're not only losing part of your body but your whole life has just been flipped upside down" (Annie). Two mothers spoke of missing the limb and what it meant: "he used to love rubbing his feet, he'd lie on his bed with you, I remember thinking probably silly little things that you'd miss" (Addison). Another experienced a painful sense of losing the PWLL, who was no longer "the baby I gave birth to" (Louise). For others across all relationship types, 
this sadness was related to "tremendous sadness for her, it was more my grieffor her that she wouldn't be able to do the things that she had always done initially" (Christina). Participants' grief was not only associated with the loss of what the PWLL had had in the past, but also what they could have had in the future: "I think it's grief at a lost future, you suddenly realise that's not going to happen. She's not got a future where she's got two legs" (Daniel). For some, this emotional response occurred whether or not the PWLL was experiencing it too, so a situation could be “heart-breaking for us, not for him" (James). However, when a PWLL did experience emotional distress, this was seen as inevitably leading to sadness for family members who witnessed it: "I think if Michael's sad, I'm sad" (Maria). This demonstrates a direct emotional response occurring as a result of witnessing.

\section{Feeling anxious}

Many, but not all, participants described fear and anxiety as an aspect of emotional responding. Their anxiety appeared to be related to potential dangers that the PWLL might face. This included a concern about physical harm, particularly where the limb loss affects the PWLL's balance, putting them at risk of falling: "So that's a bit of a worry as well because it restricts what she can do and I have a concern that if she goes off walking she might fall over, so I go with her" (Simon). Other participants across all relationship types identified their anxiety as focused on psychological or emotional hazards. These were deemed to be hypothetical hazards either now or in the future, for example a parent fearing the likelihood of bullying would be "exacerbated because he is slightly different" (James). Participants perceived dangers to the PWLL's quality of life, such as a concern that they would "miss out on things that she 
should have been doing anyway" (Annie), or for their emotional wellbeing: "I was always worried about her, how does she feel, does her disability make her not equal or does she feel that the friendship has changed because of her" (Petra). In cases involving a traumatic limb loss, participants' concerns stemmed from a fear that the PWLL could be re-traumatised by their actions:

"If I'm anxious about something like in the car, it is a responsibility and therefore it would make me feel just that much more careful. I don't want her to be traumatised in a car again." (Christina)

While many participants reported some anxiety, three in particular disclosed a significant increase in stress or anxiety, with an impact on their wellbeing which was potentially identifiable as a mental health issue. For one person, this reflected the aetiology of the limb loss itself: "Because health anxiety since his illness, has been a bit of a feature of my life" (Sue). For the others, the impact of the limb loss added to other stressors, as: "not all of that was to do with her limb loss by any means, but it was certainly a part of it" (Daniel); or acted as a catalyst for previous psychological issues:

"I pick my skin basically and that was all around anxiety and it really
peaked when my mum was ill. It kind of came back, not came back it's
always been there, but I just couldn't get control of it again." (Annie)

\section{Core category 5: Coping}

All participants spoke of the strategies they have used over time to cope with the challenges and emotional responses associated with life with limb loss. These coping strategies have been divided into three broad types: social, practical, and 
emotional. It is important to note that participants would not use one of these types of strategies exclusively, rather that they would use a combination of different strategies together. Participants provided information about their individual contexts, conceptualising their coping styles as pre-existing or suited to their personalities, such as being "factual" (James) or "pragmatic and practical" (Petra). This provided insights about why they responded and coped in the way that they did to the circumstances of limb loss.

\section{Social coping}

This relates to coping strategies that involve turning to others for support. Here participants spoke of using general limb loss and disease-specific (e.g. sepsis) charities and organisations that represent the limb loss community, particularly through the use of the internet and social media: “There's been a lot of support online and that's where we've turned to more for support for questions than to our friends" (James). Turning to others in similar situations was seen as beneficial, specifically in helping to reduce stigma and to find inspiration or information: "I was so anxious, $I$ rang the [charity]. I rang them, I found them, I was like 'I want a second opinion' all that kind of stuff' (Annie). This network was described as useful for problem-solving as "if there were a particular problem that we hadn't foreseen or didn't know, we could chat to them and ask about it" (Daniel), in order to see "how they go around things, you know, how do you work out tights?" (Louise). Three participants mentioned that interacting with these communities was either "wouldn't say necessarily helpful" (Simon) for them as a family member, or raised anxieties and distress, given the comparisons that could be made with other PWLL. For James, this therefore became an active choice to avoid this as a coping strategy: 
“We went to one of those, we've been to a couple but we're not going to anymore. We found them quite disheartening. We went in there and there were people saying it was the worst experience of my life, two days in hospital. We were always the worst case example in there by far, and that just emphasised how unlucky. He was so lucky to survive but unlucky to have it as bad as he got it. We stopped going really to those." (James)

A further social coping strategy was the use of the participants' own network of family and friends, particularly for practical support in the early stages of hospitalisation or recovery: "We have a lot of local people who supported us as well in the beginning who provided food and all sorts of things" (Simon). For parents, this network provided care to other children while they focused on the PWLL:

"So I suppose the network, the support from other people made it a lot easier to move away from this home and live another life somewhere else [in hospital with PWLL], knowing that this is ticking along is a big weight off your mind." (Addison)

This network becomes an important source of emotional support in the longer term: "we don't have a lot of family, but what we do have are very supportive" (Sue). The use of the word 'we' indicates that this support can be used jointly by both the participant and the PWLL. However, for others, this emotional support was accessed as something specifically for them to address their own needs and difficulties as a member of the family network, as "If I'm worried about Catherine then I've got a lot of friends around here" (Christina). This could be drawn on over time: 
“My boss was my own counsellor. Even though I hadn't been working there long, I used her as a counsellor, she was just that sort of person. Everyone at work was so nice, even nine years later they all ask me how Tyler is doing. " (Julie)

Five participants reported seeking support through psychological therapy. Others stated that they were offered this, particularly during the early stages of hospitalisation, but that they instead chose to use other coping strategies. Those who did access psychological therapy reported that they had found it "definitely helpful in just trying to start processing everything” (Daniel) and that talking through their experience with someone "helped me work through some of it" (Annie). One mother described psychological therapy as an important means by which she coped with the continued effects of limb loss on her wellbeing:

"Because health anxiety since his illness, has been a bit of a feature of my life. So I had a re-referral back to clinical psychology and was able to see the same person and get a refresher if you like, it was fortunate. A rerefresher on how to challenge some of the thinking, it's been a massively helpful part of my life clinical psychology." (Sue)

\section{Practical coping}

These strategies encompass all of the practical activities that participants use to manage the aspects of life with limb loss. While the specifics of these practical strategies varied between individuals, they were mentioned by almost all participants.

Some spoke explicitly of using activities as a form of distraction in order to cope: "trying to just get on with stuff, not necessarily bury the thoughts, but just try to distract myself" (Greg). This included: "trying to get into a hobby or something like 
that" (James) or trying to continue engaging in daily life, by going "to work that day, because I needed to do something” (Annie). At times this activity and distraction was achieved through exercise. Two participants mentioned running, both as a specific activity and as a form of "stress release and it meant that I could get out" (Julie). This was a way of creating space for processing, or to be in control of emotions that were occurring as a consequence of their witnessing:

"I couldn't be on my own sitting still without thinking about it, going back to a really horrific place where I'd be sobbing. Running was the only time when I was on my own and I wasn't doing that, I just felt more control, I can think about it and not go there, and not get to that point." (Annie)

Several participants also mentioned the work they did as activists for limb loss or the causal diseases. This included supporting charities, speaking at events, writing articles to raise awareness, fundraising or organising petitions. For example: "I signed up to do some fundraising for [hospital] and that definitely helped insofar as it felt like I was doing something to help, it was raising money for the hospital" (Daniel). Here it is evident as Daniel was explicit that he did this in order to feel as though he was contributing in some way. This may relate to the experience that many participants mentioned of feeling unable to help or change the situation; being an activist might enable them to feel that they are able to make some change.

Many participants reported that their best way to cope was to be pragmatic in continuing their lives and to focus on what needed to happen next, rather than on the emotional aspects: 
"But when it actually happens I think oh my goodness where do you go from here, but actually you just don't have time to think about it. Well I didn't, I just wanted to get on with things. We always think if something happened, how would I deal with this, what would I do, but actually you just do it." (Christina)

Participants often related this to a sense of finding a new normal or trying to ensure that life continues as it should, in that "Michael and I have always tried to be normal and do the normal things that everybody else does and we don't want to be conspicuous" (Maria). In continuing their lives and focusing on this pragmatic style, many participants adopted a planning approach as their main coping strategy as “everything takes a bit more planning" (Sue) but that "not everything goes to plan and I think you've also got to be flexible" (Maria). This included preparing for practical and social tasks, helping the PWLL have a fulfilling life, or planning for any potential future problems, for example: "what will happen if she were to have a problem with her leg and need to take it off, have we got a backup plan there?" (Daniel).

Many participants were able to draw on their previous life experience in working out what they could practically do to resolve situations they encountered. For some, this involved recalling serious health issues they had experienced themselves, as "I was operated on, so I could see where I needed help. Like somebody took me to an osteopath. I think if you've had that, you see a bit of what I needed, and see that would be helpful to her" (Christina). In doing so, they could facilitate problem solving or cope with the difficulties of providing care for the PWLL: "because my mum had cancer when I was 16, I think I've always learnt medical jargon and always been able to talk to doctors, social workers, hospital consultants, limb prosthetics 
people” (Maria). Three participants spoke of professional experiences which had helped them cope with the demands of providing care for the PWLL. For example, Louise spoke of the ethos of academia which assisted her in finding information about prosthetics for her daughter: “Basically that's just academic life isn't it, you just go back and google things" (Louise). Another spoke of her professional role supporting children with special educational needs making it easier for her to manage different health and social care services, as "I knew exactly who you had to contact, what you had to do and how to fight within that system really" (Sue).

\section{Emotional coping}

Participants adopted a range of emotion-based coping strategies. These were internal and cognitive-based processes which enabled them to make sense of the experiences they faced. The most prominent of these strategies was one of comparing as coping. This involved comparing themselves or their situations to people who "had it far worse" (Julie): "I realised that whatever problems we've got, there are people with some really terrible situations and they don't get anything like the support that they really need" (David). It is evident that this strategy enabled them to gain perspective and to have a sense of how bad the situation could have been. Most often, participants related this approach to instances when they were engaging with the limb loss community through charity events. This gave them a sense of the wide variety of types of limb loss: "Seeing him with the others in there, he wasn't the best in there but he wasn't the worst by far, that was really, really good. I think that was probably one of the best experiences we've had"' (James). In this example, a social comparison strategy was used in order to compare the PWLL with another. However, others 
spoke of this social comparison in terms of comparing themselves to other family members of a PWLL:

"You looked at some of the other parents and thought I don't know how they can cope with that, I don't know how they can carry on, don't know how they can deal with it." (Daniel)

For almost all participants, this process of mental comparison including considering the situation of limb loss in contrast to an imagined one in which the PWLL had died instead, thus a comparison of loss of limb to loss of life. This was a particularly prominent feature of the interviews and something that many participants would come back to repeatedly. This was referred to as a strategy they had used particularly in the early stages of recovery: "The fact that in the early days, if ever I felt an inkling of feeling sad or upset, bereft for what he'd lost, I would imagine not having my son, and it disappeared quickly as anything" (Addison); but it could also be used as time went on: "What makes me carry on is I'm just so lucky that Michael is still here. At 23, he could have been dead but look at what we've done with our lives" (Maria). It was spoken of as something that brought distinct clarity, with an important need to "concentrate on the fact she was alive" (Christina), particularly where a decision to amputate and sacrifice to limb was made to save the PWLL's life: “...If her leg hadn't been amputated then she would have died, so we were very grateful that they were able to amputate it successfully" (Daniel). From these extracts, it is evident that this strategy enables participants to feel a sense of acceptance, and for some, even relief and gratitude.

Several participants spoke of how their way of coping was to push away their own feelings in order to focus on those of the PWLL. It was deemed 
important to "get over my own feelings to concentrate on her" (Christina). For many participants, this process of focusing on the PWLL meant giving less importance to their own needs and emotions: "It's about her, and it is about her and as a mum you have to have your times when you cry at home or cry in bed" (Louise). For some, this created a conscious discrepancy between how they are feeling and how they are acting, particularly when there was still a fear for the PWLL's life in the early stages of hospitalisation: "When I went down on the Wednesday evening to see him, whilst the actual words that I spoke to him were very encouraging and optimistic, I actually went down to say goodbye to him" (Andy). This process could continue, for instance when witnessing the PWLL use prosthetics:

\footnotetext{
"For her, it was a happy event, but for me seeing her for the first time with that prosthetic was actually sad. Obviously I needed to pick up my emotions and not show that, then yes I was happy for her as she could walk and everything” (Petra).
}

These examples show how this strategy involves participants pushing away their own feelings to ensure their continuing encouragement and support for the PWLL, demonstrating an interaction between these components of participants' experience. Some participants spoke about how the use of this strategy was at odds with the structure of the research interview, where they were being asked to elaborate on their own emotions and experiences. This is something that Maria reflected on during the debrief section of the interview: 
"Michael is the person with the problem and I tend to very much focus and do what I think is right for him and don't think about my side of things, if you see what I mean, and I've always been like that. You tend to supress feelings and anxieties and things to be honest." (Maria)

Another emotion-based strategy was to use humour, where "we know this is $s^{* *} t$, we know this is horrendous. The only way we can make this any better is to make a joke, we do laugh about it" (Annie). This suggests this strategy being used when nothing further could be done in order to be practical about the situation. Others spoke of needing to use humour in moments of awkwardness, such as slips of the tongue: "I say something silly like let's run somewhere, then we would laugh together about a stupid remark or something" (Petra) and "Instead of thinking oh my goodness I can't say that, instead it just brings me a lot more pleasure that we can at times laugh about these things and yes we did the other day about something she did, we just sat there and giggled about it" (Christina). The use of "we" in all these examples shows that this particular strategy is constructed as a joint coping strategy together with the PWLL and/or other members of the family network.

A further type of emotion-based coping was to recognise positives in the situation. This was different in approach to participants recognising that the situation could be worse; participants would focus instead on their admiration for the PWLL, that they have "done amazingly" (Annie). In the face of witnessing the practical difficulties, this strategy was described as a conscious effort to "look at the positives in Catherine, I will look at the things she can do not at the things she can't do" (Christina). Many recognised that, following limb loss, there had been "more opportunity to do different things" (Louise), 
creating a sense that "in some respects, that's not a bad thing that that's happened" (Greg). These positives included any changes to friendships and activities. For example:

\footnotetext{
"Having said that, it's opened up other things. We're quite involved with other amputees up at [town] through [hospital]. We've climbed Kilimanjaro with other amputees, so that's opened up from that. We've got quite a good bunch of friends from that who we meet regularly with, which is quite nice." (Simon)
}

When witnessing emotional distress in the PWLL, this coping strategy was used to acknowledge their resilience and coping, with a recognition that the PWLL is "well adjusted" (Sue). This included acknowledging that they could continue their lives as normal, albeit with some change: “When she's done school sports days or things like that, she's been in running races and things even though she's been way slower than kids her age and she'll just run it as fast as she can" (Daniel). There was additionally a recognition of the PWLL's coping strategies in the face of these challenges: "The personification of her limb has possibly helped because her and Alan [name given to residual limb] are on this journey together" (Louise).

The final type of emotion-based strategy, was to acknowledge that "time is a great healer" (Catherine). This meant that "emotionally, as time passes you sort of forget" (Addison). Participants described becoming more used to the limb loss and its associated consequences over time, so these would gradually become less emotionally intensive. Indeed, this appeared to be a strategy used in order to manage their emotional responses to the situation. Many participants 
reflected on this in their interviews, regardless of how long it had been since the limb was lost. For example, James, who was speaking within a year of the limb loss occurring, had found that: “...as time has gone on, it gets easier to not think about it, the further away it was of him losing his leg, as time goes on he gets better with his leg and that's great to see" (James). This quote indicates that the process of acceptance with time may be linked to the PWLL's recovery process. In Daniel's case, a greater time had passed since the limb loss. While this example demonstrates a reduction in emotional intensity over time, it clearly indicates that the process of emotional responding still remains very real for participants:

“I think all the emotions surrounding Maisy's limb loss become muted over time. I'm sure they're still there, but it's less painful or I feel less frustrated, less sad over time. The longer things go on, the less you see it as a defining moment." (Daniel)

\section{Chapter conclusion}

This chapter presented five core categories which have formed an emerging theoretical model of how participants experience and cope with limb loss in their family network. In order to assess the theoretical rigour of this framework, all fourteen participants were sent a summary of the research and invited to comment on its accuracy (Appendix M and N). Of those fourteen participants, four chose to do so. All four felt the summary was a fair and reasonable portrayal of their experience, with one stating that the summary was "spot on". This process will be reflected on further in the next chapter. 


\section{Chapter 4: Discussion}

\section{Overview}

This chapter presents a summary of the research and reflects on both the practical and theoretical implications of its findings, in two parts:

Part 1: Theoretical framework. This part summarises the theoretical framework explaining the effect of acquired limb loss on the family network, placing it in context of the existing literature. This facilitates the development of the core categories and indicates how the framework contributes to existing knowledge.

Part 2: Evaluation of research. This part outlines an evaluation of the research, in terms of its strengths, limitations and implications. It also provides a reflective account of the research experience. 


\section{Part 1: Theoretical framework}

\section{Overview of theoretical model}

The research was conducted with two aims in mind. These were:

1. To understand the experiences of acquired limb loss from the perspective of members of the family network

2. To develop an explanatory framework to examine how acquired limb loss affects the family network.

This research using Grounded Theory method (GTM) provides a novel contribution to the literature on limb loss and families, given that it provides an explanatory framework of the experiences of families following on from an amputation in another person. The first aim was addressed through allowing participants to express their experiences: the findings revealed that the experiences of family members after the loss of a limb are shaped by the perceptions of the person with limb loss (PWLL) themselves, the challenges they and their families face together and how these challenges are resolved.

The second aim was addressed through the use of theoretical coding in GTM, which facilitated the development of an explanatory framework. This framework reflects the inter-relationships between the five categories: witnessing, responsibility in caring, sharing challenges and impact, emotional responding, and coping. It therefore explains the processes by which limb loss affects members of the family network, through the interaction of different components of their experience. The theory postulates that witnessing the PWLL leads to a sense of responsibility to offer 
care and support. This, together with the experience of witnessing itself, creates various shared challenges and emotional responses which are resolved through the use of coping strategies. One can reasonably conclude therefore, that the research aims in this study have been addressed. To further extend on these aims, literature searches were conducted in relation to the five core categories (see Appendix P for a summary of the search strategies). This served to integrate the categories into the existing literature, in order to develop a more thorough understanding of the mechanisms involved within the framework.

\section{Integration of theoretical \& empirical literature}

\section{Witnessing}

The model postulates that witnessing is the key explanatory category. It details the participants' main concern as their perception of the experiences of the PWLL. This focused predominately on the changes to daily life, emotional distress and pain they described the PWLL going through. These difficulties are consistent with the limb loss literature outlined in Chapter 1. This explored the difficulties from the PWLL's perspective, in particular their experiences of physical pain, practical limitations, emotional distress and a sense of no longer being able to do what could be done previously (Horgan \& MacLachlan, 2004; Murray, 2010; Senra et al., 2012). However, it is an interesting finding that these difficulties are visible to others. The previous literature does indicate other challenges for the PWLL that were not prevalent in the current data, such as disturbances to body image (Murray, 2002). This suggests that some difficulties may not be expressed by the PWLL or perceived by members of the family network. 
The category of witnessing in this research differs in that it explains what family members perceive as the difficulties for the PWLL, rather than how they are experienced by the PWLL themselves. This aspect of the model is an important and original contribution to the chronic illness and disability (CID) literature. Powerful personal accounts do exist within the literature, such as Agne's (1993) reflection on the difficulties in seeing her mother use prosthetics for the first time. However, from an empirical perspective, the act of witnessing receives little attention. One must therefore examine other schools of thought, such as social and cognitive psychology.

From a general societal perspective, it is thought that the act of witnessing is now a common aspect of modern life, in that we are constantly exposed to the distress of others through various forms of media (Shu, Hassell, Weber, Ochsner \& Mobbs, 2017). Witnessing the distress of others on an ongoing basis has been found to lead to such effects as vicarious trauma, secondary stress and burnout (Sabin-Farrell \& Turpin, 2003). These effects have been seen in professionals in caregiving roles, although the greatest impact is on those who are not trained in how to contain distress and work with trauma. Research has revealed that solicitors, for example, are more vulnerable to the effects of witnessing distress and more likely to experience vicarious trauma than mental health practitioners (Maguire \& Byrne, 2017). In applying these findings to the current study, it could be that family members find that witnessing is the aspect of their experience that causes the most distress, given that (for the most part) they do not have any prior training or experience on dealing with limb loss, disability or caregiving.

There is a wealth of psychological literature examining the mechanisms and effects of seeing either psychological or physical pain in others. Overall, research suggests that the experience of seeing pain in another person evokes an empathic 
response and facilitates helping behaviours (Bastian, Jetten, Hornsley \& Leknes, 2014). The research into witnessing pain most commonly stems from experimental social psychology whereby, for example, participants are set up to witness another person receive "electric shocks". The various types of manipulation in these experiments allow us to better understand the mechanisms involved in witnessing, in particular how it affects the emotional response and evokes acts of helping, as stated in the current theory. In one experiment, participants who witnessed electrical shocks had been assigned either to a group in which researchers elicited anxiety (by telling participants that the shocks were not their fault) or one in which they provoked guilt (by telling them that they were their fault). They were then offered the chance to share the shocks, as an act of altruism. The findings revealed that both emotion groups showed more altruistic behaviours than neutral control groups, but that there was no significant difference in behaviours between the two emotion groups (Rawlings, 1968). It seemed that witnessing facilitated the process of help, regardless of the emotional response underlining it. In applying this to the current theory, this may explain why participants reported, when relevant, that seeing pain in the PWLL was the most difficult element of witnessing.

The emotional processes involved in witnessing are complex. Other studies have emphasised the importance of the emotional dimension, although there is some debate as to which particular emotions are evoked. Some research suggests that sadness and distress, but not empathy, are evoked in seeing both the psychological and physical pain of others in video clips (Fultz, Schaller \& Cialdini, 1988). However other findings have revealed that trait and state empathic concern (the tendency to feel compassion for others and feeling it in the moment, respectively) are associated with increased vicarious anxiety in witnessing and subsequent poor sleep; but that 
trait distress (the tendency to feel stressed in situations) does not create any anxiety in witnessing (Shu et al., 2017). Therefore, the process and effects of witnessing could be determined by underlining traits in the individual which affect how they respond to stressful inter-relational situations.

The cognitive processes of subjective perception may tell us more about how individuals experience witnessing, than do the objective need and difficulty of the person being witnessed. That is, the process of caring and witnessing relates to individual differences in the perceiver, rather than the distress being expressed (Batson, Fultz \& Schoenrade, 1987). In relation to the current findings, this would mean that family members' experience of witnessing is influenced particularly by the individual differences in the subjective process, rather than the actual challenges the PWLL experiences. This is evidenced as some participants who were linked to the same PWLL did not then report identical processes of witnessing to one another.

Research into caregiving in relation to other disabilities has identified an opposite effect, that caregiving-related stress is determined by the objective impairment in the care-recipient and this causes changes to relationships and subsequently to wellbeing. For instance, in a study with adults who care for their elderly parents, it was found that a cognitive impairment (rather than a functional impairment) in the care-recipient was most significantly associated with changes in relationships, with a mediating effect on wellbeing (Townsend \& Franks, 1995). In applying these findings to the current emerging theory, limb loss can be considered a functional impairment and, as such, may result in a lesser strain for caregivers. However, the current sample will have witnessed various changes and difficulties in the PWLL. It may be that these different aspects of witnessing have a cumulative impact on wellbeing and family processes. 
Looking at the act of witnessing from the perspective of theories about disability and family systems brings additional insights into the possible mechanisms it involves. The subjectivity inherent in witnessing suggests that the problems in limb loss may be perceived by the family network regardless of whether or not the PWLL explicitly communicates that they are in difficulty. This reflects the social model of disability, which postulates that a disability is a social construct defined by the limitations imposed by others, rather than a functional limitation in the person themselves (Oliver, 1983). In applying this approach, witnessing may be seen as leading some family members to perceive a functional limitation in the PWLL and the support they offer in response, thereby creating a reduced sense of independence and increased sense of disability. Others may instead perceive that the PWLL does not have a disability, seeing them as remaining able and not constrained by any practical limitations. From a systemic perspective, this ties in with ideas from problem-determined systems theory, which postulates that a problem in a system is only generated by an agreement created through language used within the system (a phenomenon becomes a problem when the system agrees it is a problem) (Anderson et al., 1986). When applying this theory to witnessing, it may be that it is the subjective act of witnessing which allows the family member and eventually the whole system to define one aspect being witnessed (e.g. the use of prosthetics) as a problem. These concepts exist as hypothetical ideas about how witnessing might be influenced by family systems and cultural ideas about disability.

To summarise, the experimental evidence supports the interaction defined in the theoretical model between witnessing, emotional responding and providing care. This indicates that witnessing creates the urge to offer support, regardless of whether or not the individual perceives themselves to be a caregiver or even whether they feel 
responsible for the experiences of the PWLL. This is supported by the fact that all participants reported witnessing as their primary concern, regardless of whether or not they were in a formal or informal carer role, or whether they perceived themselves to be responsible for the limb loss (as was identified by two of the participants). The application of these experimental findings may be limited however, as they examine the process of witnessing, in (predominately) outdated, controlled experimental conditions where the individuals were not known to each other. This may not fully reflect the process of witnessing which occurs between known families and friends in the current socioeconomic context of healthcare in the UK. The current research therefore adds a contribution to the existing research on witnessing, in exploring the process in relation to pain and distress in the family network. Additionally, the study gave participants the freedom to report on what it is in particular that they perceive and focus on in witnessing in the PWLL. Witnessing therefore needs to be considered as a concept within systemic and CID literature, rather than just in experimental social psychology. Future research would benefit from understanding if there are any pre-cursors to or individual differences in witnessing and how it might influence people's experience of other forms of CID.

\section{Responsibility in caring}

In the theoretical model of family members' perceptions and responses to limb loss, this category of experience concerns the process of family caring, generated by a sense of responsibility to the PWLL. This includes maintaining proximity for caring, in addition to offering emotional, practical and medical care. This process of caring may be considered from the perspective of systemic theories. For example, the family systems theory postulates that family members are assigned to roles and 
responsibilities, particularly in times of crisis (Bowen, 1966). In a crisis such as limb loss, a family member may construct their role as that of one who is responsible for providing care and support.

The findings in the current study have evidenced the specific types of support that are offered by families in response to limb loss. This is in line with the broader experiences of family members and friends who act as informal carers in the UK across all types of CID, in providing health support, assistance in practical tasks and financial matters (Carers UK, 2015). In interviews with parents, siblings and friends of people with a learning disability, it was found that the experience of caring is centred around and motivated by the sense of responsibility and the belief that they, as members of the family and friends network, are the most appropriate people to offer care (Iacono et al., 2016). If this responsibility was perceived as shared with another member of the system, then carers were more likely to report satisfaction and to be content with the role they took in the care-receiver's life. This means that members of family networks who can share a felt sense of responsibility in limb loss could have a more positive sense of wellbeing. Indeed, this reflects accounts from families themselves within the limb loss literature specifically, with Agne (1993) reflecting on how the family took the dominant share of responsibility in care for her mother, as a PWLL.

Previous empirical findings help explain the motivations and precursors for feeling responsible and acting to provide support. This may involve a complex interplay of emotional processes in caregiving in the family. Spousal carers of individuals with multiple sclerosis (MS) have reported that their caring and sense of responsibility is linked to an anxiety and worry for their spouse (Cheung \& Hocking, 2004). In the context of the current study, this indicates that emotional responding 
may in itself facilitate the need to provide care to the PWLL. Further support for this idea is provided by experimental evidence from social psychology. When participants are told that their reaction times reduce the strength of an electric shock they believe they are administering to another person, then they respond faster and have a greater physiological response to stress (Geer \& Jarmecky, 1973). This suggests that the process of witnessing another in pain creates the motivation to provide help, through an evoked feeling of stress; and that a sense of responsibility creates an even stronger urge to help.

The process of help may also be influenced by other individual factors, including beliefs and cognitions about the care-receiver. In a survey of attitudes in students to providing help for family members with a hypothetical illness, it was found that an attitude of ageism led to a decrease in willingness to provide emotional, practical and medical care (Sutter, Perrin, Tabaac, Parsa \& Mickens, 2017). However, this only explained $5 \%$ of the variance and, as the survey used a hypothetical scenario of caregiving, it is not clear that these findings accurately reflect the process of witnessing which contributes to the act of helping another. This research does however indicate the potential influence of pre-existing beliefs, although the findings are limited in their application to the current study as this was not something that was particularly discussed in the interviews. It might be that attitudes of ageism are not socially desirable to disclose, or that the sample included adult offspring who felt compelled to offer support to their parents in any event.

The motivations for providing support may also be accounted for by the individual attachment styles of family members. In spousal caregivers (in the context of cancer), attachment security was related to autonomous motivations for providing care (i.e. based on carers' own individual choice and personal values), whereas 
attachment anxiety was related to introjected motivations to provide care (i.e. feeling compelled to do so, or acting to avoid feelings of guilt or shame) (Kim, Carver, Deci \& Kasser, 2008). Longitudinal research has also demonstrated the role of pre-existing personality traits in determining motivations to provide support, in that individuals with more emotionally stable personality traits are more likely to adopt a caregiving role when the opportunity arises in their family (Rohr, Wagner \& Lang, 2013).

To conclude, evidence suggests that various processes influence responsibility and caring in families who are affected by CID. The mechanisms by which this occurs may be based on individual and systemic factors in the family network; this may account for the patterns revealed in the current theory. This theoretical model presented provides a contribution to the literature by exploring how the wider network of family and friends, rather than only parents or spouses, may be driven to provide support.

\section{Sharing challenges and impact}

Within this theory, this category of experiences defines the challenges and impact of limb loss, stemming from the processes of witnessing or providing care. The shared nature of these challenges signifies that limb loss affects not just the PWLL, but also the network around them. The most prevalent challenges for the participants in the current research were centred on managing their own responses and those of others, dealing with changing identities, roles and relationships, and the loss of joint activities. The types of challenges described are consistent with the information available from the wider literature concerned with familial caregivers of PWLL, particularly with regards to changes in parental and spousal relationships 
which occur as a result of caregiving after an amputation (Agne, 1993; Livingstone et al., 2011); and the loss of shared activities (Thompson \& Haran, 1984).

From a theoretical perspective, the family life cycle theory (Carter \& McGoldrick, 1988) may account for variations in the felt impact of limb loss, in that the nature and extent of this impact may relate to the developmental stage the family were in at the time that the surgical amputation occurred. For instance, the husbands in the sample spoke of how the amputation had occurred near the time they were due to begin their retirement with their wives, impacting on the activities they would be able to do together. However, information was not systematically collected about the age of the PWLL at the time of amputation; it would therefore be inappropriate to draw any conclusions regarding the impact of the developmental life stages on the experiences of families in limb loss.

The participants here reported the specific challenges they encountered in having limb loss in their family network. Their reports of these challenges are also reflected in the wider CID literature. For instance, other carers report similar challenges involved in negotiating health and social care services, having to manage excessive paperwork and trying to access good quality assistive equipment for the home (Cheung \& Hocking, 2004). Others report systemic difficulties in communicating with services, particularly when faced with all the different roles of professionals in services. In the acute phase, this is said to add to the confusion and shock that occurs in the early stages of hospitalisation, as the family members try to make sense of their experience. Understanding these professional roles becomes of vital importance to families as they place substantial trust into these professionals and recognise the contribution that they will themselves make to the medical care being provided (Schubart, Kinzie \& Farace, 2007). Parental carers of children with 
disabilities have gone on to highlight that the fragmentation of services can make understanding who can provide what support more difficult; this is particularly relevant given that they often feel their role is often to fight and advocate in order to ensure that the best services and care are provided (Resch et al., 2010). Where services are unable to meet needs or cannot be provided locally, families are often forced to take on responsibility for paying for private services or for transporting their family member to access healthcare in other localities (Resch et al., 2010). These challenges in accessing services were all reported in the current study, including the financial impact of paying for travel, private services and high quality assistive technologies, such as prosthetics or adaptations to the home.

The wider CID literature has concluded that familial caring can have a significant impact on the caregiver and their quality of life (Lim \& Zebrack, 2004). In community samples, experimental findings suggest that the act of providing social support is particularly challenging when it is being offered to individuals with low self-esteem. The receiver (as the person with low self-esteem who requires support) is less accepting of the support, leaving the provider with negative emotions about themselves and their relationship with that person (Marigold, Cavallo, Holmes \& Wood, 2014). Within limb loss, the self-esteem of the PWLL potentially influences the impact on the family member and the dynamics of their relationship with them.

The current study did reveal the impact that limb loss has on participants' relationships and their socialisation. This is further documented in the wider CID literature, with the conclusion that these conditions do affect whole family systems rather than just the individual caregiver (e.g. Schubart et al., 2007). For familial carers in the context of brain tumours, the level of caregiving strain does have an impact on not just the caregiver's wellbeing, but also a knock-on effect on other 
familial relationships. This may result from the direct impact the illness itself has on those other family members; but also the shift that is created in the time and dynamics spent between them, coupled with difficulties in balancing all family responsibilities (Schubart et al., 2007). For instance, if a mother is caring for one child with a CID, it may mean she feels less able to meet the needs of other children, thereby affecting the relationships between them all.

The impact of caregiving on personal relationships was mentioned by spousal carers in the current study, albeit not as explicitly by the husbands. This is a finding supported by wider literature (Cheung \& Hocking, 2004). Hypothesised gender differences in caring may be important here, with male spousal carers (in the context of dementia) presenting with more difficulties in adjusting to their role and being less accepting of help from services for support with this (Baker \& Robertson, 2008). The mechanisms by which the dynamics of family relationships are affected are complex. For instance, in young carers of parents with MS, it has been found that family functioning and wellbeing are particularly affected by co-morbid depression in the care-receiver and changes in roles for the caregiver, rather than by the direct effects of the illness itself (Pakenham \& Cox, 2012). While the current study on limb loss did not include young carers, there is the potential for changes to their roles (which result from their conducting a range of caregiving duties) to add to the impact on family relationships.

Other research from caregiving literature suggests that a further mechanism affecting relationships is the extent to which the CID has an effect on the person's interactions and social activities. In mothers of children with cystic fibrosis, illness was said to account for specific rather than global changes to their daily interactions. As caregiving duties take up a significant amount of time, there was a reduction 
specifically in the time dedicated to play and leisure based activities, both with their children and their spouses (Quittner, Opipari, Regoli, Jacobsen \& Eigen, 1992). The loss of social activities associated with caring for unwell children is particularly prominent in times of conflict between the parent and child, indicating perhaps that families feel unable to cope with the combination of both relational and health crises during a social activity, so they are more likely to avoid them altogether (Murdock, Adams, Pears \& Ellis, 2012). These findings together suggest that, in the context of a CID, including limb loss, both the caregiver and other family members may see their social needs and interactions as of secondary importance. In familial caregiving, the PWLL's social and health needs are addressed by the same person, so this shift in priorities and interactions would naturally have an impact on their relationship.

In the current study on limb loss, participants reported the loss of shared social activities as a significant challenge in their lives. This is particularly important given the findings from the individual PWLL literature that recovery from an amputation is facilitated if the PWLL is able to re-engage with pre-existing social activities, assuming the limb loss does not affect their functional ability to undertake these activities (Williams et al., 2004). The loss of social activities may extend to the family network, if these activities were something that they had previously experienced together. The shared nature of the challenge of social integration has also been reported by parents of children with disabilities. One aspect of this occurs when families are interacting with people outside of their network who may comment unfavourably on the child's disability (Resch et al., 2010). In these circumstances, parents often take on responsibility for advocating for and defending their child, while balancing this with the need to encourage them to be independent and resilient in the face of such social challenges. This highlights the same interaction between 
shared challenges and the responsibility in caring which emerged in the current research on limb loss family networks. In particular, the experiences of these parents (Resch et al., 2010) is consistent with the current finding that, in limb loss, members of the family network must learn to respond in a way that offers support, without undermining the independence of the PWLL. This finding can additionally be triangulated from the research into the perspective of the PWLL, where it was reported that over-solicitous responding has a detrimental effect on their wellbeing (Hanley et al., 2004).

Overall, the types of challenges outlined in the current study are consistent with previous findings from the limb loss and CID literature. This category provides an important contribution to support the notion that limb loss is not just about the physical and medical experience, but also about its psychosocial consequences (Horgan \& MacLachlan, 2004; Sjödahl et al., 2004). The existing literature furthers our understanding of the possible mechanisms in which the challenges affect families, although research would benefit from confirming this further in limb loss specifically.

\section{Emotional responding}

This category relates to the emergence of emotional responses (acceptance, shock, sadness, grief and anxiety) to witnessing, caring and the sharing of challenges in limb loss. Overall, these emotions are noted in the wider caring and CID literature. However, research also highlights the experience of anger and denial in familial carers, which were not features evident here (Schubart et al., 2007). Within limb loss, the emotions described are consistent with other quantitative and qualitative research findings regarding PWLL and their families, who report similar psychological and 
emotional responses to amputation (Alves-Costa \& Pereira, 2017; Thompson \& Haran, 1985; Turgay \& Sonuvar, 1983).

The emotional response in families to a disability can be considered as a process in two stages: the acute phase in the first discovery of the disability; and a later phase when responding to further complications and challenges associated with the disability (Resch et al., 2010). This complements the current theory presented, as members of the family network would often relate their experience to one of two time frames: the 'then' (i.e. the acute early stages of hospitalisation and recovery) and the 'now' (i.e. the ongoing care and challenges in daily life as it exists in the present day). The feeling of shock is reported as particularly prevalent for families at the time of diagnosis, in both the current study and wider literature. This occurs most often when families have no prior experiences of disability and must therefore attempt to make sense of only the information presented to them by professionals (Schubart et al., 2007). This emphasises the hypothesised link in the emerging theory between the challenges in limb loss (i.e. managing health and social care services) and the process of emotional responding.

Peoples' experiences of grief and acceptance can be understood from a theoretical perspective using the stage theory model of grief, which is often applied to bereavement and other types of loss (Kübler-Ross, 1969). This draws upon the understanding of terminally-ill patients, as they come to terms with their own death and experience a progression of emotional stages over time: denial, anger, bargaining, depression and acceptance. It is thought that these responses may not occur in a straightforward sequential process. This was seen in the experiences of the family network in the current study: some participants reported acceptance as something which emerged over time, whereas others reported that it occurred in the immediate 
aftermath of the amputation. There is the potential that the immediate acceptance could relate specifically to the physical loss of limb, whereas the longer-term process relates to accepting the consequences and challenges that families are faced with. The application of these ideas about bereavement is appropriate in limb loss, given that PWLL and potentially their families undergo a similar process of grieving for their loss. Qualitative findings have supported this in demonstrating that there are similar internal experiences in bereavement and limb loss (e.g. disbelief, denial, numbness); these create a shift in identity, although they may differ in terms of their overt demonstrations of grief (Parkes, 1975). Longitudinal evidence from the wider research into grief indicates that bereaved individuals may also experience various emotional stages after the natural death of a loved one (Maciejewski, Zhang, Block \& Prigerson, 2007). These natural causes of death are found to be more closely associated with a sense of acceptance, with violent causes being associated with greater levels of distress and grief (Holland \& Neimeyer, 2010). In applying this to the current theory, there is the potential for emotional responding to be determined according to whether the amputation is conceptualised as resulting from a 'violent', traumatic illness or accident, or in the context of a longer-term chronic illness.

The experience of anxiety is also widely reported in carers and families of people with a CID, although individual differences exist within this. Spousal carers report high levels of anxiety, although this occurs more often in female spouses than their male counterparts (Alexander \& Wilz, 2010; Rohr et al., 2013). However, this gender effect is inversed when the care-receiver experiences both emotional difficulties (e.g. uncontrollable crying) and cognitive deficits (e.g. memory impairments), as females tend to cope with these changes better than their male counterparts (Alexander \& Wilz, 2010). This suggests the potential for gender 
differences in the emotional responding of family network members in relation to the types of impairment that they must witness in the care-recipient. Witnessing emotional distress may in particular evoke these individual and gender differences in emotional responding. However, there is other evidence to suggest that this anxiety is simply a consequence of holding responsibility in caregiving, rather than as a result of witnessing directly. Research into spousal carers in the context of MS identified the process of "caring as worrying", where worry is conceptualised as a part of caregiving. This included worrying about the person's physical health, the impact on their identity now and in the future and the potential for its shared impact on their life as a couple. Some of the emotional responses were identified as stemming directly from this shared impact (e.g. changes to relationships) and they instilled a motivation to provide care (Cheung \& Hocking, 2004). The experience of emotional distress in carers has also been found to be an important factor determining the extent to which caregiving has a significant impact on their overall quality of life (Lim \& Zebrack, 2004). This finding supports the hypothesised link between emotional responding and other elements of the theoretical model in limb loss.

For some participants here, the level of anxiety and distress was raised to the extent that they disclosed an experience of a mental health issue. This reflects findings from the wider literature which reveals increased rates of mental health difficulties in familial carers, in the context of both mental and physical health issues. This reflects the development of a shared experience in the dyads between the caregiver and care-recipient (Savage \& Bailey, 2004). For example, familial carers of patients admitted to intensive care wards report high levels of caregiver burden, depression and PTSD, particularly when there are complications arising from a brain injury (van den Born-van Zanten, Dongelmans, Dettling-Ihnenfeldt, Vink \& van der 
Schaaf, 2016; Warren et al., 2016). In the current study, some participants did mention experiences of the PWLL being admitted to intensive care, and almost all participants spoke of their emotional responses during the early stages of hospitalisation. As a hypothesis, this family members' emotional responses may be affected by interactions and processes of witnessing and caring in the acute stage, as they witness complex medical procedures, but are unable to act on a felt sense of responsibility to provide care. As the PWLL returns home, family members may be exposed to witnessing new challenges but they can now provide care, and their emotional experience may differ as a result of this.

Overall, existing research supports the idea that emotional responding is determined by witnessing and providing care. However, some research has indicated the possibility of variations in emotional responding between members of the family network, with various individual and systemic factors influencing how they emotionally respond to witnessing. When watching video clips of others in distress, participants as members of families with higher levels of cohesiveness were more likely to show sadness and empathy (Eisenberg et al., 1991). This finding is however based on an experimental design, which does not consider the inter-relational aspects of witnessing distress within the family itself and the emotional responding that occurs as a result of this. Within familial caregivers, the process of emotional responding has also been found to be related to attachment styles. Specifically, attachment security is associated with an overall sense of positive wellbeing; in contrast, attachment anxiety is associated with increased levels of depression and poor quality of life (Kim et al., 2008). In addition, parental carers experience a greater quality of life if levels of conflict with their child are low, regardless of the intensity of caring demands which are placed upon them (Murdock et al., 2012). As 
such, this suggests that the emotional responding which occurs is not simply related to the practical and emotional challenges which families are confronted with, but also to individual and systemic processes.

The wider literature into caregiving and social psychology allows us to understand the links between emotional responding and other aspects of the theoretical model. Parental caregivers report that their feelings of being stressed and depressed come as a result of the challenges which they face (e.g. having insufficient resources to care for their child) and that this directly contributes to their motivation to provide care (Resch et al., 2010). Changes in emotional responding over time also involve a greater acceptance of the changing roles and relationships within the caregiver and care-recipient dyad (Iacono et al., 2016). Evidence from experimental social psychology also suggests that witnessing evokes the process of emotional responding by eliciting anxiety, empathy and distress (Fultz et al., 1988; Rawlings, 1968; Shu et al., 2017). However, individuals may differ in their emotional responses to witnessing and their motivations for providing care: the feeling of empathy (feeling compassionate and moved) facilitates altruistic motivations for helping behaviour (i.e. to reduce the distress of the other); whereas the feeling of distress (feeling troubled and alarmed) facilitates egocentric motivations to help (i.e. to reduce one's own distress). In applying this research to the emerging theory, it is clear that there is an interaction between emotional responding and providing care, in the context of the shared challenges that families experience.

To conclude, this category described within the model provides an original contribution to the research by highlighting the pre-cursors and consequences of these emotions, and revealing that the processes involved can exist across the wider family network. 


\section{Explaining coping}

This category encapsulates the various coping strategies that participants described to resolve the practical and emotional experiences that they faced. Their coping strategies were grouped into three general domains: social, practical and emotional coping.

From a theoretical perspective, the dominant discourse in the coping literature is based on Lazarus and Folkman's (1984) theory that coping strategies are either problem- or emotion-focused; although Ell (1996) argues that these individual coping models should be considered alongside systemic ideologies. The current model attempts to do so by constructing how coping occurs as a result of the systemic effects of limb loss. Much of the pre-existing literature on coping uses questionnaires based on Lazarus and Folkman's (1984) theory, as a top-down assessment of predefined coping strategies for participants to select from. This is in contrast to a bottom-up approach, where participants are allowed the opportunity to identify coping themselves, as was done in the current study. The current model of family coping in limb loss presents a grouping of coping strategies (i.e. social, practical, emotional) that differs from grouping in the Lazarus and Folkman (1984) framework (i.e. problem- or emotion-focused).

While the data presented here could be analysed and applied within this framework, this was not done as the guidance from a GTM perspective is that the data should be analysed without theoretical preconceptions (Glaser \& Strauss, 1967). The grouping presented in the model (i.e. social, practical, emotional) represents the strategies presented by participants as they emerged within various levels of GTM analysis. This enables coping to be presented as grounded in the participants' data, rather than in previous theoretical frameworks. As such, this research provides a 
novel and alternative approach to understanding how families cope with the aftereffects of an amputation. For ease of reading, the existing literature into coping in carers will be presented here in relation to the grouping used in the current model (i.e. social, practical, emotional).

\section{Social coping}

The use of social coping has been identified as valuable to carers, with benefits to both their mental and physical health. In an intervention study, spousal carers were offered both counselling and carer support groups (with a 'treatment as usual' control group) (Roth, Mittelman, Clay, Madan \& Haley, 2005). Pre- and post-assessments included psychometric measures of depression and stress appraisals to caregiving events; alongside structured interviews about their social support network and their level of satisfaction with this support. The findings revealed that the intervention group had a more substantial improvement in the size of their social network and their satisfaction regarding their network. This effect could be based on the mechanisms of therapy, whereby carers are encouraged to consider the resources available to them as sources of social support. These improvements were found to ameliorate levels of depression and stress appraisals in caring; although interestingly this effect was only related to improvements in satisfaction with (rather than size of) support networks. This occurred regardless of whether the caring demands placed on the caregiver increased over time. This indicates that the benefits of social coping are related to the carer's perception of their network, rather than its extent, even in the face of continued difficulties. This has some significance for the current theoretical model, as it emphasises that families may only effectively use their social coping to best effect if they feel satisfied with their engagement with that network. The findings 
from Roth et al. (2005) are useful to support the idea that 'using psychological therapy' and 'using communities' have been grouped together as social coping in the current model, as those family members who have engaged with psychological therapy may have been encouraged to make use of new and existing social networks.

As mentioned above, engagement with social coping may improve mood and stress in familial carers. Research with spousal carers in the context of HIV has further revealed that social coping strategies that facilitate the greatest psychological and physical benefits for carers (Billings, Folkman, Acree \& Moskowitz, 2000). In this study, carers were asked about their experience of a real and recent stressful caregiving event, alongside a questionnaire on coping strategies based on the Lazarus and Folkman (1984) model. Findings established through a structural equational model revealed that dysfunctional coping strategies (particularly cognitive avoidance) tended to result in negative affect, which in turn creates an increase in physical health complaints. Conversely, when carers used social coping strategies they were more likely to experience positive affect and subsequently reported fewer physical health complaints. However, where carers suffered from their own CID, then the stigma attached to this impeded their access to social support. Therefore, there may be factors that limit carers from accessing necessary coping strategies and their potential benefits.

These findings are relevant to the current theoretical model, as they imply an interaction between coping and offering care. It would be more difficult for a family member to meet the needs of a PWLL if they are experiencing their own CID, with a secondary impact on the coping strategies which they can use to manage caregivingrelated stress. Billings et al. (2000) further explored links between emotional responding, coping and (potentially) provision of support, highlighting the need for 
social support for the entire network in order for the PWLL to have an optimum environment for their own rehabilitation following on from the amputation. However, they did not examine how coping relates to the specifics of the caregiving situation. This current emerging model offers an original contribution to these ideas, by considering how witnessing and providing care could facilitate coping.

The motivation and choice to use social coping may be rooted in evolution, particularly in situations that could evoke the fight or flight response. In a general population survey, biological threats (e.g. loss of employment, house fire) were presented to participants, along with a psychometric assessment of their social coping strategies (i.e. dysfunctional and functional emotional inter-relational strategies, such as blame or empathy, respectively) (Hänggi, 2008). The findings revealed a higher use of dysfunctional social coping in scenarios involving interactions with another adult (especially a partner), than in those involving a child. It was found that mothers were more likely than other family members to adopt these dysfunctional strategies, indicating that the form of family relationship may influence the use of coping. Additionally, functional strategies were only adopted in crisis situations involving close family members. These findings appear relevant to the current theory, as they suggest that individual differences in coping may relate to factors in the PWLL and in their relationships with the family network. Some strategies may only be used within the family, rather than in the wider social network. However, it is important to note methodological constraints that limit the usefulness of Hänggi’s (2008) findings. In particular, the study involved selecting coping strategies from a pre-defined theoretical list, demonstrating a top-down assessment of coping, and the coping questionnaires used only had a moderate level of reliability. The current model of families and coping in limb loss offers an original contribution to these ideas, by 
allowing coping to be defined by participants in a bottom-up approach and applying them to real inter-personal scenarios, as opposed to hypothetical ones.

\section{Practical coping}

The use of practical coping strategies in the current model was particularly dominated by the process of focusing on the practical aspects of care for the PWLL. This may be linked with the emotion-based strategy of carers supressing their own emotions, in order to focus on the needs of the PWLL. This reflects the wider PWLL literature, in which it is clear that the family network is most often used for assistance with problem-solving in relation to the challenges a PWLL encounters (Kratz et al., 2010; Tebbi et al., 1984; Tyc, 1992; Valizadeh et al., 2014). It may be that family members have adapted to this being a part of their role in providing support to the PWLL and, as such, naturally take this on as a way to cope. There is some evidence to support the idea that families (although previously only examined in spouses) do tend to use practical coping by focusing on the practicalities of care in both limb loss (Turgay \& Sonuvar, 1983) and other forms of CID (Iacono et al., 2016).

A further practical and active strategy described by participants was the use of exercise as coping, as a way to provide a release or space to process. This is consistent with research indicating that exercise is an effective active coping strategy within community samples (Cairney, Kwan, Veldhuizen \& Faulkner, 2014), clinical samples (Salmon, 2001) and caregivers (Kartalova-O’Doherty \& Doherty, 2008). Participants' reports of using practical strategies are therefore consistent with the wider literature. 


\section{Emotional coping}

Turning to emotion-based strategies, the wider CID caregiving literature suggests that friends and family members who act as carers do make use of emotionbased strategies. In some studies, these strategies are defined by researchers as constructive (e.g. positive reframing) or dysfunctional (e.g. using self-blame) (Iacono et al., 2016; Schubart et al., 2007). In research related to limb loss specifically, spouses have reported supressing their own emotions as a method of focusing on the needs of the PWLL; or comparing the limb loss to the hypothetical impact they would have experienced had the PWLL died instead (Reed \& Claunch, 2002; Turgay \& Sonuvar, 1983; Verschuren et al., 2013). The current model supports these findings, but suggests that these processes extend beyond spouses into other family relationships.

A further emotion-based strategy identified was the recognition of positives in a situation. This use of cognitive reappraisal may be particularly beneficial for coping with the emotional consequences of witnessing. Experimental research has identified that the use of cognitive re-appraisal hinders the development of the personal distress which stems from witnessing another experiencing distress or pain (Shu et al., 2017). A further emotion-based strategy emerged as family members allowed for time to act as a healer. This is understood in the wider literature about grief, which highlights the evolution over time of emotional responses to a loss and an adjustment is the meaning that is made of the loss. It is argued that this is not simply related to the passing of time, but to the development of coping strategies that enable family members to create a new meaning to their situation (Holland \& Neimeyer, 2010). 


\section{Choice of coping}

The reasons why individuals adopt the coping strategies that they do remain unclear, although various individual factors are likely to play a part here. Family network members may each adopt different strategies and there is the potential for conflict to arise when these strategies clash (Iacono et al., 2016), although this did not emerge in the current study. In considering individual differences in coping, there is limited evidence to indicate that any gender differences in adjustment are based on gender differences in coping (Baker \& Robertson, 2008). This is echoed in the current study, as the participants did not demonstrate particular gender differences in their identification of coping strategies.

The choice of strategy may also relate to factors within the caregiving process. Research into spousal carers in dementia have indicated that the use of strategies is determined by environmental demands that are placed on the caregiver and the level of burden that they experience (Papastavrou, Kalokerinou, Papacostas, Tsangari \& Sourtzi, 2007). Specifically, carers with a higher sense of burden were more likely to use emotion-focused strategies; those with a lowered sense of burden were more likely to use practical-focused strategies. The selection of strategies may also relate to a felt sense of responsibility, with family members who hold a greater sense of responsibility being more likely to use emotion-based coping strategies (Iacono et al., 2016). Those who experience and are pre-occupied with blame (directed towards themselves or others) are more likely to use 'dysfunctional' coping (DeDios-Stern \& Lee, 2017). The process of blaming was mentioned by some participants in the current study into limb loss, whether this was related to self-blame or blaming of others for the amputation. There was some evidence of the strategies used by these individuals. For instance, one participant referred briefly to his role in the accident 
that caused his wife's limb loss, but did not wish to discuss this further within the interview. This was analysed as a demonstration of how, within the interview, he used emotional suppression to cope with feelings of self-blaming, although this was not explicitly spoken about within the interview. One could conceptualise this process in the interview as one of avoidance. However, it is reasonably unlikely that individuals who use avoidant coping in this situation would have volunteered to speak in an interview about limb loss.

To summarise, the findings from the wider research may reflect a process whereby carers and members of the family network will resolve as much as is possible through practical-based strategies, but then adopt emotion-based strategies when the enormity of the situation means there is no more that they can do. This is illustrated in the interviews by one participant's description of their use of humour as an emotion-based strategy: "we know this is horrendous. The only way we can make this any better is to make a joke, we do laugh about it". The current theory provides a contribution to the coping literature by defining how coping is used within a systemic context, when family members are faced with the challenges of limb loss.

\section{Summary}

The current model is consistent with the available theoretical and empirical literature on CID and caregiving, as well as the social psychology research into how individuals witness and act on the suffering of others. Additionally, the study contributes to research in this field by providing a framework not yet available to explain how this occurs specifically within families. The literature supports the model by developing the categories it describes and by explaining their interconnectedness and the individual variations that can occur between families. 


\section{Part 2: Evaluation of research}

\section{Strengths}

The use of technology for interviews (i.e. Skype and telephones) meant that participants could be recruited nationally, rather than from one geographical area attached to a particular prosthetic limb-fitting service. Had an NHS clinic been used as the sole source of recruitment, then there would be the potential for a bias towards individuals who were actively engaging with psychological or limb prosthetics services. The choice of recruitment methods for this study avoided this potential bias. Only three individuals chose to use Skype; there was not a perception from the researcher that these interviews were qualitatively different from the telephone interviews. The interviews may have differed had they been conducted face-to-face, but it is impossible to know this with any certainty. The use of the telephone was particularly beneficial for the unstructured interviews, as the increased sense of anonymity may have allowed participants a greater open space to express and explore their views in an unrestricted way.

The initial use of unstructured interviews is a methodological strength, given that it allowed the issues of importance to be freely identified and explored by participants, particularly as there is a limited pool of previous research available with this population. The development and testing of ideas was also a strength of the study. This was ensured through ongoing analysis and interviewing, with more structured interviews and respondent validation. Many qualitative studies use respondent validation by checking the content of interview transcripts for accuracy with the participants. However, this alternative approach to validation countered bias by ensuring that ideas in the emerging theory were not based purely on a researcher's 
perspective, but rather on those of the participants themselves. Despite sending the research summary to all participants, only four replied to comment on this. It could be hypothesised that the limited response from participants simply represents a personal choice, or that participants forgot to comment or felt uncomfortable to state a different opinion to the researcher. One could reasonably expect that not all participants would respond to this, despite it not being possible to know the reasons why this occurred. The method of respondent validation remains a strength in this study, given its adherence to rigorous methods of quality assurance (Guba and Lincoln, 1994).

Pre-existing literature was used in a particular and strategic way, which represents a further strength of the study. To the extent that this was possible, the researcher avoided reading the previous literature prior to completing the data collection and analysis. The guidelines on GTM state that literature should be used in the final processes of analysis, as a method of triangulation to develop the categories (Dunne, 2011; Glaser \& Strauss, 1967; Lo, 2016). This was covered earlier in this chapter, which has presented each of the individual categories and related them to existing research and theory from the fields of caregiving, systemic ideologies, health psychology and social psychology. Therefore, the process of analysis has emerged from the participants' accounts, rather than it being limited by a priori concepts within existing literature.

A further strength of this research is the adoption of a modern and liberal definition of family. This broad inclusion was beneficial as it reflected the wider experiences of families in society, particularly within specific cultural communities who emphasise the role that voluntary kin play within families. Within this study, three of the fourteen participants were close friends as members of the family 
network: one of these was self-identified, one was identified by the PWLL and another was identified by another individual through snowballing methods of recruitment. It was useful therefore to consider PWLL and participants' perceptions of who is identified within their family network. As several participants held such relationships, this was appropriate and beneficial to the research.

\section{Limitations}

The recruitment strategy may have been biased towards those who have responded relatively positively and empathically towards the limb loss, especially those who have provided support for the PWLL. This emerging theory may not therefore take full account for the experiences of families whose emotional responding (e.g. denial, anger) may not facilitate a responsibility to offer support. A social desirability bias is also possible, with individuals more likely to come forward for interviewing if they perceive themselves to be offering a socially favourable level of support to the PWLL. Given that the recruitment strategy was targeted largely towards support groups and charities, there is a bias here towards individuals who use communities as a social coping strategy. Some bias may additionally have been caused by the wording in the recruitment advertisement (Appendix B) which called for individuals who support a PWLL. This wording was selected to reach those individuals in the support network of a PWLL, regardless of whether they consider themselves to be a caregiver. However, it is possible that this strategy neglected those who are affected by limb loss but do not provide care or support.

The sample did not include some types of family dynamics (e.g. step-relations, in-laws), nor did it cover every specific aetiology of limb loss. Including these relationships would have been more fully reflective of the nature of blended families 
in the UK (Miller, 2013). Interestingly, none of those who came forward were from families of PWLL who had lost a limb through vascular causes and diabetes. This is surprising, given that this remains the most prevalent cause of limb loss in the UK (Limbless Statistics, 2013). This is a limitation of the study, given that the risk of amputation is considered possible from the time of diagnosis in diabetes and so there may be different processes for these PWLL and their family networks. Understanding these exceptions and differences would enable more thorough knowledge of the mechanisms involved within the theoretical framework.

At this stage, the theory presented only informs us about the experience of these family members from their perspective, rather than providing an explanation of the relational processes as they occur between members of the family system. Additionally, the sample here does combine various factors of limb loss (e.g. time passed since amputation) and families (e.g. attachment figures and structures, emotional and physical proximity, etc.). Subsequently, the theory presented represents a general description of the processes that occur for affected families. However, there will most likely be nuances within each category, based on individual factors such as attachment style. This warrants further research to identify how these specific factors may potentially alter the process of the theory presented. However, the heterogeneity of the sample has attempted to develop the scope of the theory.

Triangulation is often used in qualitative research as a method of quality assurance (Guba \& Lincoln, 1994). Here, this included using the views of participants in a range of relationships with the PWLL; and integrating literature for building the theoretical concepts. However, the research did not use triangulation through interviewing the PWLL themselves, as this extended beyond the scope and remit available at this time. This would have been useful in order to establish whether 
the process of witnessing from the perspective of the family does relate accurately to the experience of the PWLL. However, the inclusion of the wider literature shows that the processes of witnessing as described by the participants generally reflects the challenges which are reported by PWLL in research, such as difficulties with assistive technologies, pain and emotional distress.

\section{Research implications}

This theory of the effect of limb loss on the family network has implications for the existing theoretical and empirical literature into healthcare, families and carers. Part 1 of this chapter has embedded the current theory within this available literature, in order to understand where the existing and new findings about families in healthcare can extend to one another. As such, research implications have been identified throughout this chapter. However, there are gaps that could be addressed through future research. Within GTM, this would relate to developing a deeper understanding of the properties and degrees within each of the categories. This would mean focusing future research on the competencies or tasks that must be achieved by members of the family network to enable them to respond and cope to limb loss in a particular way. This would help to identify why individuals experience limb loss in the way they do, perhaps based on factors related to attachment, or other systemic processes. The researcher attempted to address this through the literature integration in Part 1 of this chapter. It would be useful to go on to test the theory through other methods, such as quantitative surveys and clinical service research. This could include testing of the family processes that may differ with specific demographic characteristics that were not examined as part of this research, such as age of the PWLL at the time of amputation, or the effects of culture and ethnicity. 
As mentioned in Chapter 1 (Introduction), it is anticipated that the results of this study will be combined with findings from a complementary study into the effects of acquired limb loss on military family networks. Combining these will create a larger pool of data to enable greater understanding of the processes that occur within various relationships and the influence of the wider social context that may be at play. Other future research would also benefit from exploring the experiences of family members who only became known to the PWLL after the limb loss occurred (e.g. partners, in-laws and close friends). All participants spoke in the first phase of interviewing (i.e. during unstructured interviews) about their experience in witnessing the process of transition and what the PWLL could no longer do as a result of the amputation. As part of theoretical sampling, only participants known to the PWLL before the amputation were included in later interviews, for the purposes of developing a greater depth of understanding about this transition process in limb loss. Later research could also explore the experiences of children and adolescents as family members, as these were excluded here for practical reasons.

\section{Practice implications}

The theory holds implications for clinical practice, particularly for understanding the family system during recovery and rehabilitation from an amputation. The potential application of practice implications from the current study would only be appropriate in civilian (i.e. non-military) services, given that this is the sample that was used. As explained in Chapter 1, research should provide an understanding of the experiences of PWLL and their families in both civilian and military contexts, as both types of services are concerned with the after-effects of limb loss. As such, the combined findings of this research and the complementary 
study (into military veterans and their families affected by limb loss) will provide a richer understanding of the applications for these services. The current study is relevant to Clinical Psychologists in an NHS, civilian context who may see PWLL and/or their network for psychological therapy to support them in coping with the after-effects of amputations. It is also relevant to the wider professional team who will be involved with the PWLL's rehabilitation, for example physiotherapists who must consider the psychosocial factors that may influence the PWLL's physical rehabilitation.

Services must consider that the after-effects of an amputation do not lie solely with the PWLL, but also the individuals around them. These effects influence the care and support that can be offered to the PWLL and therefore will ultimately influence their physical and psychological rehabilitation. In particular, families need to be supported in relation to witnessing, as well as the potential changes in family relationships and socialisation which they may face. Families may be at a reduced risk of relational disturbances if they are encouraged to continue shared activities which are not focused on caring. They should additionally be supported and encouraged to use their existing coping strategies where necessary. This should apply to all members of the family network, rather than solely the identified carers who may present with the PWLL at their routine appointments. Those who are providing other types of informal support may be neglected by services, despite the impact that limb loss can have on them. This has implications for the construction of narratives around the definition of carers and entitlement to support, as outlined in future NICE guidelines on adult carers due to be published in 2019 (NICE, 2017).

The participants additionally reported specific challenges in navigating health and social care services. These experiences have direct implications for services, 
indicating the need for practical steps to ease the process for families. This should include providing families with sufficient information with clear communication about the causes and needs of limb loss. This information should be delivered clearly and sensitively, recognising the level of shock family members may well be experiencing and which may affect their comprehension, particularly while the PWLL is in hospital. Most importantly, families should be provided with clear definitions into the terminology and professional roles in teams, including an overview of the role each professional has in meeting the needs of the PWLL and their family. There is the potential that greater clarity in the medical process may allow families to feel more emotionally prepared for the process of witnessing.

The findings of this research underline the importance of social support for the whole family network and not just the PWLL. Services can be particularly motivated to encourage their patients and families to utilise social support, given its dominance within the healthcare and coping literature (Ross et al., 1998; Uchino et al., 1996). However, services should consider whether this social support is appropriate and of sufficient quality, including psychological therapy and signposting towards charities and organisations. Some participants spoke of how therapy did not feel right for them, or feeling that charity events were an unhelpful forum to be influenced by the negativity of others. As such, individuals should be supported to consider the choice of specific types of social support, or encouraged to use other coping strategies if social coping does not benefit them.

\section{Impact of research}

In line with the dissemination process, the research was presented to clinicians, PWLL and their families through various formats. Firstly, this was presented to 
clinicians within regional NHS networks of clinical health psychology, in both paediatric and adult settings. The research will additionally be presented at a national conference for the British Psychological Society. These are important processes to ensure that the clinical recommendations can be highlighted directly to services. During the regional presentations, the clinicians responded with useful reflections about how this applied to their work with PWLL and their carers, as well as considering the implications for these findings across other client groups. For instance, the concept of "witnessing" was discussed as being relevant when families on a children's burns ward have witnessed the injury, in addition to witnessing painful dressing changes in hospital and responses from strangers to their altered body. Secondly, the research was presented to the charities accessed as sources of recruitment, by sending them the same research summary that had been sent to participants (Appendix N). This ensures that the implications are understood by services in the charity sector who support this population. From this, an invitation was made for the researcher to attend a family event for limb loss, in order to discuss the research to PWLL and their families. Furthermore, these charities will be able to distribute the findings directly to this population and will hopefully provide validation to the experience of affected families.

\section{Critical self-reflection}

As part of the process of self-reflexivity described in Chapter 2 (Methodology), researchers should consider their experience of engaging with the material when interviewing participants in qualitative research, including GTM (Alvesson \& Sköldberg, 2009). The exercise of critical self-reflection can be applied as a strategy 
for reviewing the whole experience of the research process. This will be written here in the first person, for ease of reading.

My experience of conducting qualitative interviews was particularly interesting given the duality of my professional role as both a researcher and clinician. I had no professional experience of limb loss, but the participants all knew my job title. Throughout the interviews, I was very aware that I held both of these roles, and that my clinical self could not be forgotten whilst adopting the role of researcher. My role as a clinician meant that I would feel a substantial level of guilt for hearing these stories or distress, but not being able to offer psychological therapy afterwards. It was difficult at times to spend an interview holding and observing their distress, rather than working with it therapeutically. However for the most part, I felt that my skills as a clinician were very useful in conducting the interviews. I felt comfortable in the process of asking appropriate and difficult questions sensitively, while holding several ideas in mind at any one time. I felt skilled in the practicalities of interviewing, such as being able to write notes while also listening, considering my own reflections and formulating the next question.

There were two instances when my status as a psychologist was mentioned in the interviews. One of these was in an interview where I asked a reflective question and the response was: “That's very good, you're proper psychologist!'. In hindsight, I wonder whether this was a communication of a felt experience of being interviewed by a psychologist who may psychoanalyze the responses, or whether this led her to provide responses that she believed I would want to hear as a clinician. In another interview where my role as a clinician was mentioned, a historic risk of suicide in the PWLL was discussed and the participant expressed concern for their wellbeing. He therefore required some assistance in considering risk management and signposting to 
appropriate services. In this instance, I felt it necessary to step out of the role as an observational researcher towards the end of the interview, in order to follow steps to manage the risk. Both I and the participant felt this was sufficiently resolved.

I was led to wonder at times what impact my role had on the power dynamics between us, as it may have put me in a position of being more knowledgeable due to my professional title. At times, the participants would explain the technical components of limb loss and would ask me how much I knew about these aspects. I would avoid answering this directly, in order to allow them the freedom to express their own understanding. I wonder, however, whether their being able to provide an explanation allowed them to regain a greater sense of power in the interview. I can only speculate as to whether in the interviews participants saw me more as a researcher, a psychologist or a peer. When it came to the more structured interviews, I felt it was more evident that I had knowledge of the topic, given that I was presenting ideas about what was understood from other family members. I could equally have come across as a knowledgeable academic, or an understanding peer.

My experience of conducting interviews was difficult at times, as I am a person who stammers. I had considered this in the early stages of the research development, as soon as I knew I would be conducting interviews. I chose to manage this by disclosing my stammer by email when making practical arrangements for the interview, as I find disclosure to be the most effective strategy to improve my fluency. Some participants acknowledged this by email by saying this was fine with them, or by offering reassurance that they knew someone else who stammers. This was not something that was spoken about by any of the participants during the interviews themselves. I noticed that I did stammer more than usual in the interviews, particularly when interviewing in the evening after a day spent on clinical placement. 
I sought out support for this from this from other researchers who stammer. I can only speculate on the potential influence this may have had on the participants and the process of the interviews, including whether this shifted the power dynamics between us. Potentially, the stammer created a greater sense of humanity to an unknown researcher to whom they were disclosing their personal experiences.

The process of interviewing and the research as a whole has evoked a strong personal emotional response in me. I felt a deeper emotional connection with some participants more than others. I noticed that at times, the transference of their emotional experience would be so strong and would leave me feeling exhausted and distressed. This particularly occurred when I was juggling the demands of interviewing, analysing, writing, and being on a placement in a general hospital. I received adequate support for this by discussing the emotional impact in supervision and personal therapy. Overall, I felt humbled and trusted to hear the participants' stories and it is an experience that I will never forget.

\section{Conclusions}

The purpose of the research was to understand and explain the experiences of family members, including close friends, of someone who has lost a limb. The theoretical model presented explains how family members witness the transition and difficulties the PWLL goes through in limb loss, leading to the provision of care and support. Subsequently, families experience various challenges and emotions, which are resolved through coping strategies. The importance of this research is defined by the original contribution of the explanatory concept of witnessing, given that this is a new conceptualisation of a process previously considered in experimental social psychology. The mechanisms within and between each element of the theoretical 
model can be better understood through the integration of existing research and theory. However, the model presents an initial overview of the experiences of families affected by limb loss, which may be further developed through future research. In its current form, the theoretical model remains of importance given its applications to services, in that it highlights the needs of family members and those experiences that they may need support with. It highlights the priority that should be given to these individuals, as they continue to support the PWLL and be involved with their ongoing medical and psychosocial rehabilitation. 


\section{References}

Agne, C. R. A., (1993). Rehabilitating a loved one: A personal story. Rehabilitation Nursing, 23(1), 23-25. doi:10.1002/j/2048-7940.1993.tb01281.x

Alexander, T., \& Wilz, G. (2010). Family caregivers: Gender differences in adjustment to stroke survivors' mental changes. Rehabilitation Psychology, 55(2), 159-169. doi:10.1037/a0019253

Alves-Costa, M. S., \& Pereira, M. G. (2017). Predictors and moderators of quality of life in caregivers of amputee patients by type 2 diabetes. Scandinavian Journal of Caring Sciences, doi:10.1111/scs.12528.

Alvesson, M., \& Sköldberg, K. (2009). Reflexive methodology: New vistas for qualitative research ( $2^{\text {nd }}$ Ed.). London: Sage Publications Ltd.

Amputation Coalition of America (2008). Factsheet: Limb loss definitions. Retrieved on $31^{\text {st }}$ December 2017 from: www.amputation-coalition.org

Anderson, H., Goolishian, H. A., \& Winderman, L. (1986). Problem determined systems: Towards transformation in family therapy. Journal of Strategic and Systemic Therapies, 5(4), 1-13. doi:10.1521/jsst.1986.5.4.1

Annells, M. (1996). Grounded theory method: Philosophical perspectives, paradigm of inquiry, and postmodernism. Qualitative Health Research, 6(3), 379-393. doi:10.1177/104973239600600306

Baker, K. L., \& Robertson, N. (2008). Coping with caring for someone with dementia: Reviewing the literature about men. Aging and Mental Health, 12(4), 413-422. doi:10.1080/13607860802224250 
Bastian, B. Jetten, J., Hornsley, M.J., \& Leknes, S. (2014). The positive consequences of pain: A biopsychosocial approach. Personality and Social Psychology Review, 18(3), 256-279. doi:10.1177/1088868314527831

Batson, C. D., Fultz, J., \& Schoenrade, P. A. (1987). Distress and empathy: Two qualitatively distinct vicarious emotions with different motivational consequences. Journal of Personality, 55(1), 19-39. doi:10.1111/j.14676494.1987.tb00426.x

Benetato, B. B. (2011). Posttraumatic growth among operation enduring freedom and operation Iraqi freedom amputees. Journal of Nursing Scholarship, 43(4), 412420. doi:10.1111/j.1547-5069.2011.01421.x

Berger, R. (2013). Now I see it, now I don't: Researcher's position and reflexivity in qualitative research. Qualitative Research, 15(2), 219-234. doi:10.1177/1468794112468475

Biddiss, E. (2010). Need-directed design of prostheses and enabling resources. In C.D. Murray (Ed.), Amputation, prosthesis use and phantom limb pain: An interdisciplinary perspective (pp. 7-22). London: Springer Ltd.

Billings, D. W., Folkman, S., Acree, M., \& Moskowitz, J. T. (2000). Coping and physical health during caregiving: The roles of positive and negative affect. Journal of Personality and Social Psychology, 79(1), 131-142. doi:10.1037//0022-3514.79.1.131

Birch, M., \& Miller, T. (2000). Inviting intimacy: The interview as therapeutic opportunity. International Journal of Social Research Methodology, 3(3), 189202. doi:10.1080/13645570050083689

Birks, M., \& Mills, J. (2015). Grounded theory: A practical guide. London: Sage Publications Ltd. 
Bishop, M. (2005). Quality of life and psychosocial adaptation to chronic illness and disability: Preliminary analysis of a conceptual and theoretical synthesis. Rehabilitation Counselling Bulletin, 48(4), 219-231. doi:10.1177/00343552050480040301

Bogart, K. R. (2014). The role of disability self-concept in adaptation to congenital or acquired disability. Rehabilitation Psychology, 59(1), 107-115. doi: $10.1037 / \mathrm{a} 0035800$

Bowen, M. (1966). The use of family theory in clinical practice. Comprehensive Psychiatry, 7(5), 345-374. doi:10.1016/S0010-440X(66)80065-2

Boyle, M., Tebbi, C. K., Mindell, E. R., \& Mettlin, C. J. (1982). Adolescent adjustment to amputation. Pediatric Blood \& Cancer, 10(3), 301-312. doi: 10.1002/mpo.2950100312

Braithwaite, D.O., Bach, B.W., Baxter, L.A., DiVerniero, R., \& Hammonds, J.R. (2010). Constructing family: A typology of voluntary kin. Journal of Social and Personal Relationships, 27(3), 388-407. doi:10.1177/0265407510361615

Brier, M. J., Williams, R. M., Turner, A. P., Henderson, A. W., Roepke, A. M., Norvell, D. C., Henson, H., \& Czerniecki, J. M. (2018). Quality of relationships with caregivers, depression, and life satisfaction after dysvascular lower extremity amputation. Archives of Physical Medicine and Rehabilitation, 99(3), 452-458. doi:10.1016/j.apmr.2017.09.110

British Healthcare Trades Association (2016). Funding new and improving technology and introducing nationally agreed currencies for Prosthetic Care. Retrieved $3^{\text {rd }}$ April 2018, from www.bhta.com

British Society of Rehabilitation Medicine (2003). Amputee and Prosthetic Rehabilitation: Standards and Guidelines ( $2^{\text {nd }}$ Ed.). Retrieved $18^{\text {th }}$ January 
2016, from www.bsrm.org.uk

Broom, A., \& Willis, E. (2007). Completing paradigms and health research. In M. Saks \& J. Allsop (Eds). Researching Health: Quantitative and mixed methods (pp. 16-31). London: Sage Publications Ltd.

Bryant, A. \& Charmaz, K.C. (2010). Sage Handbook of Grounded Theory. London: Sage Publications Ltd.

Bulpitt, H. \& Martin, P. J. (2010). Who am I and what am I doing? Becoming a qualitative research interviewer: Helen Bulpitt and Peter J Martin discuss using reflexion to make research processes in studies transparent. Nurse Researcher, 17(3), 7-16. doi:10.7748/nr2010.04.17.3.7.c7741

Burgoyne, L. L., Billups, C. A., Jirón Jr, J. L., Kaddoum, R. N., Wright, B. B., Bikhazi, G. B., Parish, M.E., \& Pereiras, L. A. (2012). Phantom limb pain in young cancer-related amputees: Recent experience at St. Jude Children's Research Hospital. The Clinical Journal of Pain, 28(3), 222-225. doi:10.1097/AJP.0b013e318227ce7a

Cairney, J., Kwan, M. Y., Veldhuizen, S., \& Faulkner, G. E. (2014). Who uses exercise as a coping strategy for stress? Results from a national survey of Canadians. Journal of Physical Activity and Health, 11(5), 908-916. doi:10.1123/jpah.2012-0107

Carers UK (2015). Facts about carers. Retrieved on $1^{\text {st }}$ February 2018 from $\underline{\text { www.carersuk.org }}$

Carter, B., \& McGoldrick, M. (Eds.). (1988). The changing family life cycle: A framework for family therapy (2nd Ed.) New York: Gardner Press. 
Cater, J. K. (2012). Traumatic amputation: Psychosocial adjustment of six Army women to loss of one or more limbs. The Journal of Rehabilitation Research and Development, 49(10), 1443-1455. doi:10.1682/JRRD.2011.12.0228

Cavanagh, S. R., Shin, L. M., Karamouz, N., \& Rauch, S. L. (2006). Psychiatric and emotional sequelae of surgical amputation. Psychosomatics, 47(6), 459-464. doi:10.1176/appi.psy.47.6.459

Chametzky, B. (2016). Coding in classic grounded theory: I've done an interview, now what? Sociology Mind, 6, 163-172. doi:10.4236/sm.2016.64014

Chan, R. C. (2000). Stress and coping in spouses of persons with spinal cord injuries. Clinical Rehabilitation, 14(2), 137-144. doi:10.1191/026921500675826560

Charmaz, K.C. (2006). Constructing grounded theory: A practical guide through qualitative research. London: Sage Publications Ltd.

Cheung, J., \& Hocking, P. (2004). Caring as worrying: the experience of spousal carers. Journal of Advanced Nursing, 47(5), 475-482. doi: 10.1111/j.13652648.2004.03126.x

Coffey, L., Gallagher, P., \& Desmond, D. (2014). Goal pursuit and goal adjustment as predictors of disability and quality of life among individuals with a lower limb amputation: a prospective study. Archives of Physical Medicine and Rehabilitation, 95(2), 244-252. doi:10.1016/j.apmr.2013.08.011

Copuroglu, C., Ozcan, M., Yilmaz, B., Gorgulu, Y., Abay, E., \& Yalniz, E. (2010). Acute stress disorder and post-traumatic stress disorder following traumatic amputation. Acta Orthopaedica Belgica, 76(1), 90-93.

Corbin, J., \& Strauss, A. (1990). Grounded theory research: Procedures, canons and evaluative criteria. Zeitschrift für Soziologie, 19(6), 418-427. doi:10.1007/BF00988593 
DeDios-Stern, S., \& Lee, E. J. (2017). Blame, coping, and psychosocial outcomes in caregivers of individuals with brain injury. Rehabilitation Psychology, 62(3), 353-362. doi:10.1037/rep0000143

Department of Health (2017). Guidance - Children's sports prostheses funding: How to apply. Retrieved on $10^{\text {th }}$ November 2017 from www.gov.uk

Desmond, D. M. (2007). Coping, affective distress, and psychosocial adjustment among people with traumatic upper limb amputations. Journal of Psychosomatic Research, 62(1), 15-21. doi:10.1016/j.jpsychores.2006.07.027

Desmond, D., \& Gallagher, P. (2008). Coping and psychosocial adjustment to amputation. In P. Gallagher, D. Desmond, \& M. MacLachlan (Eds.), Psychoprosthetics (pp. 11-22). London: Springer.

Desmond, D. M., \& MacLachlan, M. (2006). Coping strategies as predictors of psychosocial adaptation in a sample of elderly veterans with acquired lower limb amputations. Social Science \& Medicine, 62(1), 208-216. doi:10.1016/j.socscimed.2005.05.011

Desmond, D.M., \& MacLachlan, M. (2010). Prevalence and characteristics of phantom limb pain and residual limb pain in the long term after upper limb amputation. International Journal of Rehabilitation Research, 33, 279-282. doi:10.1097/MRR.0b013e328336388d

Diabetes UK (2016). Twenty devastating amputations every day. Retrieved on $12^{\text {th }}$ March 2018 from www.diabetes.org.uk

Dunne, C. (2011). The place of the literature review in grounded theory research. International Journal of Social Research Methodology, 14(2), 111124. doi:10.1080/13645579.2010.494930 
Dunne, S., Coffey, L., Gallagher, P., Desmond, D., \& Ryall, N. (2015). Beyond function: Using assistive technologies following lower limb loss. Journal of Rehabilitation Medicine, 47(6), 561-568. doi:10.2340/16501977-1962

Edwards, D. S., Phillip, R. D., Bosanquet, N., Bull, A. M., \& Clasper, J. C. (2015). What is the magnitude and long-term economic cost of care of the British military Afghanistan amputee cohort? Clinical Orthoptics and Related Research, 473(9), 2848-2855. doi:10.1007/s11999-015-4250-9

Ehde, D. M., Czerniecki, J. M., Smith, D. G., Campbell, K. M., Edwards, W. T., Jensen, M. P., \& Robinson, L. R. (2000). Chronic phantom sensations, phantom pain, residual limb pain, and other regional pain after lower limb amputation. Archives of Physical Medicine and Rehabilitation, 81(8), 10391044. doi:10.1053/apmr.2000.7583

Ehde, D. M., Smith, D. G., Czerniecki, J. M., Campbell, K. M., Malchow, D. M., \& Robinson, L. R. (2001). Back pain as a secondary disability in persons with lower limb amputations. Archives of Physical Medicine and Rehabilitation, 82(6), 731-734. doi:10.1053/apmr.2001.21962

Ehde, D.M., \& Wegener, S.T. (2008). Management of chronic pain after limb loss. In P. Gallagher, D. Desmond, \& M. MacLachlan (Eds.), Psychoprosthetics (pp. 35-52). London: Springer.

Eisenberg, N., Fabes, R. A., Schaller, M., Miller, P., Carlo, G., Poulin, R., Shea, C., \& Shell, R. (1991). Personality and socialization correlates of vicarious emotional responding. Journal of Personality and Social Psychology, 61(3), $459-470$. 
Eliott, T.R., \& Rivera, P. (2006). The experiences of families and their carers in health care. In P. Kennedy, \& S. Llewelyn (Eds.), The essentials of clinical health psychology (pp. 39-56). Chichester: John Wiley \& Sons.

Ell, K. (1996). Social networks, social support and coping with serious illness: The family connection. Social Science \& Medicine, 42(2), 173-183. doi: $10.1016 / 0277-9536(95) 00100-X$

Engel, G. L. (1977). The need for a new medical model: A challenge for biomedicine. Science, 196(4286), 129-136. doi:10.1126/science.847460

Engward, H., \& Davis, G. (2015). Being reflexive in qualitative grounded theory: Discussion and application of a model of reflexivity. Journal of Advanced Nursing, 71(7), 1530-1538. doi:10.1111/jan.12653

Ephraim, P. L., Dillingham, T. R., Sector, M., Pezzin, L. E., \& MacKenzie, E. J. (2003). Epidemiology of limb loss and congenital limb deficiency: A review of the literature. Archives of Physical Medicine and Rehabilitation, 84(5), 747761. doi:10.1016/S0003-9993(02)04932-8

Ephraim, P. L., Wegener, S. T., MacKenzie, E. J., Dillingham, T. R., \& Pezzin, L. E. (2005). Phantom Pain, residual limb pain, and back pain in amputees: Results of a national survey. Archives of Physical Medicine and Rehabilitation, 86(10), 1910-1919. doi:10.1016/j.apmr.2005.03.031

Epstein, R. A., Heinemann, A. W., \& McFarland, L. V. (2010). Quality of life for veterans and service-members with major traumatic limb loss from Vietnam and OIF/OEF conflicts. The Journal of Rehabilitation Research and Development, 47(4), 373-385. doi:10.1682/JRRD.2009.03.0023

Equality Act (2010). London: Her Majesty’s Stationary Office. 
Etters, L., Goodall, D., \& Harrison, B. E. (2008). Caregiver burden among dementia patient caregivers: a review of the literature. Journal of the American Association of Nurse Practitioners, 20(8), 423-428. doi: 10.1111/j.17457599.2008.00342.x

Evans, G. L. (2013). A novice researcher's first walk through the maze of grounded theory. Grounded Theory Review, 12(1), 37-55.

Ferguson, A. D., Sperber-Richie, B., \& Gomez, M. J. (2009). Psychological factors after traumatic amputation in landmine survivors: The bridge between physical healing and full recovery. Disability and Rehabilitation, 26(14-15), 931-938. doi:10.1080/09638280410001708968

Fitzgibbon, B. M., Enticott, P. G., Rich, A. N., Giummarra, M. J., GeorgiouKaristianis, N., Tsao, J. W., Weeks, S.R., \& Bradshaw, J. L. (2010). High incidence of 'synaesthesia for pain' in amputees. Neuropsychologia, 48(12), 3675-3678. doi:10.1016/j.neuropsychologia.2010.07.029

Foss, C., \& Ellefsen, B. (2002). The value of combining qualitative and quantitative approaches in nursing research by means of method triangulation. Journal of Advanced Nursing, 40(2), 242-248. doi:10.1046/j.1365-2648.2002.02366.x

Fossey, M., \& Hacker-Hughes, J. (2014). Traumatic limb loss and the needs of the family. London: Blesma.

Fultz, J., Schaller, M., \& Cialdini, R. B. (1988). Empathy, sadness, and distress: Three related but distinct vicarious affective responses to another's suffering. Personality and Social Psychology Bulletin, 14(2), 312-325. doi:10.1177/0146167288142009

Gallagher., P., Desmond, D., \& MacLachlan, M. (2008). Psychoprosthetics: An introduction. In P. Gallagher, D. Desmond, \& M. MacLachlan (Eds.), 
Psychoprosthetics (pp. 1-10). London: Springer.

Gallagher, P., Horgan, O., Franchignoni, F., Giordano, A., \& MacLachlan, M. (2007). Body image in people with lower-limb amputation: A Rasch analysis of the Amputee Body Image Scale. American Journal of Physical Medicine \& Rehabilitation, 86(3), 205-215. doi:10.1097/PHM.0b013e3180321439

Gallo, L. C., \& Matthews, K. A. (2003). Understanding the association between socioeconomic status and physical health: Do negative emotions play a role? Psychological Bulletin, 129(1), 10-51. doi:10.1037/0033-2909.129.1.10

Geer, J. H., \& Jarmecky, L. (1973). The effect of being responsible for reducing another's pain on subjects' response and arousal. Journal of Personality and Social Psychology, 26(2), 232-237.

Gergen, K. J. (1985). The social constructionist movement in modern psychology. American Psychologist, 40(3), 266-275. doi:10.1037/0003066X.40.3.266

Gibson, B. \& Hartman, J. (2013). Rediscovering grounded theory. London: Sage Publications Ltd.

Giummarra, M. J., Georgiou-Karistianisl, N., Nichollsl, M. E.R., Gibsonl, S. J., Choul, M., \& Bradshawl, J. L. (2011). The menacing phantom: What pulls the trigger? European Journal of Pain, 15, 691-699. doi:10.1016/j.ejpain.2011.01.005

Glaser, B. G. (1978). Theoretical sensitivity: Advances in the methodology of grounded theory. Chicago: Sociology Press.

Glaser, B. G. (1998). Doing grounded theory: Issues and discussions. Chicago: Sociology Press. 
Glaser, B.G. (1999). The future of grounded theory. Qualitative Health Research, 9(6), 836-845. doi:10.1177/104973299129122199

Glaser, B., \& Strauss, A. (1967). Discovering grounded theory. Chicago: Sociology Press.

Guba, E. G., \& Lincoln, Y. S. (1994). Competing paradigms in qualitative research. In N. Denzin, \& Y. Lincoln (Eds.), Handbook of qualitative research (pp. 105-117). London: Sage.

Hamill, R., Carson, S., \& Dorahy, M. (2010). Experiences of psychosocial adjustment within 18 months of amputation: An interpretative phenomenological analysis. Disability and Rehabilitation, 32(9), 729-740. doi:10.3109/09638280903295417

Hänggi, Y. (2008). Social coping in everyday life and in crisis situations: An evolutionary psychology perspective. Swiss Journal of Psychology, 67(3), 153163. doi:10.1024/1421-0185.67.3.153

Hanley, M. A., Jensen, M. P., Ehde, D. M., Hoffman, A. J., Patterson, D. R., \& Robinson, L. R. (2009). Psychosocial predictors of long-term adjustment to lower-limb amputation and phantom limb pain. Disability and Rehabilitation, 26(14-15), 882-893. doi:10.1080/09638280410001708896

Hawamdeh, Z. M., Othman, Y. S., \& Ibrahim, A. I. (2008). Assessment of anxiety and depression after lower limb amputation in Jordanian patients. Neuropsychiatric Disease and Treatment, 4(3), 627-633.

Hirsh, A. T., Dillworth, T. M., Ehde, D. M., \& Jensen, M. P. (2010). Sex differences in pain and psychological functioning in persons with limb loss. The Journal of Pain, 11(1), 79-86. doi:10.1016/j.jpain.2009.06.004 
Holland, J. M., \& Neimeyer, R. A. (2010). An examination of stage theory of grief among individuals bereaved by natural and violent causes: A meaning-oriented contribution. OMEGA-Journal of Death and Dying, 61(2), 103-120. doi:10.2190/OM.61.2.b

Horgan, O., \& MacLachlan, M. (2004). Psychosocial adjustment to lower-limb amputation: a review. Disability and Rehabilitation, 26(14-15), 837-850. doi:10.1080/09638280410001708869

Iacono, T., Evans, E., Davis, A., Bhardwaj, A., Turner, B., Torr, J., \& Trollor, J. N. (2016). Family caring of older adults with intellectual disability and coping according to loci of responsibility. Research in Developmental Disabilities, 57, 170-180. doi:10.1016/j.ridd.2016.07.004

Ibsen, C. A., \& Klobus, P. (1972). Fictive kin term use and social relationships: Alternative interpretations. Journal of Marriage and Family, 34(4), 615-620. doi: $10.2307 / 350312$

Jaraway, D., Perry, S., Phillips, M., Ziegler, P., Wolgemuth, A., \& Scott, S.D. (2013). Preparing parents to help support their child post-amputation for bone cancer. ORNAC Journal, 31(4), 12-25.

Jeppsen, J.M.C. (2006). A qualitative study of military veteran's resilience and body self-esteem following combat-related limb amputation (Unpublished doctoral thesis). The University of Utah, USA.

Kartalova-O’Doherty, Y., \& Doherty, D. T. (2008). Coping strategies and styles of family carers of persons with enduring mental illness: A mixed methods analysis. Scandinavian Journal of Caring Sciences, 22(1), 19-28. doi:10.1111/j.1471-6712.2007.00583.x 
Ketz, A.K. (2008). The experience of phantom limb pain in patients with combatrelated traumatic amputation. Archive of Physical Medical Rehabilitation, 89, 1127-1132. doi:10.1016/j.apmr.2007.11.037

Kim, Y., Carver, C. S., Deci, E. L., \& Kasser, T. (2008). Adult attachment and psychological well-being in cancer caregivers: The mediational role of spouses' motives for caregiving. Health Psychology, 27(2S), 144-154. doi:10.1037/0278-6133.27.2(Suppl.).S144

Kratz, A. L., Davis, M. C., \& Zautra, A. J. (2012). Attachment predicts daily catastrophizing and social coping in women with pain. Health Psychology, 31(3), 278-285. doi:10.1037/a0025230

Kratz, A. L., Williams, R. M., Turner, A. P., Raichle, K. A., Smith, D. G., \& Ehde, D. (2010). To lump or to split? Comparing individuals with traumatic and nontraumatic limb loss in the first year after amputation. Rehabilitation Psychology, 55(2), 126-138. doi:10.1037/a0019492

Krueger, C. A., Wenke, J. C., Cho, M. S., \& Hsu, J. R. (2014). Common factors and outcome in late upper extremity amputations after military injury. Journal of Orthopaedic Trauma, 28(4), 227-231. doi:10.1097/BOT.0b013e3182a665f5

Kübler-Ross. E. (1969). On death and dying. New York: Macmillan.

Kulkuarni, J., \& Grady, K. (2010). Post amputation chronic pain profile and management. In C. Murray (Ed.), Amputation, prosthesis use and phantom limb pain: An interdisciplinary perspective (pp. 129-136). London: Springer Ltd.

Kvale, S. (1994). Ten standard objections to qualitative research interviews. Journal of Phenomenological Psychology, 25(2), 147-173. doi:10.1163/156916294X00016 
Lazarus, R.S., \& Folkman, S. (1984). Stress, appraisal and coping. New York: Springer.

Legro, M.W., Reiber, G., del Aguila, M., Ajax, M.J., Boone, D.A., Larsen, J.A., Smith, D.G., \& Sangeorzan, B. (1999). Issues of importance reported by persons with lower limb amputations and prostheses. Journal of Rehabilitation Research and Development, 36(3), 155-163.

Li, L., \& Moore, D. (1998). Acceptance of disability and its correlates. The Journal of Social Psychology, 138(1), 13-25. doi:10.1080/00224549809600349

Lim, J. W., \& Zebrack, B. (2004). Caring for family members with chronic physical illness: a critical review of caregiver literature. Health and Quality of Life Outcomes, 2(1), 50-59. doi:10.1186/1477-7525-2-50

Limbless Association (2012). Types of amputation. Retrieved on $1^{\text {st }}$ December 2017, from www.limbless-association.org

Limbless Association (2017a). Directory map. Retrieved on $20^{\text {th }}$ January 2018, from $\underline{\text { www.limbless-association.org }}$

Limbless Association (2017b). News: NHS England prosthetics service review. Retrieved on $30^{\text {th }}$ March 2018, from www.limbless-association.org Limbless Statistics (2013). A repository for quantitative information on the UK limbless population referred for prosthetic treatment. Retrieved on $2^{\text {nd }}$ January 2018, from www.limbless-statistics.org

Livingstone, W., Van De Mortel, T. F., \& Taylor, B. (2011). A path of perpetual resilience: Exploring the experience of a diabetes-related amputation through grounded theory. Contemporary Nurse, 39(1), 20-30.

doi:10.5172/conu.2011.39.1.20 
Lo, C. O. (2016). Literature integration: An illustration of theoretical sensitivity in grounded theory studies. The Humanistic Psychologist, 44(2), 177-189. doi:10.1037/hum0000029

Maciejewski, P. K., Zhang, B., Block, S. D., \& Prigerson, H. G. (2007). An empirical examination of the stage theory of grief. Jama, 297(7), 716-723. doi:10.1001/jama.297.7.716

Maguire, G., \& Byrne, M. K. (2017). The law is not as blind as it seems: Relative rates of vicarious trauma among lawyers and mental health professionals. Psychiatry, Psychology and Law, 24(2), 233-243. doi:10.1080/13218719.2016.1220037

Marigold, D. C., Cavallo, J. V., Holmes, J. G., \& Wood, J. V. (2014). You can’t always give what you want: The challenge of providing social support to low self-esteem individuals. Journal of Personality and Social Psychology, 107(1), 56-80. doi:10.1037/a0036554

Messinger, S.D. (2008). Anthropology and its individual, social and cultural contributions to psychoprosthetics. In P. Gallagher, D. Desmond, \& M. MacLachlan (Eds.), Psychoprosthetics (pp. 107-118). London: Springer.

Miller, L.R. (2013). Definition of family. In C. Shehan (Ed.), The Wiley Encyclopedia of Family Studies (pp. 532-538). New York: Whiley-Blackwell.

Ministry of Defence (2013). £11 million funding boost to improve NHS care for war veterans. Retrieved on $5^{\text {th }}$ January 2017 , from www.gov.uk

Morse, J. M. (2009). Tussles, tensions, and resolutions. In J. M. Morse, P. N. Stern, J. Corbin, B. Bowers, K. Charmaz, \& A. E. Clarke (Eds). Developing grounded theory: The second generation (pp. 13-22). Oxford: Routledge. 
Murdock, K. K., Adams, S. K., Pears, E., \& Ellis, B. (2012). Caregiving load and pediatric asthma morbidity: Conflict matters. Families, Systems \& Health, 30(2), 101-113. doi:10.1037/a0028604

Murray, C.D. (2010). Developing an interdisciplinary perspective on amputation, prosthesis use and phantom limb pain: An introduction. In C.D. Murray (Ed.). Amputation, prosthesis use and phantom limb pain: An interdisciplinary perspective (pp. 1-6). London: Springer Ltd.

Murray, C.D., \& Fox, J. (2002) Body image and prosthesis satisfaction in the lower limb amputee. Disability and Rehabilitation, 24(17), 925-931. doi:10.1080/09638280210150014

Murray, C. D., Simpson, J., Eccles, F., \& Forshaw, M. J. (2015). Involvement in rehabilitative care and wellbeing for partners of people with an amputation. Psychology, Health \& Medicine, 20(1), 71-76.

doi:10.1080/13548506.2014.901545

Murrison, A. (2011). A Better Deal for Military Amputees. London: Department of Health.

Newby, N. M. (1996). Chronic illness and the family life-cycle. Journal of Advanced Nursing, 23(4), 786-791. doi:10.1111/j.1365-2648.1996.tb00052.x

NHS England (2015). Schedule 2 service specifications: Complex disability equipment - prosthetic specialised services for people of all ages with limb loss. Retrieved on $20^{\text {th }}$ February 2018, from www.england.nhs.uk/commissioning NHS England (2017). Prosthetics service review. Retrieved on $26^{\text {th }}$ March 2018, from www.england.nhs.uk/commissioning

NICE (2006). Dementia: Supporting people with dementia and their carers in health and social care. Retrieved on $5^{\text {th }}$ December 2017, from www.nice.org.uk 
NICE (2013). Neuropathic pain in adults: Pharmacological management in specialist settings. Retrieved on $5^{\text {th }}$ December 2017, from www.nice.org.uk

NICE (2015). Diabetic foot problems: Prevention and management. Retrieved on $5^{\text {th }}$ December 2017, from www.nice.org.uk

NICE (2017). Guideline scope: Provision of support for adult carers. Retrieved on $5^{\text {th }}$ December 2017, from www.nice.org.uk

Oaksford, K., Frude, N., \& Cuddihy, R. (2005). Positive Coping and Stress-Related Psychological Growth Following Lower Limb Amputation. Rehabilitation Psychology, 50(3), 266-277. doi:10.1037/0090-5550.50.3.266

Oliver, C. (2011). Critical realist grounded theory: A new approach for social work research. British Journal of Social Work, 42(2), 371-387. doi:10.1093/bjsw/bcr064

Oliver, M. (1983). Social work with disabled people. Basingstoke: Macmillan. Oliver, M. (2013). The social model of disability: Thirty years on. Disability \& Society, 28(7), 1024-1026. doi:10.1080/09687599.2013.818773

Orlikowski, W. J., \& Baroudi, J. J. (1991). Studying information technology in organizations: Research approaches and assumptions. Information Systems Research, 2(1), 1-28. doi:10.1287/isre.2.1.1

Pakenham, K. I., \& Cox, S. (2012). Test of a model of the effects of parental illness on youth and family functioning. Health Psychology, 31(5), 580-590. doi:10.1037/a0026530

Papastavrou, E., Kalokerinou, A., Papacostas, S. S., Tsangari, H., \& Sourtzi, P. (2007). Caring for a relative with dementia: family caregiver burden. Journal of Advanced Nursing, 58(5), 446-457. doi:10.1111/j.1365-2648.2007.04250.x 
Parkes, C. M. (1975). Psycho-social transitions: Comparison between reactions to loss of a limb and loss of a spouse. The British Journal of Psychiatry, 127(3), 204-210. doi:10.1192/bjp.127.3.204

Pequegnat, W., \& Bray, J.H. (1997). Families and HIV/AIDS: Introduction to the special section. Journal of Family Psychology, 11(1), 3-10. doi:10.1037/08933200.11 .1 .3

Perkins, Z. B., De'Ath, H. D., Sharp, G., \& Tai, N. R. (2012). Factors affecting outcome after traumatic limb amputation. British Journal of Surgery, 99(1), 7586. doi:10.1002/bjs.7766

Phelps, L. F., Williams, R.M., Raichle, K.A., Turner, A.P., \& Ehde, D.M. (2008). The importance of cognitive processing to adjustment in the 1st year following amputation. Rehabilitation Psychology, 53(1), 28-38. doi:10.1037/00905550.53 .1 .28

Pitceathly, C., \& Maguire, P. (2003). The psychological impact of cancer on patients' partners and other key relatives: a review. European Journal of Cancer, 39(11), 1517-1524. doi: 10.1016/S0959-8049(03)00309-5

Poundja, J., Fikretoglu, D., \& Brunet, A. (2006). The co-occurrence of posttraumatic stress disorder symptoms and pain: Is depression a mediator? Journal of Traumatic Stress, 19(5), 747-751. doi:10.1002/jts.20151

Quittner, A. L., Opipari, L. C., Regoli, M. J., Jacobsen, J., \& Eigen, H. (1992). The impact of caregiving and role strain on family life: Comparisons between mothers of children with cystic fibrosis and matched controls. Rehabilitation Psychology, 37(4), 275-290. doi:10.1037/h0079107

Rae, H. M. (1992). Fictive kin as a component of the social networks of older people. Research on Aging, 14(2), 226-247. doi:10.1177/0164027592142004 
Rawlings, E. I. (1968). Witnessing harm to other: A reassessment of the role of guilt in altruistic behavior. Journal of Personality and Social Psychology, 10(4), 377-380. doi:10.1037/h0026819

Rawnsley, M. M. (1998). Ontology, epistemology, and methodology: A clarification. Nursing Science Quarterly, 11(1), 2-4. doi:10.1177/089431849801100102

Reed, D. B., \& Claunch, D. T. (2002). Behind the scenes: Spousal coping following permanently disabling injury of farmers. Issues in Mental Health Nursing, 23(3), 231-248. doi:10.1080/016128402753542983

Resch, J. A., Mireles, G., Benz, M. R., Grenwelge, C., Peterson, R., \& Zhang, D. (2010). Giving parents a voice: A qualitative study of the challenges experienced by parents of children with disabilities. Rehabilitation Psychology, 55(2), 139-150. doi:10.1037/a0019473

Richardson, C. (2010). Phantom limb pain; prevalence, mechanisms and associated factors. In C.D. Murray (Ed.), Amputation, prosthesis use and phantom limb pain: An interdisciplinary perspective (pp. 137-156). London: Springer Ltd.

Rohleder, P. (2012). Critical issues in clinical and health psychology. London: Sage Publications Ltd.

Rohr, M. K., Wagner, J., \& Lang, F. R. (2013). Effects of personality on the transition into caregiving. Psychology and Aging, 28(3), 692-700. doi:10.1037/a0034133

Ross, C. E., Mirowsky, J., \& Goldsteen, K. (1990). The impact of the family on health: The decade in review. Journal of Marriage and Family, 52(4), 10591078. doi: $10.2307 / 353319$ 
Roth, D. L., Mittelman, M. S., Clay, O. J., Madan, A., \& Haley, W. E. (2005). Changes in social support as mediators of the impact of a psychosocial intervention for spouse caregivers of persons with Alzheimer's disease. Psychology and Aging, 20(4), 634-644. doi:10.1037/08827974.20.4.634

Rybarczyk, B., \& Behel, J. (2008). Limb loss and body image. In P. Gallagher, D. Desmond, \& M. MacLachlan (Eds.), Psychoprosthetics (pp. 23-32). London: Springer.

Sabin-Farrell, R., \& Turpin, G. (2003). Vicarious traumatization: implications for the mental health of health workers? Clinical Psychology Review, 23(3), 449-480. doi:10.1016/S0272-7358(03)00030-8

Salmon, P. (2001). Effects of physical exercise on anxiety, depression, and sensitivity to stress: a unifying theory. Clinical Psychology Review, 21(1), 33-61. doi:10.1016/S0272-7358(99)00032-X

Savage, S., \& Bailey, S. (2004). The impact of caring on caregivers' mental health: a review of the literature. Australian health review, 27(1), 111-117. doi:10.1071/AH042710111

Schaffalitzky, E., Gallagher, P., Desmond, D., \& MacLachlan, M. (2010). Adaptation to amputation and prosthesis use. In C.D. Murray (Ed.), Amputation, prosthesis use and phantom limb pain: An interdisciplinary perspective (pp. 65-80). London: Springer Ltd.

Schubart, J. R., Kinzie, M. B., \& Farace, E. (2008). Caring for the brain tumor patient: Family caregiver burden and unmet needs. Neuro-oncology, 10(1), 6172. doi:10.1215/15228517-2007-040 
Scioli-Salter, E. R., Forman, D. E., Otis, J. D., Gregor, K., Valovski, I., \& Rasmusson, A. M. (2015). The shared neuroanatomy and neurobiology of comorbid chronic pain and PTSD: therapeutic implications. The Clinical Journal of Pain, 31(4), 363-374. doi:10.1097/AJP.0000000000000115

Scott, H. (2011). Conducting grounded theory interviews online. In V. B. Martin, \& A. Gynnild (Eds.), Grounded theory: The philosophy, method, and work of Barney Glaser (pp. 87-102). Boca Raton: Universal-Publishers.

Senra, H., Oliveira, R. A., Leal, I., \& Vieira, C. (2012). Beyond the body image: a qualitative study on how adults experience lower limb amputation. Clinical Rehabilitation, 26(2), 180-191. doi: 10.1177/0269215511410731

Shu, J., Hassell, S., Weber, J., Ochsner, K. N., \& Mobbs, D. (2017). The role of empathy in experiencing vicarious anxiety. Journal of Experimental Psychology: General, 146(8), 1164-1188. doi: 10.1037/xge0000335

Sjödahl, C., Gard, G., \& Jarnlo, G. B. (2004). Coping after trans-femoral amputation due to trauma or tumour — a phenomenological approach. Disability and Rehabilitation, 26(14-15), 851-861. doi: 10.1080/09638280410001662996

Stajduhar, K.I. (1998). Palliative care at home: Reflections on HIV/AIDS family caregiving experiences. Journal of Palliative Care, 14(2), 14-22.

Starks, H., \& Brown-Trinidad, S. (2007). Choose your method: A comparison of phenomenology, discourse analysis, and grounded theory. Qualitative Health Research, 17(10), 1372-1380. doi: 10.1177/1049732307307031

Stevelink, S. A. M., Malcolm, E. M., Mason, C., Jenkins, S., Sundin, J., \& Fear, N. T. (2014). The prevalence of mental health disorders in (ex-) military personnel with a physical impairment: a systematic review. Occupational and Environmental Medicine, 72, 243-251. doi: 10.1136/oemed-2014-102207 
Stutts, L. A., Bills, S. E., Erwin, S. R., \& Good, J. J. (2015). Coping and posttraumatic growth in women with limb amputations. Psychology, Health \& Medicine, 20(6), 742-752. doi: 10.1080/13548506.2015.1009379

Sutter, M., Perrin, P. B., Tabaac, A. R., Parsa, L., \& Mickens, M. (2017). Do ableism and ageism predict college students' willingness to provide care for a family member with a chronic health condition? Stigma and Health, 2(2), 110-120. doi: $10.1037 / \mathrm{sah} 0000045$

Tebbi, C. K., Stern, M., Boyle, M., Mettlin, C. J., \& Mindell, E. R. (1985). The role of social support systems in adolescent cancer amputees. Cancer, 56(4), 965971. doi: 10.1002/1097-0142(19850815)56:4<965::AID-

\section{CNCR2820560444>3.0.CO;2-Q}

Thompson, D. M., \& Haran, D. (1985). Living with an amputation: the helper. Social Science \& Medicine, 20(4), 319-323. doi:10.1016/0277-9536(85)90004-8

Townsend, A. L., \& Franks, M. M. (1995). Binding ties: Closeness and conflict in adult children's caregiving relationships. Psychology and Aging, 10(3), 343351. doi:10.1037/0882-7974.10.3.343

Treuthart, M. P. (1990). Adopting a more realistic definition of family. Gonzaga Law Review, 26, 91-123.

Tweed, A. \& Priest, H. (2015). Grounded theory. In P. Rohleder, \& A.C. Lyons (Eds.), Qualitative research in clinical and health psychology (pp. 114-132). Basingstoke: Palgrave Macmillan.

Tyc, V. L. (1992). Psychosocial adaptation of children and adolescents with limb deficiencies: A review. Clinical Psychology Review, 12(3), 275-291. doi:10.1016/0272-7358(92)90138-X 
Uchino, B. N., Cacioppo, J. T., \& Kiecolt-Glaser, J. K. (1996). The relationship between social support and physiological processes: a review with emphasis on underlying mechanisms and implications for health. Psychological Bulletin, 119(3), 488-531. doi:10.1037/0033-2909.119.3.488

United Nations (2008). United Nations Convention of the Rights of Persons with Disability. Retrieved on $5^{\text {th }}$ December 2017, from www.un.org

Urquhart, C. (2013). Grounded Theory for Qualitative Research: A practical guide. London: Sage Publications.

Urquhart, C., \& Fernandez, W. (2006). Grounded theory method: The researcher as a blank slate and other myths. In ICIS 2006 Proceedings, paper 31.

Valizadeh, S., Dadkhah, B., Mohammadi, E., \& Hassankhani, H. (2014). The perception of trauma patients from social support in adjustment to lower-limb amputation: a qualitative study. Indian Journal of Palliative Care, 20(3), 229238. doi:10.4103/0973-1075.138401

van den Born-van Zanten, S., Dongelmans, D. A., Dettling-Ihnenfeldt, D., Vink, R., \& van der Schaaf, M. (2016). Caregiver strain and posttraumatic stress symptoms of informal caregivers of intensive care unit survivors. Rehabilitation Psychology, 61(2), 173-178. doi:10.1037/rep0000081

Vasluian, E., de Jong, I. G., Janssen, W. G., Poelma, M. J., van Wijk, I., ReindersMesselink, H. A., \& van der Sluis, C. K. (2013). Opinions of youngsters with congenital below-elbow deficiency, and those of their parents and professionals concerning prosthetic use and rehabilitation treatment. PLOS ONE, 8(6), 1-9. doi:10.1371/journal.pone.0067101

Verschuren, J. E., Zhdanova, M. A., Geertzen, J. H., Enzlin, P., Dijkstra, P. U., \& Dekker, R. (2013). Let's talk about sex: Lower limb amputation, sexual 
functioning and sexual well-being: A qualitative study of the partner's perspective. Journal of Clinical Nursing, 22(23-24), 3557-3567. doi:10.1111/jocn. 12433

Wade, D. T., \& Halligan, P. W. (2004). Do biomedical models of illness make for good healthcare systems? British Medical Journal, 329, 1398-1401. doi:10.1136/bmj.329.7479.1398

Warren, A. M., Rainey, E. E., Weddle, R. J., Bennett, M., Roden-Foreman, K., \& Foreman, M. L. (2016). The intensive care unit experience: Psychological impact on family members of patients with and without traumatic brain injury. Rehabilitation Psychology, 61(2), 179-185. doi:10.1037/rep0000080

Wegener, S.T., Hofkamp, S.E., \& Ehde, D.M. (2008). Interventions for psychological issues in amputation: A team approach. In P. Gallagher, D. Desmond, \& M. MacLachlan (Eds.), Psychoprosthetics (pp. 67-90). London: Springer.

Williams, R. M., Ehde, D. M., Smith, D. G., Czerniecki, J. M., Hoffman, A. J., \& Robinson, L. R. (2004). A two-year longitudinal study of social support following amputation. Disability and Rehabilitation, 26(14-15), 862-874. doi:10.1080/09638280410001708878

Willig, C. (2012). Perspectives on the epistemological bases for qualitative research. In H. Cooper, P. M. Camic, D. L. Long, A. T. Panter, D. Rindskopf, \& K. J. Sher (Eds.), APA handbook of research methods in psychology (Vol. 1, pp. 5 21). Washington: American Psychological Association.

Wimpenny, P., \& Gass, J. (2000). Interviewing in phenomenology and grounded theory: Is there a difference? Journal of Advanced Nursing, 31(6), 1485-1492. doi:10.1046/j.1365-2648.2000.01431.x 


\section{Appendices}

\section{Appendix A: Systematic literature search strategy}

Search: Qualitative research into perspectives of families and carers in limb loss.

Inclusion criteria:

o Acquired limb loss (upper and/or lower limb)

$\circ$ PWLL in any social context (military/civilian) or age

$\circ$ Inclusion of family members, regardless of official carer status

$\circ$ Qualitative methods (including thesis studies)

Exclusion criteria:

○ Congenital limb loss

o Secondary data

o Duplicate studies

o Quantitative methodology

EBSCO electronic search: EBSCO Host (PsycINFO, CINAHL Complete, E-Journals, MEDLINE, PsycARTICLES), all years.

Search run: $13^{\text {th }}$ December 2017

\begin{tabular}{lll} 
Number & Search terms & Results \\
\hline 1 & "limb loss" OR limb-loss OR "loss of limb" OR amput* & 83,305 \\
2 & $\begin{array}{l}\text { Family } \text { OR carer• OR spouse OR partner OR parent• OR } \\
\text { husband } \text { OR wife } \text { OR sibling }\end{array}$ & $3,285,045$ \\
& \#1 $A N D \# 2$ & 1,1778 \\
4 & Limiter: methodology "qualitative study" & 17 \\
\hline
\end{tabular}

Selection flow-chart:

\begin{tabular}{|c|c|}
\hline Search results $(n=29)$ & Excluded articles $(n=24)$ \\
\hline Electronic $(\mathrm{n}=17)$ & Reasons for exclusion: \\
\hline Manual $(n=12)$ & Only uses PWLL: 12 \\
\hline & No loss of limb: 3 \\
\hline Articles screened by title or abstract & Professional carer perspective: 1 \\
\hline & $\begin{array}{l}\text { Not qualitative methodology: } 3 \\
\text { Duplicate: } 1\end{array}$ \\
\hline $\begin{array}{l}\text { Included for reading } \\
\qquad(\mathrm{n}=5)\end{array}$ & $\begin{array}{l}\text { No mention family experience: } 3 \\
\text { Unavailable for public access: } 1\end{array}$ \\
\hline
\end{tabular}


Appendix B: Recruitment advert

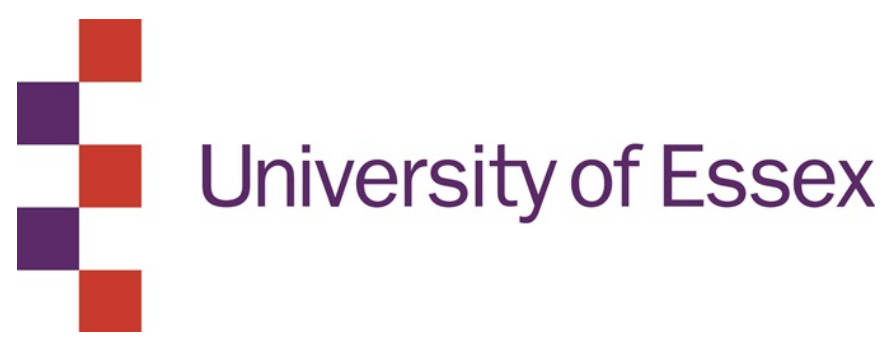

\section{Do you provide support to someone who has lost a limb?}

Would you be willing to talk about your experiences privately as part of a research project?

I am looking for individuals who provide support to a partner, close friend or family member, who has lost a major limb (i.e. arm or leg) as a result of an illness, trauma or accident to talk about your experiences of coping with this. Interviews will take place on the phone or Skype and will take approximately 30-60 minutes. You will receive a $£ 10$ shopping voucher to thank you for your time and effort.

If you are an individual who has suffered loss of a major limb and you know someone who would be suitable to take part, then please pass this advert along to them.

If you are interested in taking part and would like to find out more information, please contact Sophie Mitchell at smitcha@essex.ac.uk 
Appendix C: Information sheet

\section{University of Essex}

\section{Research looking at the experience of families with limb loss}

Thank you for showing an interest in taking part in this research study. Please read the following sheet which will provide you with all the information you will need to make a decision about whether you would like to take part.

\section{What is the study about?}

The research study is aiming to look at the impact of limb loss on those in their close family or social network. We hope from this research that we can understand how families are affected by limb loss and how they cope with any of the challenges they may experience. We aim to use this to guide the way to developing better support services for families who are living with limb loss.

\section{Am I eligible to take part?}

We would be interested in speaking to you if you are:

- Providing support to someone (family member, partner/spouse, close friend) who lost their arm or leg due to an illness, accident or trauma

- Over the age of 18

Due to the aims of this study, you are not eligible to take part if:

- The person lost their limb from a birth defect (i.e. congenital limb loss)

- The person lost their limb in a military setting (or are currently/previously employed in a military setting)

- You are under the age of 18.

\section{What will happen in the interview?}

These interviews would be done over the phone or Skype, depending on your preference, at a time to suit you. There will be some questions that may feel quite personal, but I will aim to help you to feel supported and comfortable in this. We do not anticipate that you will experience distress as a result of taking part, but you can stop the interview at any point if you wish. We anticipate that this will take approximately an hour, and you will receive a small retail voucher of $£ 10$ to thank you for your time. 


\section{Who is doing the research?}

I am Sophie Mitchell, a Trainee Clinical Psychologist in the NHS and at the University of Essex. This study is part of my Doctorate in Clinical Psychology. I have research and clinical experience in working with individuals with various physical and mental health difficulties. I will be arranging and conducting the interviews for this project.

This research is in collaboration with the Anglia Ruskin University. The primary supervisor is Dr Leanne Andrews (Senior Lecturer, University of Essex), who can be contacted on 01206874466 or landre@essex.ac.uk if you have any questions about the study or me.

\section{What will happen to my information?}

We take your privacy and confidentiality very seriously. We will not share what you say with any member of your family. We will take steps to keep your data as anonymous as possible. However, we will need to break this clause of confidentiality, should anything come up in the interview which indicates a risk of harm to yourself or someone else. We would aim to tell you if this needs to happen.

Your interview will be recorded electronically and transcribed. The electronic recording will be destroyed as soon as possible, therefore the only record of the interview will be the transcript. It may be possible to identify you based on your experiences, but we will take every step we can to avoid this. We will remove anything that could obviously identify you, for instance we will change both your name and the names of anyone you mention in the interview.

The anonymised transcript will be used for data analysis purposes, by both the researcher and the academic supervisors. This will be held in password protected encrypted formats. Some of the segments of things you say may be included in the full write-up of the study, either for the purposes of the project or for further scientific publication. We will ensure that you cannot be identified in the final report. We will need to keep the anonymised version of your interview for any further scientific work.

\section{Next steps:}

If you have any further questions after reading this information sheet or would like to take part, then please contact me on smitcha@essex.ac.uk 


\section{Appendix D: Research consent form}

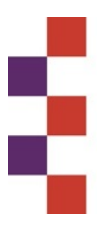

\section{University of Essex}

\section{Research consent form}

Please read the following statements carefully and place your initials in the box to confirm that you agree with each of the statements.

\begin{tabular}{|l|l|}
\hline $\begin{array}{l}\text { I confirm that I am willing to take part in the current research study to } \\
\text { investigate the experience of limb loss in the 'family network'. I confirm } \\
\text { that I am taking part in this study of my own free-will. }\end{array}$ \\
\hline $\begin{array}{l}\text { I have had the opportunity to ask any questions to the researcher and I } \\
\text { am satisfied with any responses I received. }\end{array}$ \\
\hline $\begin{array}{l}\text { I understand that the interviews will be carried out over telephone or } \\
\text { Skype. }\end{array}$ \\
\hline $\begin{array}{l}\text { I understand that the interviews will be audio-recorded and transcribed. } \\
\text { shared with other members of my family. I understand that confidentiality } \\
\text { will need to be broken if there is a risk of harm to myself or others. }\end{array}$ \\
\hline $\begin{array}{l}\text { I understand that I can leave the study at any time, should I feel this is } \\
\text { necessary. }\end{array}$ \\
\hline $\begin{array}{l}\text { I understand that an anonymised version of my data will be shared with } \\
\text { research supervisors. }\end{array}$ \\
\hline $\begin{array}{l}\text { I understand that this anonymised version of the data will be kept for } \\
\text { future research use. }\end{array}$ \\
\hline
\end{tabular}

Name:

Signature:

Date: 
Appendix E: Demographics questionnaire

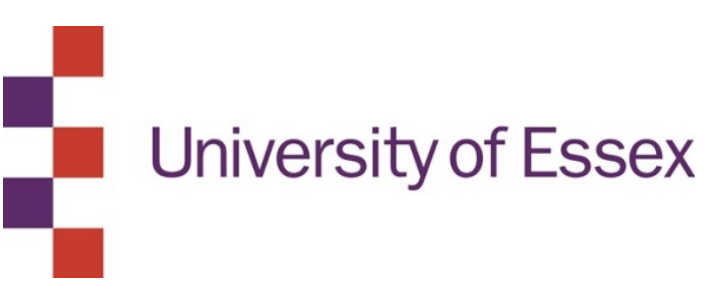

\section{Basic information questionnaire}

Please answer the following questions regarding your background and about the person in your family/social network with limb loss.

\section{Questions about you}

1. Name:

2.Age (in years):

3. Gender (place a tick)

\begin{tabular}{|l|l|}
\hline Female & \\
\hline Male & \\
\hline Transgender & \\
\hline Unspecified & \\
\hline Prefer not to say & \\
\hline
\end{tabular}

4.Employment status (place a tick)

\begin{tabular}{|l|l|}
\hline Employed & \\
\hline Unemployed & \\
\hline Student & \\
\hline Retired & \\
\hline
\end{tabular}

5.Marital status (place a tick)

\begin{tabular}{|l|l|}
\hline Married & \\
\hline Cohabiting & \\
\hline Single & \\
\hline Divorced & \\
\hline Widowed & \\
\hline
\end{tabular}




\section{Questions about the person with limb loss}

6. What is their relation to you? (i.e. son, daughter, wife, family friend, etc.)

7. How did they lose their limb? (brief description required, e.g. "car accident" "complications from diabetes")

8. Approximately how long ago did they lose the limb?

9. Do they use a prosthesis? (please tick \& indicate frequency)

\begin{tabular}{|l|l|}
\hline $\begin{array}{l}\text { Yes } \\
\text { (occasionally/often/always) }\end{array}$ & \\
\hline No & \\
\hline
\end{tabular}

10. What type of limb was lost? (please tick)

\begin{tabular}{|l|l|}
\hline Leg & \\
\hline Arm & \\
\hline
\end{tabular}

\section{Contact details}

How would you like to be contacted for the interview? (Skype/telephone)

Please provide contact details for the interview to take place:

Skype:

Telephone:

Please state if you have any preferred days/times to be contacted for interview: 


\section{Appendix F: Example extract from field notes}

Interview 30th March 2017

- Before interview: No particular expectations or thoughts this time, feeling open to going into whatever the experience is.

- After interview: I felt more of a sense of connection with her and her story. Perhaps as she was my age, or perhaps that she was more honest with her distressing experience and the difficult emotions and thoughts she had to face. Not worried about telling me things that may paint her in a bad light. She has been one that has stayed with me. I feel the sense that they are helpless, trying to be active in doing something. Does the interview in itself allow them to do an activity, to give back to the limb loss community in some way? She also sent me her article about her mum after the interview.

Interview 4th April 2017

- Before interview: First interview where I have already interviewed someone else in the family. I already feel a sense of connection to the family, I'm wondering how that will come across. I wonder whether he has spoken to his daughter about me and our interview together, whether this creates an expectation for him already or a 'rehearsal' of what could be discussed. I wonder if already knowing the story of the woman with limb loss will mean I could at some level, push the interview in another direction. I feel more confident going into this, more relaxed as I already feel more connected, perhaps more so than i have done with the other interviews. I've told him I have a stammer, so feeling better about this this time around.

-After interview: felt less of a sense of connectedness, less about the emotion but more about the practical, what happened to his wife rather than his experience. At times when this was mentioned, he seemed to move away to a different topic or would move the screen away from him. I found more of a sense of restlessness - perhaps as I already knew the limb loss story, or perhaps due to it being harder to connect? Would relate to how family members feel, rather than putting ownership on his experience of this. Asked me to make a donation to a charity rather than give him the $£ 10$, but did this for GOSH rather than a limb loss or sepsis charity. 


\section{Appendix G: Semi-structured interview schedule}

\section{Providing support:}

a) What is your experience of providing practical support for [PPWL's name]?

Follow-up: Do you provide help with housework duties, dressing, personal care, etc.?

b) What is your experience of providing emotional support for [PPWL]?

c) What is your experience of supporting for managing health and social care services?

d) Are there any other things you need to do for [PPWL] on a day to day basis because of their limb loss?

\section{Challenges:}

a) Other family and friends of people with limb loss have told us that there are some things that are difficult for them to experience. If we take each in turn, tell me about your experience of whether or not this is something that is difficult or frustrating to you:

- Seeing [PPWL] use practical equipment, such as prosthetics, wheelchairs, or adaptations to the home.

- Seeing them experience phantom pain or sensations

- Seeing how other people react to [PPWL]'s limb loss

- Negotiating with health and care services.

- Learning how you should respond to their limb loss

- Allowing them to become independent by letting go of caregiving

b) How do you think those challenges have affected you and your relationship with [PPWL]?

\section{Emotional response:}

a) Other family and friends of people with limb loss have also told us that they may experience different emotions regarding the limb loss. Again, we will take each in turn, for you to tell me whether or not this is something that you may have or do experience.

- Acceptance

- Fear or anxiety

- Sadness or grief

- A positive emotion

- Any other emotion? 


\section{Coping:}

a) There are several ways in which other family members have told us that they cope with or process the experiences they are going through. Again, we will take each in turn, for you to tell me whether or not this is something that you have used to help you cope:

- Comparing your situation with those of other people.

Follow up: sometimes we might compare ourselves to people who we feel are worse off or better off to us. Do you experience either of these?

- Using humour

- Recognising positives

- Using your own support network of family and friends

- Using the limb loss community and charities

- Accessing therapy for yourself

- Allowing for the process of time

b) Are there any other things you have done to help you cope? 


\section{Appendix H: Structured interview schedule}

\section{Witnessing}

Other family members have said that there are some things that are hard to see the other person go through. For example, if they are in pain, if they are upset, if they are unable to do something they used to be able to do, or if they now have to use prosthetics or wheelchairs.

Does this sound familiar to you? YES/NO

Do you have anything you want to add to this?

\section{Responsibility in caring}

Other family members have said that they support the person in different ways. For example, helping to navigate health and social care services, helping with medical care, helping with practical tasks, or offering comfort when they are upset with their situation.

Does this sound familiar to you? YES/NO

Do you have anything you want to add to this?

\section{Sharing impact}

Other family members have said that the limb loss affects some things in their lives. For example, their relationship with that person, the roles in the family, allowing them to be independent, managing how other people respond to it, and adjusting to a new life with disability.

Does this sound familiar to you? YES/NO

Do you have anything you want to add to this?

\section{Emotional responding}

Other family members have also told us that they may experience different emotions regarding the limb loss. This might include acceptance and trying to get on with it, or anxiety, fear, worry, or a sense of loss or grief.

Does this sound familiar to you? YES/NO

Do you have anything you want to add to this?

Some people tell us that they might also try to push away their own feelings to focus on the person with limb loss. 
Does this sound familiar to you? YES/NO

Do you have anything you want to add to this?

\section{Coping}

Other family members have also told us that they have different ways to cope with or process the experiences they are going through.

a) One type of coping is to use social strategies, such as turning to limb loss charities, getting support from their own friends and family, or accessing therapy.

Does this sound familiar to you? YES/NO

Do you have anything you want to add to this?

b)Another type of coping is to use practical and active strategies, such as being distracted, focusing on something else, or focusing on planning ahead for that person.

Does this sound familiar to you? YES/NO

Do you have anything you want to add to this?

c) Another type of coping is more about processing. This might include comparing to other people who are worse off, or comparing the situation to if the person had died, using humour, recognising positives or allowing for time to act as a healer.

Does this sound familiar to you? YES/NO

Do you have anything you want to add to this? 


\section{Appendix I: Payment receipt form}

\section{University of Essex}

\section{SCHOOL OF HEALTH AND HUMAN SCIENCES Participant Payments}

I ....................................have taken part in a research study conducted by ............................... for which I claim the sum of $£ \ldots \ldots \ldots$

Address

I have not received any other payments from the University in the current tax year (ie since 5 April 2016)

\section{OR}

I have already received the following payments from the University since 5 April 2016.

£...........for ...

$£ \ldots \ldots$......for.

$£ \ldots \ldots . . .$. for.

NOTE: If you have received more than $£ 20$ in total already, you must tell us so that this and future claims can be processed through the University payroll system, to ensure compliance with the tax laws of the United Kingdom.

Signed Date 


\section{Appendix J: Example of open coding (Louise)}

Interviewer (I): Is she still experiencing the pain?

Participant (P): Dccasionally. The limb isn't there but to her it is there. So if you were sat at a chair, her leg is simply going down in a 90-degree angle. She has sensation but it's not necessarily pain.|So she calls it Casper so he's either a friendly ghost and she knows he's there. If I tickle her prosthetic foot, it feels like l'm tickling her foot. But it can be the phantom menace if she can get a sharp pain in it. But that's quite rare these days.

I: How is that for you to see the phantom sensation?

P: That's fine to be honest. I didn't know that much about mirror therapy. But what I did do is I would give her a mirror, even when she had her stiches in. I would give her a mirror so she could look and investigate and see if she as much, because it's her body. Where I struggle I suppose now, sometimes it's bizarre, l'll forget. And l'll look at her and I'm so shocked and it's like she's my baby and she's my perfect baby. But she's not the baby I gave birth to [cries] if that makes sense. I married my partner a month ago and when I say to him, I get upset that she's not perfect. And he says 'can you tell me that child is not perfect?' and l'm like 'she is, she's

completely perfect. But she's not the child, she had a beautiful little freckle between her big toe and her first toe. And she's adamant that when she gets an adult prosthetic leg she's going to get that freckle tattooed back on. I just miss her leg. It's difficult because people think l'm a bit nuts because it's not my leg [cries]. So they understand that she can grieve but I get side-lined.|

I: Is that what people have told you or is that how you feel in yourself?

P: No the whole journey has been about Grace. I sometimes have to be her voice if she been tired or poorly but no support has ever been there, no counselling. It's about her, and it is about her and as a mum you have to have your times when you cry at home or cry in bed.|

Microsoft Office... PWLL phantom pain \& sensation

Microsoft Office... PWLL using naming

Microsoft Office... PWLL phantom pain \& sensation Microsoft Office... PWLL phantom pain \& sensation Microsoft Office... Having previous limited knowledge Microsoft Office... Giving help to manage sensation Microsoft Office... Feeling shocked

Microsoft Office... Loss/grief for the person Microsoft Office... Sadness

Microsoft Office... Grief \& missing limb Microsoft Office... PWLL wanting body back Microsoft Office... Grief \& missing limb Microsoft Office... Reactions from other people Microsoft Office... Side-lined grief as family member Microsoft Office... Not getting help as family member Microsoft Office... Pushing aside own feelings 


\section{Appendix K: Example of selective coding (Petra)}

Interviewer (I): So did you accept it from the very, very start or did it take you time to get to that point?

Participant $(P)$ : $\mid$ think I did accept from the very beginning, however it was a little bit more difficult in the Microsoft Office User beginning, not just to accept but maybe to get used to the idea of what's happening.|But I did accept because for her, it was due to her reasons why she's like that, the cancer, and I told her if she doesn't actually have an amputation then her life is at risk. So it was almost lifesaving. What else can you do at this point? So it was Microsoft Office User
EMOTION: ACCEPTANC difficult to accept but I took it on as a positive thing, saying this is the way for her to stay alive.|There are measures in which she can improve her life, or these adaptations, so I thought yes I accept.

I: OK. and the next emotion that people tell us about is a sense of fear, anxiety or worry.

$\mathrm{P}$ : Yeah I had it more regarding her general health and diagnosis, rather than loss of limb. I did have doubts whether she would have to go through amputation and still the cancer would not be cured or would disseminate around the body, so I was thinking should she do it or not.| Otherwise, no anxiety, no.

I: OK. because you mentioned you might be more overcautious with her.

$\mathrm{P}$ : Y Yes, it feels anxiety how a person like her will continue her life because of practical reasons, shopping and all this, because you can have all family around and even carers, but you can't have them 24/7. Unfortunately, she was divorced and didn't have a husband around, so there are times when probably she would struggle, that was my concern.|

I: And the next one people tell us about is a sense of sadness or grief.

$P$ : YYes, I mean this is a very tricky situation because even in the wheelchair she's always sitting down, she's always low, I was always above standing. That for example is something which bothers me the most. I don't know, she's always there siting down. When we're sitting its fine, but walking or going and chatting with the walk that's something that I don't like.| 


\section{Appendix L: Example of memo writing}

Category: Emotional responses.

4th September 2017: In doing open coding, there's a whole range of different emotional responses. Perhaps what affects this is the impact of time to help them to adjust to them, they might have some initial first responses that change over time. Maybe the emotional response emerges from their sense of responsibility in taking care of that person. It doesn't seem to come from the family position and relationship, given that everyone has some kind of emotional reaction and there doesn't seem to be a particular pattern for the type of emotional response.

15th November 2017: There seems to be some behaviours that are linked to the emotions. What's coming out is what people do in relation to the emotion, e.g. whether they express, or whether they push it down. Perhaps this might be about how they cope given that they experience these feelings, in relation to what they are going through, both in themselves and what they are seeing their loved one experience. It seems like there is no particular pattern that one type of emotion will relate to one type of coping strategy, e.g. that people who get on with things and are more pragmatic have generally been more accepting of the situation?

2nd December 2017: In doing the theoretical coding, I'm wondering more about the process of pushing down emotions that seems to happen. At first I thought this was just an emotional response to what was going on, i.e. they see the person suffer, but just try to push their own response to it. But now I wonder whether it's a type of emotional coping that they do, i.e. that they repress their feelings in order to both manage their own internal experience, and because they think it will help them to focus on that person? This differs from those people who perhaps can express their emotions, although it has been more common that people push them down. Perhaps that the interview allows those people to express what needs to be felt. 


\section{Appendix M: Participant respondent email}

Dear [particpant's name],

Recently you took part in a research study examining the impact of limb loss on the family network. The research has now been completed and I have attached a summary of the findings. It would be helpful to know how accurate you feel the summary is and if you feel there is anything you would like to add to this, including something you may have thought about since our interview. It is your choice as to whether or not you would like to comment on the accuracy of this summary. However, should you wish to, it would be helpful for you to consider the following questions and to reply to these by email:

1. Do you feel this summary is a fair and reasonable portrayal of your experience?

2. Is there anything else you would like to add?

3. Do you have any other comments related to the summary, the interview, or the research generally?

With thanks,

Sophie

Sophie Mitchell

Trainee Clinical Psychologist

University of Essex 
Appendix N: Research summary

\section{Examining the impact of limb loss on the family network}

\section{Sophie Mitchell, Trainee Clinical Psychologist, University of Essex}

\section{Why the research was done}

This research was conducted as it is known that when an individual loses a limb, the network around them is very important in their recovery. However, little is known about what that experience is like for those who belong to that network.

This was explored in the present research study by interviewing members of the family network of someone who has lost a limb through various causes. The interviews were done with people from all types of relationships with this person, from parents, spouses, adult offspring and close friends. From these interviews, a theory was developed to explain how members of this network cope with the impact of limb loss on both themselves and their loved one.

\section{Summary of the research}

The most important concern for people was having to witness the difficulties that the person with limb loss experiences. This included having to see the person with limb loss in pain, being upset, having difficulties with practical tasks, or generally being unable to do things that they used to do. Where relevant, it was also difficult to see that person use practical aids such as prosthetics or wheelchairs.

To manage this, people will take on a role for providing care and support to the person with limb loss. They spoke about providing support in different ways. For example, in helping to navigate health and social care services, helping with medical care, helping with practical tasks, or offering comfort in times of upset.

These experiences will lead to various consequences. Firstly, the loss of the limb will affect some things in their lives. These might be things that are individual to them as a member of the family network, or that they might share it with that person who has lost the limb. Limb loss can affect their relationship with that person, the activities they do together, the roles in the family, trying 
to allow them to be independent, managing how other people respond to it, and adjusting to a new life with disability.

Secondly, people may experience different emotions regarding the limb loss. This might include acceptance and trying to get on with it, or anxiety, fear, worry, shock, or a sense of loss or grief.

To manage these emotions and all the other experiences they have gone through, people in this network will make use of different types of coping strategies. Each person is individual in terms of how much they use each different type. One type of coping is to use social strategies, such as turning to limb loss charities, getting support from their own friends and family, or accessing therapy. Another type of coping is to use practical and active strategies, such as being distracted, focusing on something else, becoming an activist about limb loss or disease, or focusing on planning ahead for the person with limb loss. The final type of coping is more about trying to make sense of the experience on their own. This might include comparing to other people who are worse off, or comparing the situation to if the person had died, using humour, recognising positives or allowing for time to act as a healer. Some people tell us that they might also try to push away their own feelings to focus on the person with limb loss. 


\section{Appendix O: University of Essex ethical approval documentation}

University of Essex

14 February 2017

MISS S. MITCHELL

FLAT 4

CAESAR COURT

ROMAN CIRCUS WALK

COLCHESTER

ESSEX

CO2 7NG

Dear Sophie,

Re: Ethical Approval Application (Ref 15044a)

Further to your application for ethical approval, please find enclosed a copy of your application which has now been approved by the School Ethics Representative on behalf of the Faculty Ethics Committee.

Yours sincerely,

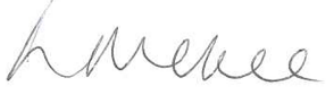

Lisa McKee

Ethics Administrator

School of Health and Human Sciences

cc. Research Governance and Planning Manager, REO Supervisor 


\section{Application for Ethical Approval of Research Involving Human Participants}

This application form must be completed for any research involving human participants conducted in or by the University. 'Human participants' are defined as including living human beings, human beings who have recently died (cadavers, human remains and body parts), embryos and foetuses, human tissue and bodily fluids, and human data and records (such as, but not restricted to medical, genetic, financial, personnel, criminal or administrative records and test results including scholastic achievements). Research must not commence until written approval has been received (from departmental Director of Research/Ethics Officer, Faculty Ethics Sub-Committee (ESC) or the University's Ethics Committee). This should be borne in mind when setting a start date for the project. Ethical approval cannot be granted retrospectively and failure to obtain ethical approval prior to data collection will mean that these data cannot be used.

Applications must be made on this form, and submitted electronically, to your departmental Director of Research/Ethics Officer. A signed copy of the form should also be submitted. Applications will be assessed by the Director of Research/Ethics Officer in the first instance, and may then passed to the ESC, and then to the University's Ethics Committee. A copy of your research proposal and any necessary supporting documentation (e.g. consent form, recruiting materials, etc) should also be attached to this form.

A full copy of the signed application will be retained by the department/school for 6 years following completion of the project. The signed application form cover sheet (two pages) will be sent to the Research Governance and Planning Manager in the REO as Secretary of the University's Ethics Committee.

1. Title of project:

"Examining the impact of limb losss on the family network."

2. The title of your project will be published in the minutes of the University Ethics Committee. If you object, then a reference number will be used in place of the title. Do you object to the title of your project being published?

3. This Project is: $\square$ Staff Research Project $\quad$ Student Project

4. Principal Investigator(s) (students should also include the name of their supervisor):

\begin{tabular}{|l|l|}
\hline Name: & Department: \\
\hline Sophie Mitchell (student) & Health \& Human Sciences \\
\hline Dr Leanne Andrews (supervisor) & Health \& Human Sciences \\
\hline Hilary Engward (external supervisor) & $\begin{array}{l}\text { Veterans \& Families Institute, Anglia Ruskin } \\
\text { University (ARU) }\end{array}$ \\
\hline
\end{tabular}

5. Proposed start date: Desember 2016 il February 2017

6. Probable duration: 1 year and 7 months

7. Will this project be externally funded?

If Yes,

8. What is the source of the funding?

N/A 
9. If external approval for this research has been given, then only this cover sheet needs to be submitted External ethics approval obtained (attach evidence of approval) Yes $\square /$ No $\square$

\section{Declaration of Principal Investigator:}

The information contained in this application, including any accompanying information, is, to the best of my knowledge, complete and correct. I/we have read the University's Guidelines for Ethical Approval of Research Involving Human Participants and accept responsibility for the conduct of the procedures set out in this application in accordance with the guidelines, the University's Statement on Safeguarding Good Scientific Practice and any other conditions laid down by the University's Ethics Committee. I/we have attempted to identify all risks related to the research that may arise in conducting this research and acknowledge my/our obligations and the rights of the participants.

Signature(s): $\quad$ freteto

Name(s) in block capitals: SOPHIE MITCHELL

Date: .........22 $2^{\text {nd }}$ January 2017

\section{Supervisor's recommendation (Student Projects only):}

I have read and approved the quality of both the research proposal and this application.

Supervisor's signature: ..

\section{Outcome:}

The departmental Director of Research (DoR) / Ethics Officer (EO) has reviewed this project and considers the methodological/technical aspects of the proposal to be appropriate to the tasks proposed. The DoR / EO considers that the investigator(s) has/have the necessary qualifications, experience and facilities to conduct the research set out in this application, and to deal with any emergencies and contingencies that may arise.

This application falls under Annex $B$ and is approved on behalf of the ESC

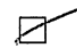

This application is referred to the ESC because it does not fall under Annex $B$

This application is referred to the ESC because it requires independent scrutiny

Signature(s):

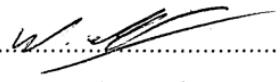

Name(s) in block capitals:

$$
\text { WA-Mon Willow }
$$

Department: .....S..t.t.....

Date: ............. 8/2/.1.7.

The application has been approved by the ESC

The application has not been approved by the ESC

The application is referred to the University Ethics Committee

Signature(s):

Name(s) in block capitals:

Faculty:

Date: 


\section{Appendix P: Summary of core categories literature search strategy}

Electronic search method: PsycINFO, CINAHL Complete, E-Journals, MEDLINE, PsycARTICLES

Manual search method: Hand searching, pursuing reference lists

Search run: $29^{\text {th }}$ January 2018

Screening method: Title \& abstract

Inclusion: All years of publication; secondary data; unpublished research

\begin{tabular}{ll}
$\begin{array}{l}\text { Core } \\
\text { category }\end{array}$ & Search terms \\
\hline Witnessing & $\begin{array}{l}\text { "witnessing pain" OR "witness* distress" OR "vicarious distress" OR } \\
\text { "vicarious distress" OR "vicarious trauma" OR "vicarious suffering" }\end{array}$ \\
$\begin{array}{ll}\text { Responsibility } \\
\text { in caring }\end{array}$ & $\begin{array}{l}\text { "family caring responsibility" OR "responsibility in caring" OR } \\
\text { "practical support" OR "practical assistance" OR "emotional support" }\end{array}$ \\
& $O R$ "medical support"
\end{tabular}

Sharing "impact" $O R$ "relationship change" $O R$ "family change"; AND: carers impact \& $\quad O R$ caregivers $O R$ "family members" $O R$ relatives $O R$ informal challenges carers

Emotional grief $O R$ loss $O R$ anxiety $O R$ fear $O R$ worry $O R$ shock $O R$ responding acceptance; AND: carers $O R$ caregivers $O R$ "family members" $O R$ relatives $O R$ informal carers

Coping "social coping" $O R$ "emotional coping" $O R$ "practical coping" $O R$ "problem solving" $O R$ "social support" $O R$ "exercise as coping" $O R$ "fundraising as coping" 